OAK RIDGE

NATIONAL LABORATORY

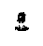
MANAGED BY UT-BATTELLE

FOR THE DEPARTMENT OF ENERGY

\title{
Characterization of Soluble Organics in Produced \\ Water
}

D. T. Bostick

H. Luo

B. Hindmarsh

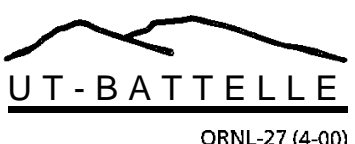




\title{
DOCUMENT AVAILABILITY
}

IReports produced after January 1,1996, are generally available free via the U.S. Department of Energy (DOE) information Bridge.

\section{Web site http://www.osti.gov/bridge}

Reports produced before January 1, 1996, may be purchased by members of the public from the following source.

\author{
National Technical information Service \\ 5285 Port Royal Road \\ Springfield, VA 22161 \\ Telephone 703-605-6000 (I-800-553-6847) \\ TDD 703-487-4639 \\ Fax 703-605-6900 \\ E-mail info@ntis.fedworld.gov \\ Web site http://www.ntis.gov/support/ordernowabout.htm
}

Reports are available to DOE employees, DOE contractors, Energy Technology Data Exchange (ETDE) representatives, and international Nuclear Information System (INIS) representatives from the following source.

Office of Scientific and Technical Information

P.O. Box 62

Oak Ridge, TN 37831

Telephone 865-576-8401

Fax 865-576-5728

E-mail reports@adonis.osti.gov

Web site http://www.osti.gov/contact.html

This report was prepared as an account of work sponsored by an agency of the United States Government. Neither the United States Government nor any agency thereof, nor any of their employees, makes any warranty, express or implied, or assumes any legal liability or responsibility for the accuracy, completeness, or usefulness of any information, apparatus, product, or process disclosed, or represents that its use would not infringe privately owned rights. Reference herein to any specific commercial product, process, or service by trade name, trademark, manufacturer, or otherwise, does not necessarily constitute or imply its endorsement, recommendation, or favoring by the United States Government or any agency thereof. The views and opinions of authors expressed herein do not necessarily state or reflect those of the United States Government or any agency thereof. 
Chemical Technology Division

\title{
CHARACTERIZATION OF SOLUBLE ORGANIC? IN PRODUCED WATER
}

\author{
Debra T. Bostick
}

H. Luo, and B. Hindmarsh

Date Published: January 2002

Department of Energy Project FEAB3 12

(Funded through the Natural Gas and Oil Technology Partnership Office)

Supporting Petroleum Energy Research Forum

Project 98-04

Prepared by

OAK RIDGE NATION\& LABOR\&TO\&Y

Oak Ridge, Tennessee 3783 1-6285

operated by

UT-BATTELLE, LLC

for the

U.S. Department of Energy

under contract DE-AC05-000R22725 


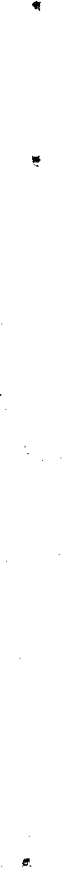

. 


\section{TABLE OF CONTENTS}

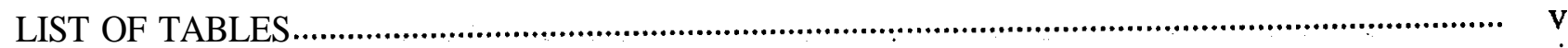

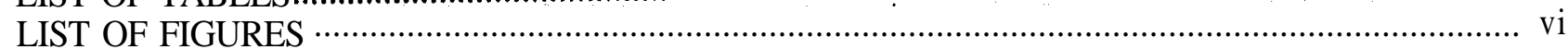

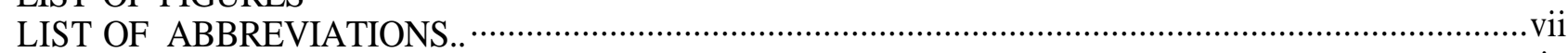

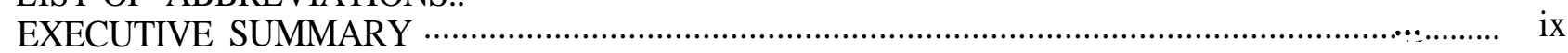

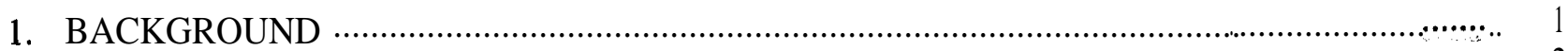

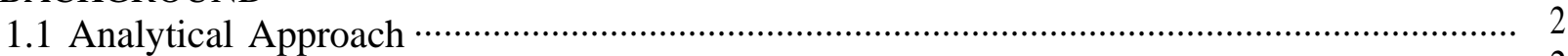

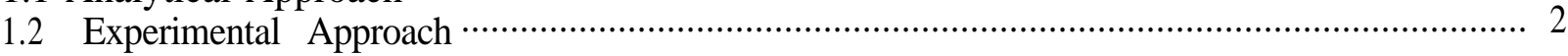

2. COLLECTION AND SAMPLING OF ACTUAL OIL AND PRODUCED

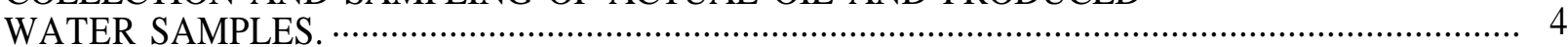

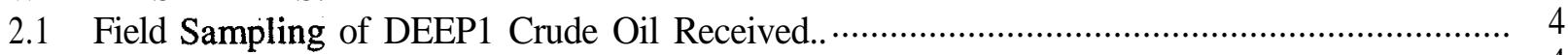

2.2 Determination of Water Content of As-received Oil Samples .......................................... 4

2.3 Laboratory Sampling of as-Received Crude Oil........................................................... 5

3. EXPERIMENTAL PROTOCOL FOR AMBIENT-PRESSURE TESTING …............................ 5

4. EXPERIMENTAL PROTOCOL FOR HIGH-PRESSURE TESTING …................................. 5

5. SYNTHETIC GOM BRINE ……………………………………………………………. 6

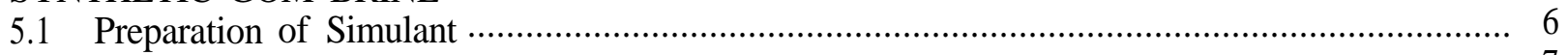

5.2 Verification of GOM Brine Simulant Content ......................................................... 7

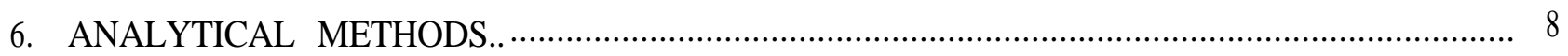

6.1 Identification of Semi-Volatile Organic Compounds (SVOC) 8

in Actual Oil and Produced Water by GC/MS ….......................................................... 8

6.2 GC/FID Analysis of Total Petroleum Hydrocarbons.. ….............................................. 10

6.3 Infrared Analysis of Total Recoverable Petrochemical Hydrocarbons................................. 11

6.4 Fractionation of WSO in Simulated Produced Water ...................................................... 11

6.5 Determination of $\mathrm{pH}$ Water Content in Crude Oil …................................................... 15

6.6 Determination of $\mathrm{pH}$ and Bicarbonate/Carbonate Content in Water …............................... 15

6.7 Determination of Chloride Content in Produced Water .................................................... 16

6.8 Determination of Metal Content in Produced Water ….................................................. 16

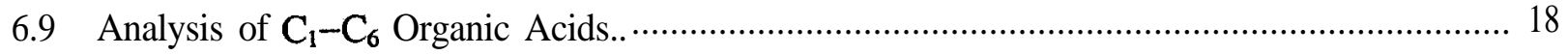

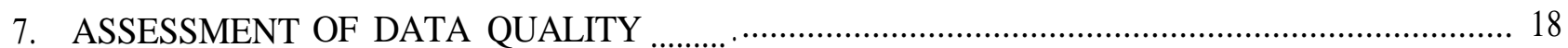

7.1 Correspondence Between Analytical Methods for WSO Constituents............................... 18

7.2 Surrogate Recovery And Blank Levels For Open LC Fractionation and GC/FID Analysis .... 20

7.3 Biases Associated with LC Fractionation Protocol …............................................................ 21

7.4 Comparison of LC Fractionation Protocol with Infrared Spectrometric Analysis.................. 23

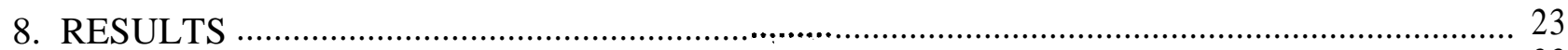

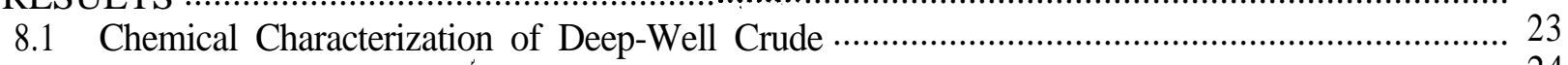

8.2 WSO as a Function of Percent Water Cut .................................................................. 24

8.3 WSO Distribution Coefficients as a Function of Percent Water Cut ..................................... 24

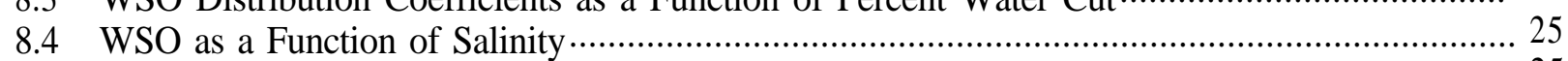

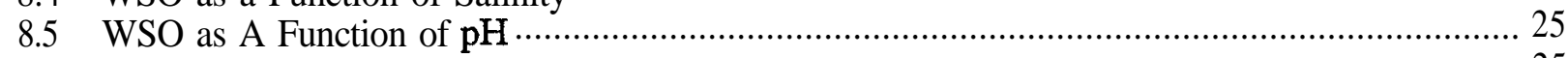

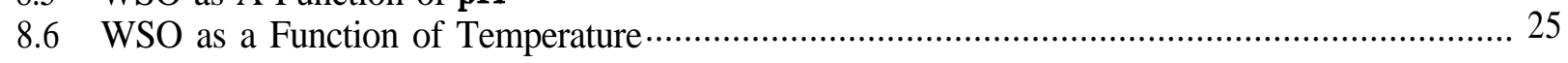


8.7 WSO as a Function of Pressure ................................................................................. 26

8.8 Composition of $\mathbf{C}_{1}-\mathbf{C}_{6}$ Organic Acids in Produced Water ........................................... 26

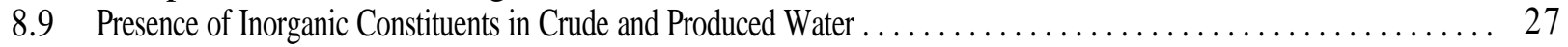

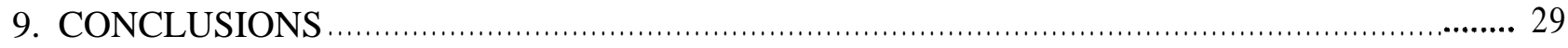

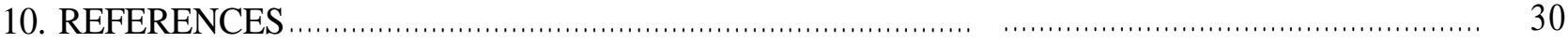

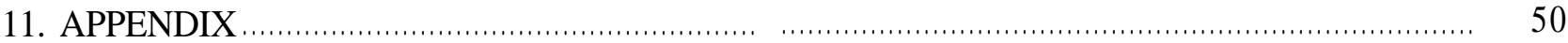




\section{LIST OF TABLES}

$\underline{\text { Table }}$

Page

1.1 Experimental test matrix for crude oil/GOM brine contacts.......................................... 3

Average concentrations of GOM brine components................................................. 6

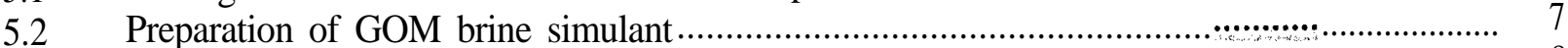

5.3 Anion concentrations in GOM brine...

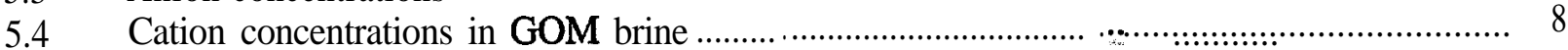

6.1 USEPA semivolatile organic compounds of interest to petrochemical applications …......... 8

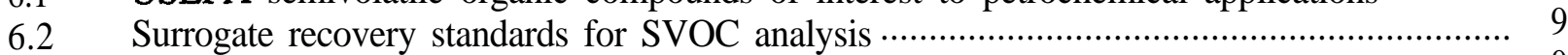

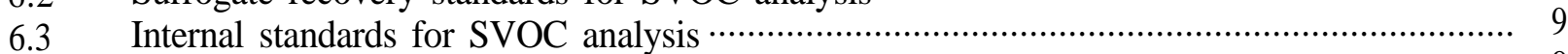

$6.4 \therefore$ Compounds included in laboratory control spike standard ......................................... 9

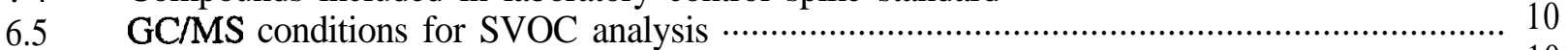

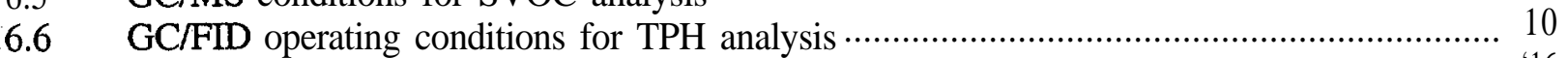

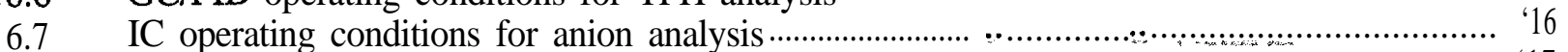

6.8 Inorganic analysis of GOM brine simulant, using ICP-MS …...................................... "17

6.9 IC Operating conditions for Cl-C6 organic acid analysis …..................................... 18

7.1 Correspondence of analytical methods in the characterization of deep-well crude -............. 19

7.2 Surrogate spike recovery compounds for LC fractionation protocol................................. 21

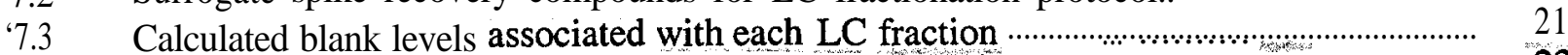

7.4 Correspondence of TPH results between LC fractionation and.IR spectroscopy............... 23

8.1 Chemical fraction data for GOM deep-well crude........................................................ 24

8.2 Chemical fraction data for GOM synthetic produced water ........................................ 24

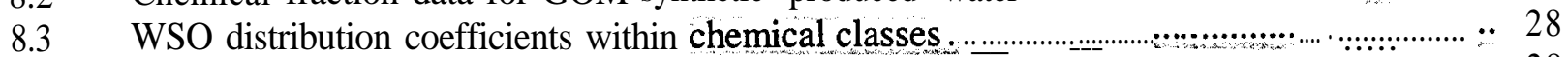

8.4 WSO distribution coefficients within carbon ranges for TEM fractions …....................... 28

A.1 PERF experiments associated with each oil/water. contact parameter.. .......................... 52

A.2 Starting experimental conditions for PERF experiments .......................................... 53

A.3 Equilibrium concentrations of inorganic constituents …........................................... 55

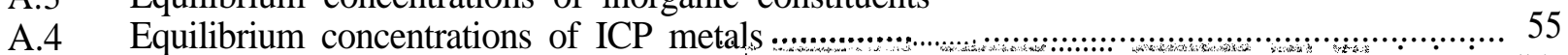

A.5 Equilibrium concentrations of organic matter by gravimetric and IR analyses ……........... "56

A.6 Equilibrium concentrations of WSO in open LC fractions TEM, HEX, and TSAT …......... 57

A.7 Equilibrium concentrations of WSO in open LC fractions TARO, TPOL(subtract), 


\section{LIST OF FIGURES}

Figure

Page

4.1 Schematic diagram of oil/water contact pressure vessel....................................... 34

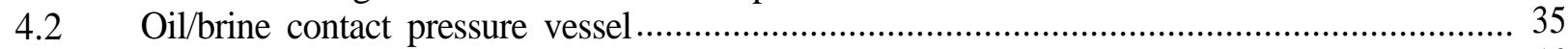

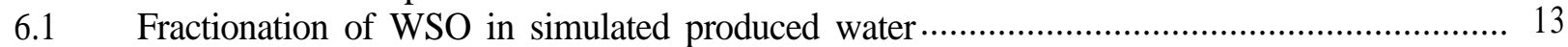

6.2 Open liquid chromatographic column for fractionation of TPH.................................... 14

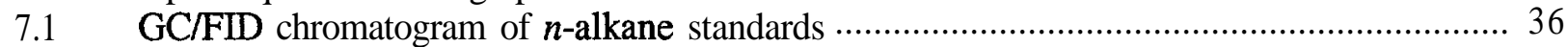

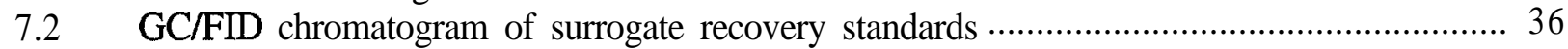

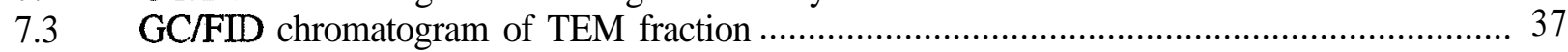

7.4 GC/FID chromatogram of HEX fraction ........................................................... 37

7.5 GC/FID chromatogram of TSAT fraction......................................................... 38

7.6 GC/FID chromatogram of TARO fraction ...................................................... 38

7.7 GC/FID chromatogram of TPOL fraction .............................................................. 39

8.1 WSO chemical character versus percent water cut ..................................................... 40

8.2 WSO carbon content versus percent water cut....................................................... 40

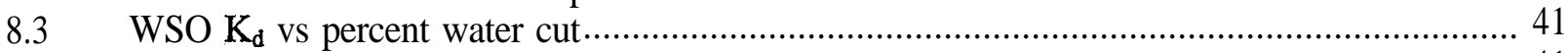

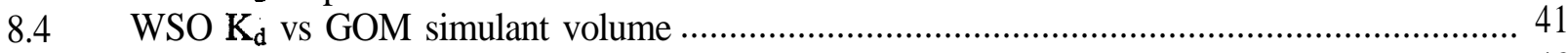

8.5 Total dissolved solids (as $\mathrm{Cl}-$ ) as a function of chemical fraction ................................. 42

8 . 6 Total dissolved solids (as $\mathrm{Cl}$-) as a function of carbon content ...................................42

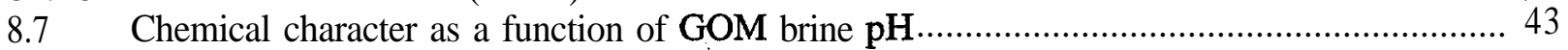

8.8 Carbon content in TEM fractions as a function of GOM brine pH................................ 43

8.9 Chemical character as a function of GOM brine temperature....................................... 44

8.10 Carbon content in TEM fractions as a function of GOM brine temperature ...................... 44

8.11 Chemical character as a function of GOM brine pressure ............................................. 45

8.12 'Carbon content in TPOL as a function of GOM brine pressure ..................................... 45

8.13 Influence of percent water cut on organic acid content .................................................. 46

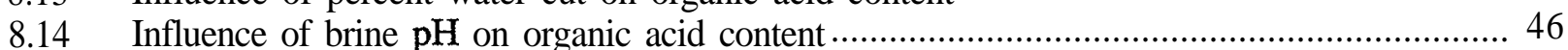

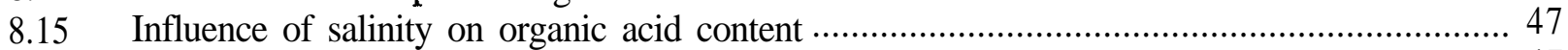

8.16 Influence of brine temperature on organic acid content .......................................... 47

8.17 Ion chromatogram of organic acids in produced water .............................................. 48 


\section{LIST OF ABREVIATIONS}

$\begin{array}{ll}\text { DRO } & \text { Diesel range organic compounds } \\ \text { GC } & \text { Gas chromatography } \\ \text { GOM } & \text { Gulf of Mexico } \\ \text { FID } & \text { Flame ionization detector } \\ \text { GRO } & \text { Gasoline range organic compounds } \\ \text { HEX } & \text { Hexane fraction } \\ \text { HP } & \text { Hewlett Packard } \\ \text { IC } & \text { Ion chromatography } \\ \text { ICP-AES } & \text { Inductively coupled plasma-atomic emission spectrometry } \\ \text { IR } & \text { Infrared } \\ \text { ISA } & \text { Ionic adjustor solution } \\ \text { ISE } & \text { Ion selective electrode } \\ \text { K-D } & \text { Kudema-Danish } \\ \text { LC } & \text { Liquid chromatography } \\ \text { MS } & \text { Matrix spike sample } \\ \text { MSD } & \text { Mass selective detector } \\ \text { ORNL } & \text { Oak Ridge National Laboratory } \\ \text { PAH } & \text { Polynuclear aromatic hydrocarbons } \\ \text { PERF } & \text { Petroleum Environmental Research Forum } \\ \text { PI } & \text { Principal investigator } \\ \text { ppm } & \text { Parts per million (by weight or volume) } \\ \text { S V c s } & \text { Semi-volatile organic compounds } \\ \text { SW } & \text { Statement of Work } \\ \text { TARO } & \text { Total aromatic fraction } \\ \text { TDM } & \text { Total dissolved material } \\ \text { TEM } & \text { Total extractable material } \\ \text { TPH } & \text { Total petroleum hydrocarbons } \\ \text { TPOL(gc) } & \text { Total polar fraction determined by gas chromatographic analysis } \\ \text { TPOL( sub) } & \text { Total polar fraction determined by subtraction from TEM fraction data } \\ \text { TS A T } & \text { Total saturate fraction } \\ \text { USEPA } & \text { United States Environmental Protection Agency } \\ \text { WAF } & \text { Water accumulated fraction } \\ \text { W s o } & \text { Water soluble organic compounds } \\ & \\ & \\ & \end{array}$




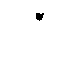




\section{EXECUTIVE SUMMARY}

Soluble organics in produced water and refinery effluents represent treatment problems for the petroleum industry. Neither the chemistry involved in the production of soluble organics nor the impact of these chemicals on total effluent toxicity is well understood. The U.S. Department of Energy provides funding for Oak Ridge National Laboratory (ORNL) to support a collaborative project with Shell, Chevron, Phillips, and Statoil entitled "Petroleum and Environmental Research Forum project (PERF 98-04: "Manage Water-Soluble Organics in Produced Water"). The goal of this project, which involves characterization and evaluation of these water-soluble compounds, is aimed at reducing the future production of such contaminants.

To determine the effect that various drilling conditions might have on water-soluble organics (WSO) content in produced water, a simulated brine water containing the principal inorganic components normally found in Gulf of Mexico (GOM) brine sources was prepared. The GOM simulant was then contacted with as-received crude oil from a deep well site to study the effects of water cut, producedwater $\mathrm{pH}$, salinity, pressure, temperature, and crude oil sources on the type and content of the WSO in produced water. The identities of individual semivolatile organic compounds (SVOCs) were determined in all as-received crude and actual produced water samples using standard USEPA Method (8270C) protocol. These analyses were supplemented with the more general measurements of total petroleum hydrocarbon (TPH) content in the gas $\left(\mathrm{C}_{6}-\mathrm{C}_{10}\right)$, diesel $\left(\mathrm{C}_{10}-\mathrm{C}_{20}\right)$, and oil $\left(\mathrm{C}_{20}-\mathrm{C}_{28}\right)$ carbon ranges as determined by both gas chromatographic (GC) and infrared (IR) analyses. An open liquid chromatographic procedure was also used to differentiate the saturated hydrocarbon, aromatic hydrocarbon, and polar components within the extractable TPH. Inorganic constituents in the produced water were analyzed by ion-selective electrodes and inductively coupled plasma (ICP)-atomic emission spectrometry (AES).

The WSO found in produced water samples was primarily polar in nature and distributed between the low and midrange carbon ranges. Typical levels of total extractable material (TEM) was about $20 \mathrm{mg} / \mathrm{L}$; that associated with the aromatic fraction was present at $0.2 \mathrm{mg} / \mathrm{L}$ and that in the saturated hydrocarbon fraction was present at less than $0.02 \mathrm{mg} / \mathrm{L}$. Formic, acetic, and propionic acids were also found in the produced water, occurring at a total concentration of $30 \mathrm{mg} / \mathrm{L}$. It was estimated that the presence of 30 $\mathrm{mg} / \mathrm{L}$ organic acids would artificially overstate TEM content by $2 \mathrm{mg} / \mathrm{L}$.

Of the five tested parameters, the factor that most controlled the total WSO in produced water was that of aqueous phase $\mathrm{pH}$. Beyond a value of $\mathrm{pH} 7$ significant quantities of $\mathrm{C}_{10}-\mathrm{C}_{20}$ range material become markedly soluble as they deprotonate in a basic aqueous phase. Both the absolute and relative volumes of GOM brine and crude additionally affected total WSO. Produced water appeared to reach a saturation level of WSO at a 50\% water/oil ratio. Pressure slightly enhanced WSO by increasing the relative quantity of $\mathrm{C}_{6}-\mathrm{C}_{10}$ range material. Temperature primarily altered the relative ratio of carbon ranges within the WSO without significantly elevating the total WSO in the GOM brine. Salinity had the least affect on the chemical character or the carbon size of WSO in produced water. 



\section{BACKGROUND}

Soluble organics in produced water and refinery effluents represent treatment problems for the petroleum industry. Production installations and refineries take special efforts to meet increasingly stringent regulatory discharge requirements for dissolved organics. Early data from the Gulf of Mexico (GOM) wells indicate that the more polar hydrocarbons from deep-water drilling will significantly increase the dissolved hydrocarbon content in produced water from these sites. Neither the chemistry involved in the production of soluble organics nor the impact of these chemicals on total effluent toxicity is well understood.

The U.S. Department of Energy provides funding for Oak Ridge National Laboratory (ORNL) to support a collaborative project with Shell, Chevron, Phillips, and Statoil, entitled "Petroleum and Environmental Research Forum Project (PERF 98-04: "Manage Water-Soluble Organics in Produced Water"). The goal of this project, which involves characterization and evaluation of these water-soluble compounds, is aimed at reducing the future production of such contaminants. The information obtained in the project will increase our understanding of the generation of water-soluble organics (WSO) and ultimately result in strategies to minimize WSO production and lead to the development of guidelines for effluent treatment. This, information will be used to design the next generation of offshore platforms for deep-water wells; and could also help reduce construction costs.

The first phase of the task was to acquire characterization data for produced water. A subsequent task will be to use the data to construct a model that can be used to predict WSO content based on the composition of a specific crude source. This report describes 'results acquired for phase one of the task. Analysis of produced water was performed at both ORNL and Statoil Company. ORNL characterized WSO derived from sources of GOM crude, whereas Statoil accumulated characterization data from North Sea oil sources. The objective of this report is to provide the sponsor of the project with a description of the analytical procedures used and the data acquired by ORNL. The format of the document follows closely the document submitted by staff at Statoil. This was done in order to aid the customer in compiling data from both ORNL and Statoil studies. The format of the report is designed to:

1) briefly describe the scope of the study (Chapter 1);

2) report the sampling of the crude by industrial partners (Chapter 2) ;

3) provide a detailed discussion of analytical procedures (Chapters 3-6),

4) validate analytical results through a discussion of QC data (Chapter 7); and, finally,

5) present WSO characterization data derived from the contact of the GOM crude with brine (Chapters 8,9 and appendix tables).

Because the primary objective of the project was to provide a database from which a second party would use to design a mathematical model to predict WSO content in produced water, the pertinent data was set aside as a separate group of tables in the appendix. All tables within the report text summarize information concerning objectives, analytical procedures, QC performance, results non-essential to the data base (although included as points of interest), etc. This approach in format should facilitate modeling by obviously separating types of data and clearly defining information that will be incorporated into the predictive model.

Finally, several limitations were placed on the format this document due to information held proprietary by the PERF committee. The well site from which the crude was derived is not specifically named; it is only stated as Deep 1 Well. This report tabulates WSO data information specific to this well site. The Deep 1 Well data amplifies a proprietary report written for the 
PERF members that summarizes general levels and character of WSO found in national and international literature. Because the proprietary nature of the summary report and its availability to PERF committee members, no effort was made in this document to compare Deep 1 Well results to general trends. Comparisons were made in closed session with PERF committee members. The primary goal of this document is data compilation for the project.

\subsection{ANALYTICAL APPROACH}

Quantitative characterization data were needed as the first step in understanding the generation of WSO in produced water. To achieve this objective, industrial partners provided ORNL samples of GOM deep-water crudes and their associated produced water. Together with industrial partners, ORNL selected methods to characterize the WSO in both actual and simulated samples of produced water. The identities of individual semi-volatile organic compounds (SVOCs) were determined in all as-received crude and actual produced water samples using standard USEPA Method (8270C) protocol. These analyses were supplemented with the more general measurements of total petroleum hydrocarbon $(\mathrm{TPH})$ content in the gas $\left(\mathrm{C}_{6}-\mathrm{C}_{10}\right)$, diesel $\left(\mathrm{C}_{10}-\mathrm{C}_{20}\right)$, and oil $\left(\mathrm{C}_{20}-\mathrm{C}_{28}\right)$ carbon ranges as determined by both GC (USEPA SW-846 Method 8015B) and infrared (IR) analyses. An open liquid chromatographic procedure was used to differentiate the saturated hydrocarbon, aromatic hydrocarbon, and polar WSO components contained in the TPH extract. Inorganic constituents in the produced water were analyzed by ionselective electrodes and inductively coupled plasma (ICP)-atomic emission spectrometry (AES).

Since the methods primarily follow those established by the U.S. Environmental Protection Agency (USEPA), the terminology used in this report follows that of USEPA regulatory nomenclature. The stated carbon ranges $\left(\mathrm{C}_{6}-\mathrm{C}_{10}, \mathrm{C}_{10}-\mathrm{C}_{20}, \mathrm{C}_{20}-\mathrm{C}_{28}\right)$ refer to sample components eluting from a gas chromatograph between n-alkane standards within each of these carbon size ranges. The terminology does not define the identity of the sample component eluting, merely that it has a volatility within the given saturated alkane range. The regulatory nomenclature is specific to the USEPA method used, in this case USEPA SW-846 Method 8015B. A description of the analytical procedures is presented in chapters 3 through 6 to fully explain under what condition the data was acquired.

TPH is also regulatory nomenclature, referring to all components extracted using either USEPA SW-846 Method 8015B or USEPA SW-846 Method 1664. Since polar WSO is also extracted in these procedures, TPH results include some mass that is actually not petroleum hydrocarbons. One of the goals of this study was to estimate the positive bias introduced into TPH results from these non-TPH components.

\subsection{EXPERIMENTAL APPROACH}

Only a limited volume of produced water was present in the crude oil samples shipped from drilling sites. To determine the effect that various drilling conditions might have on WSO content in produced water, a simulated brine water containing the principal inorganic components normally found in GOM brine sources was prepared. The GOM simulant was then contacted with as-received crude oil to study the effects of water cut, produced-water $\mathrm{pH}$, salinity, pressure, temperature, and crude oil sources on the type and content of the WSO in produced water. The test plan involved the analysis of the WSO content of simulated produced-water samples derived from oil/brine contacts covering the following operating ranges: 
- pressures of 1-100 bar;

- temperatures of $90-200^{\circ} \mathrm{F}\left(25-100^{\circ} \mathrm{C}\right)$;

- $\mathrm{pH}$ level of $6.5 \pm 2$;

- water cuts of 20,50 , and $80 \%$; and

- salinities of 35,000-150,000 ppm.

The test matrix presented in Table 1.1 below was used for the Deep1 crude ail source. The specific name for each experiment associated with a given experimental variable is denoted as "PEW-" in the table. A complete description of each PEW experiment and its associated data are summarized in the appendix of this document.

Table 1.1. Experimental test matrix for crude oil/GOM brine contacts

\begin{tabular}{|c|c|c|c|c|c|c|c|}
\hline Experimental variable & Pressure & $\begin{array}{r}\text { Temper } \\
\left({ }^{\circ} \mathrm{C}\right)\end{array}$ & ture & $\begin{array}{c}\text { Produced } \mathrm{H}_{2} \mathrm{O} \\
\text { source }\end{array}$ & $\mathrm{PH}$ & $\begin{array}{c}\text { Salinity } \\
\text { (ppm) }\end{array}$ & $\begin{array}{c}\text { Water cut } \\
(\%)\end{array}$ \\
\hline $\begin{array}{c}\text { As received } \\
(\text { PERIL8, 16, 20) }\end{array}$ & Ambient & 25 & & GOM simulant & 7 & 63,000 & 80 \\
\hline $\begin{array}{l}\text { Water cut } \\
\text { (PERP-6) }\end{array}$ & Ambient & 25 & & GOM simulant & 7 & 63,000 & 67 \\
\hline $\begin{array}{c}\text { Water cut } \\
\text { (PERF-7, 10) }\end{array}$ & Ambient & 2 & 5 & GOM simulant & 7 & 63,000 & 50 \\
\hline $\begin{array}{l}\text { Water cut } \\
\text { (PERF-9) }\end{array}$ & Ambient & 25 & & GOM simulant & 7 & 63,000 & 20 \\
\hline (PEE-13) & Ambient & 25 & & GOM simulant & 8.1 & 63,000 & 80 \\
\hline (PEE-1 1) & Ambient & 25 & & GOM simulant & 9.0 & 63,000 & 80 \\
\hline $\begin{array}{c}\mathrm{pH} \\
\text { (PERP-12) }\end{array}$ & Ambient & 2 & & GOM simulant & 4.7 & 63,000 & 80 \\
\hline $\begin{array}{c}\mathrm{pH} \\
\text { (PERF-19) }\end{array}$ & Ambient & 2 & & GOM simulant & 6.0 & 63,000 & 80 \\
\hline $\begin{array}{c}\text { Salinity } \\
\text { (PERP-14) }\end{array}$ & Ambient & 25 & & GOM simulant & 7 & 41,000 & 80 \\
\hline $\begin{array}{c}\text { Salinity } \\
\text { (PERF-15) }\end{array}$ & Ambient & 25 & $; \quad-$ & GOM simulant & 7 & 115,000 & 80 \\
\hline $\begin{array}{l}\text { Temperature } \\
\text { (PERF-17) }\end{array}$ & Ambient & 47 & & GOM simulant & 7 & 63,000 & 80 \\
\hline $\begin{array}{l}\text { Temperature } \\
\text { (PERF-18) }\end{array}$ & Ambient & 75 & & GOM simulant & 7 & 63,000 & 80 \\
\hline
\end{tabular}


Table 1.1. Experimental test matrix for crude oil/GOM brine contacts (cont.)

\begin{tabular}{|c|c|c|c|c|c|c|}
\hline $\begin{array}{l}\text { Pressure } \\
\text { (PERF-26) }\end{array}$ & 14 bar & 50 & GOM simulant & 7 & 63,000 & 80 \\
\hline $\begin{array}{l}\text { Pressure } \\
\text { (PERF-27) }\end{array}$ & 35 bar & 50 & GOM simulant & 7 & 63,000 & 80 \\
\hline $\begin{array}{c}\text { Pressure } \\
\text { (PEW-28) }\end{array}$ & 60 bar & 50 & GOM simulant & 7 & 63,000 & 80 \\
\hline
\end{tabular}

The distribution and partitioning of WSO components were then calculated for the operating ranges. The resulting information was forwarded to industrial partners for incorporation into a model to predict the production of water-soluble organics as a function of crude composition and formation characteristics.

\section{COLLECTION AND SAMPLING OF ACTUAL OIL AND PRODUCED WATER SAMPLES}

\subsection{FIELD SAMPLING OF DEEP1 CRUDE OIL}

Two 5-gallon samples were collected directly from the Deep1 Well flowline; these samples were transferred directly into 5-gal DOT-approved containers. According to field notes, the crude oil had a 22.2 API gravity at a collection temperature of $75^{\circ} \mathrm{F}$. Each sample was collected slowly over a 1-h interval to allow the oil to degas. While the samples were being collected, the operators performed a shakeout test, which gave a $10 \%$ water cut when heated with solvent at $140^{\circ} \mathrm{F}$.

\subsection{DETERMINATION OF WATER CONTENT IN AS-RECEIVED OIL SAMPLES}

Crude oil samples were shipped from the drilling site in 5-gal barrels equipped with two bunghole ports in the lid. The ports were opened slowly to vent the slight overpressure of the barrels. Any actual produced water was collected by dropping weighted tubing (Tygon ${ }^{\circledR}$ F40440-A) down to the bottom of the slightly tipped barrel. A peristaltic pump, operating in the forward direction, was used to create a slight positive pressure to displace any oil from the tubing prior to withdrawing the water phase. Pumping was continued until all water had been collected; the volume of water was then estimated relative to the initial volume of sample present in the barrel.

In the case of Deep 1 crude, a separate aqueous phase could not be removed directly, so 0.5 to $1 \mathrm{~L}$ of oil was withdrawn from the bottom of the. barrel and allowed to settle in a glass bottle. Again a separate aqueous phase did not form. Ten-mL aliquots of withdrawn oil were then transferred to $15-\mathrm{mL}$ tapered centrifuge tubes. The oil was then acidified to $0.001 \mathrm{M} \mathrm{HCl}$ by the addition of 10 $\mu \mathrm{L}$ of $1 M \mathrm{HCI}$ to separate any produced water that might have emulsified during shipment. When an aqueous phase was not observed at the base of the tube after $15 \mathrm{~min}$, the acidified oil samples were centrifuged at $2000 \mathrm{rpm}$ for $20 \mathrm{~min}$ to enhance phase separation. No distinct water phase was noted at the base of the tube, indicating the water content was too low to visually

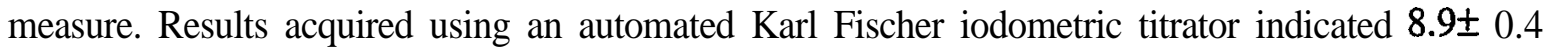
$\%$ water content, as opposed to field testing results of 10-12\%. 


\subsection{LABORATORY SAMPLING 'OF AS-RECEIVED CRUDE OIL}

Consistent testing of the WSO contents in the oil/water mixing experiments was predicated on the use of homogeneous oil samples. Toward this end, a 5-gal barrel of oil was placed horizontally on a barrel roller and rotated at the rate of $8 \mathrm{rpm}$ for $2 \mathrm{~h}$. The barrel was then set upright and oil was withdrawn using submersed tubing and a peristaltic pump. No entrained air bubbles were observed in the withdrawn oil.

\section{EXPERIMENTAL PROTOCOL FOR AMBIENT PRESSURE TESTING}

Simulated produced water samples were prepared under ambient pressure conditions using a Water Accumulated Fraction (WAF) vessel. The WAF procedure is typically used for the aquatic toxicity testing of acute and chronic exposures of marine life to lubricants in contact with water sources. The glass vessel was fabricated according to dimensions stipulated in ASTM D6081, in which the height:diameter ratio of the liquid phases in the 5-L vessel can be varied from 1: 1 to 2: 1. Testing was initiated by first adding up to $3 \mathrm{~L}$ of GOM simulant to the vessel. Up to $4 \mathrm{~L}$ of oil were slowly drained down the side of the vessel so that it was layered over the water without undo turbulence. Typical water/oil ratios used in testing varied from $20-80 \%$. A baseline value of $80 \%$ was used for testing all experimental variables except water cut. A Teflon®-coated stirring bar submersed in the GOM simulant was used to stir the oil/water interface such that the vortex of the oil phase descended to a depth of approximately $15-30 \%$ into the aqueous phase. Although the ASTM protocol indicates that a 24-h mixing time is sufficient to reach equilibrium extraction of WSO, a mixing time of 4 days was typically used to duplicate the experimental setup employed by Statoil in the testing of North Sea oil samples. Produced water was collected at the end of the equilibration time by opening a Teflon® stopcock located at the base of the WAF vessel. If necessary, any dispersed oil in the withdrawn water was removed using a separatory funnel. Several $20-\mathrm{mL}$ aliquots of the produced water were stored in glass bottles at $-4^{\circ} \mathrm{C}$ for subsequent analysis of carbonate/bicarbonate, inorganic metals, chloride, and lowmolecular weight organic acids. One liter of produced water was then acidified with concentrated hydrochloric acid $(\mathrm{HCl})$ to bring the $\mathrm{pH}$ level to less than 2. Surrogate recovery standards were added to the produced water fraction prior to the solvent extraction of WSO.

\section{EXPERIMENTAL PROTOCOL FOR HIGH PRESSURE TESTING}

A factory-assembled pressure vessel incorporating armored sight glasses on opposing walls, was used to generate produced water samples at pressures up to $1000 \mathrm{psi}$ and $50^{\circ} \mathrm{C}$. This vessel having an internal volume of $300 \mathrm{~mL}$, is fabricated of mild steel, that has been certified as to chemical composition, hardness, and tensile strength. Additional hardware supplied by Pressure Products Company, Inc. (4540 W. Washington St., Charleston, W. VA 25313) included a 1200 psi pressure relief valve, a 1-1000 psi liquid-filled pressure gauge, an inlet for a digital thermometer, an inlet to pressurize the vessel with helium, and tubing and needle valves to allow filling and draining of solution from the vessel (Figs. 4.1 and 4.2). The 60-lb pressure vessel was clamped onto a Ro-Tap Model B Sieve Shaker (C. M. Tyler Co.), which rotated the system horizontally at approximately $60 \mathrm{rpm}$ to produce a slight vortex at the oil/water solution interface. During mixing, the temperature was maintained at $50^{\circ} \mathrm{C}$ by controlling the voltage output to a heating tape wrapped around the circumference of the vessel.

Two hundred $\mathrm{mL}$ of brine simulant were added to the heated vessel; the system was then pressurized with helium, heated, and mixing for 4 days to determine blank concentration levels for TPH in the vessel. A Hoke ${ }^{\circledR}$ sample chamber was connected to the gas sampling port of the 
vessel. at the end of the equilibration time. Pressure was vented into the evacuated gas sample vessel by opening the gas sampling valve located at the top of the pressure chamber. Once the chamber had been brought to ambient pressure, the Hokeß vessel was sealed. The exit valve located at the base of the pressure chamber was subsequently opened to collect the water phase.

The gases that collected in the Hoke ${ }^{\circledR}$ sampling vessel were vented through an $-5 \mathrm{~cm}$ length of $1 / 4$-inch stainless steel tube packed with sorbents to retain hydrocarbon components and then through a mass flow meter. The tube contained Carbotrap $C$ to capture high-molecular-weight material, followed by Carbotrap for the majority of components and, finally, Carbosieve SIII for low $\left(\mathrm{C}_{2}-\mathrm{C}_{3}\right)$ molecular-weight organics. These sample tubes have been sealed and archived should the need for their analysis exist.

Once the TPH blank levels of pressure vessel were suitably low, actual oil/brine experiments were conducted by loading the heated chamber with $200 \mathrm{~mL}$ of GOM brine simulant and $30 \mathrm{~mL}$ of crude oil. The first experiment was performed at ambient pressure and $50^{\circ} \mathrm{C}$ for comparison with data derived from oil/water contacts in the WAF vessel. The remaining experiments were conducted at pressures of 14,35 , and $60 \mathrm{bar}$ and a temperature of $50^{\circ} \mathrm{C}$. Again, the gases in the chamber were vented into a gas sampling vessel to depressurize the pressure chamber at the end of a 4-day equilibration time. Immediately after being depressurized, the produced water phase was collected at the drain port for subsequent analysis using the open LC fractionation protocol (see Sect. 6.4).

\section{SYNTHETIC GOM BRINE}

\subsection{PREPARATION OF SIMULANT}

The staff of the Phillips Company provided the recipe for the preparation of GOM brine simulant. Table 5.1 summarizes the average concentrations of actual GOM brine components as derived from data members of Phillips staff members have collected from 300 past and present GOM wells. These accumulated data provided the basis for the recipe formulation.

\section{Table 5.1. Average concentrations of GOM brine components ${ }^{\mathrm{a}}$}

\begin{tabular}{lc}
\hline $\begin{array}{l}\mathrm{GOM} \text { brine } \\
\text { Component }\end{array}$ & $\begin{array}{c}\text { Concentration } \\
(\mathrm{mg} / \mathrm{L})\end{array}$ \\
\hline $\mathrm{Cl}^{-}$ & 63,000 \\
$\mathrm{SO}_{4}{ }^{2-}$ & 3 \\
$\mathrm{HCO}_{3}{ }^{-}$ & 220 \\
$\mathrm{Na}^{+}$ & 35,354 \\
$\mathrm{Ca}^{2+}$ & 3,260 \\
$\mathrm{Mg}^{2+}$ & 910 \\
$\mathrm{Ba}^{2+}$ & 95 \\
$\mathrm{Sr}^{2+}$ & 131 \\
$\mathrm{Fe}^{3+}$ & 23 \\
Dissolved $\mathrm{CO}_{2}$ & 68 \\
Temperature & $90^{\circ} \mathrm{F}$ \\
$\mathrm{pH}$ & 6.7 \\
\hline
\end{tabular}

${ }^{\mathrm{a}}$ Data provided by D. Bourg, Philips Co., May 9, 2000. 
Table 5.2 summarizes the results of a spreadsheet devised by Phillips staff that delineates the chemical components and their quantities required to prepare 1- and 4-L batches of produced water simulant. Once prepared, the simulant was stored in a refrigerator and then brought to the required experimental temperature just before use.

\subsection{VERIFICATION OF GOM BRINE SIMULANT CONTENT}

Ion chromatography (IC) and ion-selective electrodes were used to determine anion concentrations in the prepared simulant brine. ICP-AES was used to verify dissolved metal components. Complete descriptions of the analytical procedures used for cation/anion determinations can be found in Sects. 6.6 and 6.7 of this document. IC was initially selected for the analysis of brine salinity; however, results based on IC appeared to negatively bias the total chloride concentration in GOM brine simulant. The high sodium concentration in the simulant mandated that the brine samples be chemically treated with a cation exchange resin column to reduce the level of sodium ion before the sample was introduced into IC equipment. As can be seen in Table 5.3, significant error was introduced by the pretreatment procedure since the electrochemical balance of the cation content in the simulant (Table 5.4) indicated that the chloride content should be approximately $65,000 \mathrm{ppm}$. Chloride analysis based on the use of a chloride selective electrode was considered more accurate for this application because this analysis is typically performed in the presence of $5 \mathrm{MNaNO}_{3}$, a matrix having an in ionic strength similar to that of the simulant brine.

Ferrous ion was initially included at a concentration of $23 \mathrm{ppm}$ to reflect the concentration present in actual GOM brine. However, precipitation of ferric oxide at near neutral $\mathrm{pH}$ required filtration of the simulant. prior to use. The final soluble iron concentration in the filtrate was less than the detection limit of the ICP. Therefore, ferrous sulfate was not included in simulant preparation for any of the oil/water contact experiments in this study.

\begin{tabular}{|c|c|c|}
\hline Component & $\begin{array}{l}\text { 1-L Preparation } \\
\text { requires }(\mathrm{g})\end{array}$ & $\begin{array}{l}\text { 4-L Preparation } \\
\text { Requires (g) }\end{array}$ \\
\hline $\mathrm{NaCl}$ & 89.708 & 358.832 \\
\hline $\mathrm{CaCl}_{2} \bullet 2 \mathrm{H} 20$ & 11.959 & 47.835 \\
\hline $\mathrm{MgCl}_{2} \bullet 6 \mathrm{H}_{2} \mathrm{O}$ & 7.613 & 30.453 \\
\hline $\mathrm{BaCl}_{2} \bullet 2 \mathrm{HzO}$ & 0.16 & 0.676 \\
\hline $\mathrm{SrCl}_{2} \bullet \quad 6 \mathrm{H} \&$ & 0.39 & $9 \quad 1.595$ \\
\hline $\mathrm{FeSO}_{4} \bullet 7 \mathrm{H} 20$ & 0.000 & 0.000 \\
\hline $\mathrm{NaHCO}_{3}$ & 0.3 & $\begin{array}{ll}3 & 1.212\end{array}$ \\
\hline $\mathrm{Na}_{2} \mathrm{SO}_{4}$ & 0.063 & 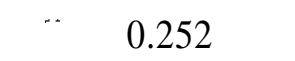 \\
\hline $\mathrm{H}_{2} \mathrm{O}$ & 889.740 & $3,559.0$ \\
\hline Final solution $(\mathrm{g})$ & $1,000.0$ & $3,999.8$ \\
\hline $\begin{array}{l}\text { Total dissolved material } \\
\text { (TDM, ppm) }\end{array}$ & 102,971 & 102,971 \\
\hline Salinity as $\mathrm{Cl}^{-}$(ppm) & 62,975 & 62,975 \\
\hline
\end{tabular}


Table 5.3. Anion concentrations in GOM brine

\begin{tabular}{lccc} 
& & \multicolumn{2}{c}{ Simulant Analysis Results (ppm) } \\
\cline { 3 - 4 } Anion & $\begin{array}{c}\text { Actual GOM brine } \\
\text { concentration }\end{array}(\mathrm{ppm})$ & Chromatography & $\begin{array}{c}\text { Ion Selective } \\
\text { Electrode }\end{array}$ \\
\hline $\mathrm{SO}_{4}{ }^{2-}$ & 3 & $<10$ & $\mathrm{NA}^{\mathrm{a}}$ \\
$\mathrm{Cl}^{-}$ & 62,975 & 41,500 & $62,600 \pm 1,700$ \\
$\mathrm{HCO}_{3}{ }^{-}$ & 220 & $\mathrm{NA}$ & $153 \pm 1$ \\
\hline${ }^{a} \mathrm{NA}=$ not analyzed. & & &
\end{tabular}

Table 5.4. Cation concentrations (mg/L) in GOM brine

\begin{tabular}{lcccccc}
\hline & \multicolumn{5}{c}{ Cation $(\mathrm{mg} / \mathrm{L})$} \\
\cline { 2 - 7 } & $\mathrm{Na}^{+}$ & $\mathrm{Ca}^{2+}$ & $\mathrm{K}^{+}$ & $\mathrm{Sr}^{2+}$ & $\mathrm{Ba}^{2+}$ & $\mathrm{Fe}^{3+}$ \\
\hline Actual brine & 35,400 & 3,260 & 0.0 & 0.131 & 0.095 & 0.023 \\
Simulant by ICP & 35,400 & 3,270 & $<0.004$ & 0.139 & 0.044 & $<0.020$ \\
\hline
\end{tabular}

\section{ANALYTICAL METHODS}

\subsection{IDENTIFICATION OF SEMI-VOLATILE ORGANIC COMPOUNDS (SVOC) IN ACTUAL OIL AND PRODUCED WATER BY GC/MS}

Specific chemical compounds were identified and quantitated in as-received crude oils and actual produced water using USEPA SW-846 Method $8270 \mathrm{C}$. (This method is also identified as USEPA Method 525.2 of the "500 series" in the USEPA compendium for the analysis of contaminants is drinking water.) The protocol uses GC-MS to identify a core group of over 45 semi-volatile organic target compounds in environmental samples. Within the list of target compounds, those that are of particular interest to petrochemical applications are included in Table 6.1:

$\begin{gathered}\text { Table 6.1. USEPA Semi-volatile organic compounds } \\
\text { of interest to petrochemical applications }\end{gathered}$
\begin{tabular}{ll} 
Acenaphthene & Fluoranthene \\
Acenaphthylene & Fluorene \\
Anthracene & Indeno(1,2,3-c,d)pyrene \\
Benzo(a)anthacene & 2-Methylnaphthalene \\
Benzo(a)pyrene & 2-Methyl phenol \\
Benzo(b)fluoranthene & Naphthalene \\
Benzo(e)pyrene & Phenanthrene \\
Benzo(k)fluoranthene & P yrene \\
Chrysene & \\
\hline
\end{tabular}

Although polynuclear aromatic hydrocarbons (PAHs) are included in the list due to the toxicity imparted by these compounds to environmental samples, the PERF activity reported here did not 
address toxicity concerns as part of its scope of work. Therefore, PAH data were not acquired in samples derived from GOM wells.

Crude oil and actual produced water samples were analyzed by Mountain States Analytical, Inc. (1645 West 2200 South, Alt Lake City, Utah 84119). The protocol from this off-site testing facility includes the analyses of over 120 semi-volatile compounds pertinent to the petroleum industry. Protocol requirements include the addition of surrogate recovery standards (see Table 6.2) to samples prior to their extraction with methylene chloride. These standards are used to monitor the variability in extraction efficiency of the solvent for individual target compounds.

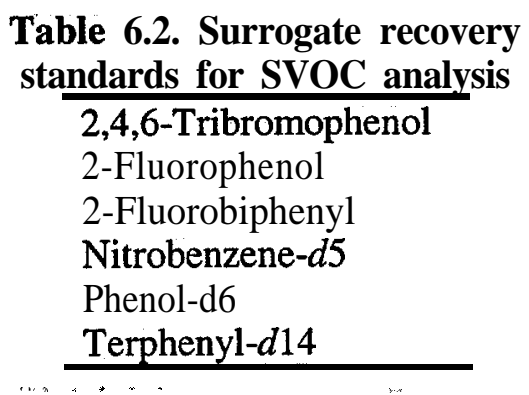

Neat oil samples were initially diluted by a factor of 25 with methylene chloride prior to GC-MS analysis. Produced water samples were acidified to $\mathrm{pH} 2$ prior to extraction of WSOs. Three 30$\mathrm{mL}$ contacts with methylene chloride were then used to serially extract organic compounds from 200 to $1000 \mathrm{~mL}$ of produced water in a separatory funnel. Internal standards were also added after solvent extraction as a means of checking the GC-MS instrument sensitivity and linearity. These compounds are listed in Table 6.3.

\begin{tabular}{l} 
Table 6.3. Internal standards \\
for SVO compound analysis \\
\hline 1,4-Dichlorobenzene \\
Naphthalene- $d 8$ \\
Acenaphthene- $d 10$ \\
Phenanthrene- $d 10$ \\
Chrysene- $d 12$ \\
Perylene- $d 12$ \\
\hline
\end{tabular}

The combined extracts were dried with sodium sulfate and congentrated to $1 \mathrm{~mL}$ a laboratory control spike standard provided an additional quality control check. The spike solution containing the compounds listed in Table 6.4, was added to an aliquot of the concentrated methylene chloride extract to check for the interference of sample matrix components with the quantitation of individual target compounds.

Table 6.4. Compounds included in the laboratory control spike standard

\begin{tabular}{lc}
\hline Acenaphthene & N-Nitroso-di-N-propylamine \\
4-Chloro-3-methylphenol & Pentachlorophenol \\
2-Chlorophenol & Phenol \\
1,4-Dichlorobenzene & P yrene \\
2,4-Dinitrotoluene & 4-Nitrophenol \\
1,2,4-Trichlorobenzene & \\
\hline
\end{tabular}


Prepared methylene chloride extracts were then injected into a GC-MS system (operated under the conditions listed in Table 6.5) to identify and quantitate individual SVOCs.

Table 6.5. GC-MS conditions for SVOC analysis

\begin{tabular}{ll}
\hline Instrumentation: & Hewlett Packard (HP) 6890 plus Gas Chromatograph with a 5973 MSD \\
GC column: & $30 \mathrm{~m} \mathrm{X} 0.25 \mathrm{~mm}$ (or $0.32 \mathrm{~mm}$ ) ID 1-ym-film-thickness silicone-coated \\
& fused-silica capillary column \\
Software: & HP MSD ChemStation with EnviroQuant \\
Ionization: & Electron impact, $70 \mathrm{eV}$ \\
Ion source & $230^{\circ} \mathrm{C}$ \\
temperature: & \\
Carrier gas & Helium, $30 \mathrm{~cm} / \mathrm{s}$ \\
Initial pressure: & $16 \mathrm{psi}$ \\
Inlet: & Pulsed splitless, initial temperature $270{ }^{\circ} \mathrm{C}$ \\
Oven program: & $50{ }^{\circ} \mathrm{C}(4 \mathrm{~min}), 10^{\circ} \mathrm{C} / \mathrm{min}$ to $350^{\circ} \mathrm{C}$, hold until dibenz(a,e)pyrene elutes \\
Sample Volume: & $1 \mu \mathrm{L}$ \\
\hline
\end{tabular}

\subsection{GC/FID ANALYSIS OF TOTAL PETROLEUM HYDROCARBONS}

A modification of SW-846 Method 8015B was used to determine the concentrations of nonhalogenated volatile organic compounds and semivolatile organic compounds by GC using flame ionization detection (FID). This method analyzes total petroleum hydrocarbons (TPH) in specific carbon ranges defined as

- TPH-Gasoline (GRO): $\mathrm{C}_{6}-\mathrm{C}_{10}$,

- TPH-Diesel (DRO): $\mathrm{C}_{10}-\mathrm{C}_{20}$, and

- TPH-Oil: $\mathrm{C}_{20}-\mathrm{C}_{28}$.

TPH-GRO represent alkanes having a boiling point range of $60-170^{\circ} \mathrm{C}$; the remaining compounds correspond to alkanes having a boiling point range of $170-430^{\circ} \mathrm{C}$. Prior to solvent extraction, the surrogate recovery standards (n-dodecane-d26, naphthalene- $d 8$, and n-phenol-d6 or tribromophenol) were added at a level of $40 \mu \mathrm{g}$ each to produced water in order to estimate the variability in extraction efficiency of alkanes, aromatic, and polar compounds, respectively. The concentrated solvent extracts containing WSO were then injected into a gas chromatograph using the operating conditions summarized in Table 6.6.

Table 6.6. GC/FID operating conditions for TPH analysis

Instrumentation: $\quad$ HP 5890 Series II Gas Chromatograph with an FID

GC column:

Software:

Carrier gas flow rate:

Makeup gas flow rate:

Injector temperature:

FID temperature:

Hydrogen flow rate:

Air flow rate:
$30 \mathrm{~m}$ X $0.53 \mathrm{~mm}$ ID fused silica capillary column bonded with $5 \%$ methyl silicone (HP-5), 0.88- $\mu \mathrm{m}$ film thickness

HP ChemStation version 3365 Series II

Helium, $4 \mathrm{~mL} / \mathrm{min}$

Helium, $26 \mathrm{~mL} / \mathrm{min}$

$200^{\circ} \mathrm{C}$

$340^{\circ} \mathrm{C}$

$30 \mathrm{~mL} / \mathrm{min}$

$375 \mathrm{~mL} / \mathrm{min}$ 
Table 6.6. GC/FID operating conditions for TPH analysis (cont.)

\begin{tabular}{ll}
\hline Oven program & \\
Initial temperature: & $45^{\circ} \mathrm{C}$ (hold $3 \mathrm{~mm}$ ) \\
Program: & $45^{\circ} \mathrm{C}$ to $275^{\circ} \mathrm{C}$ at $12^{\circ} \mathrm{C} / \mathrm{min}$ \\
Final temperature: & Hold $12 \mathrm{~mm}$ \\
Sample size: & $0.5-3 \mu \mathrm{L}$ \\
\hline
\end{tabular}

Detector response was externally standardized using a six-point calibration curve. The calibration data set was constructed from dilutions of a certified standard (Absolute Standards, catalog no. 90814 , lot 030700 ) containing $2000 \mu \mathrm{g} / \mathrm{mL}$ each of n-alkanes spanning the range $\mathrm{C}_{6}$ $\mathrm{C}_{28}$. The FID response was linear over the range of $0.01-0.1 \mu \mathrm{g}$ injected mass of each alkane, corresponding to a TPH range of $0.2-1.4 \mu \mathrm{g} / \mathrm{mL}$ for each alkane in produced water. HP Chem Station@ software was used to integrate peak area over the three carbon ranges: $\mathrm{C}_{6}-\mathrm{C}_{10}, \mathrm{C}_{10}-\mathrm{C}_{20}$, and $\mathrm{C}_{20}-\mathrm{C}_{28}$ to obtain the TPH mass in each of the solvent extraction concentrates.

\subsection{INFRARED ANALYSIS OF-TOTAL RECOVERABLE PETROCHEMICAL HYDROCARBONS}

The analysis of WSO in produced water samples was also supplemented using USEPA Method 418.1. The infrared (IR) method is more commonly used in the field or as a screening technique due to the simplicity of the procedure. As modified for this task, the protocol uses $10 \mu \mathrm{L}$ of $4 M$ $\mathrm{HCI}$ to acidify $2 \mathrm{~mL}$ of produced water to a value less than $\mathrm{pH} 2$. The oil-and-grease components are then extracted from the treated sample with $3 \mathrm{~mL}$ of $\mathbb{R}$-grade tetrachloroethylene. The organic phase is subsequently transferred to a $1-\mathrm{cm}$ path length $\mathbb{R}$ cell. The absorbance at a wavelength of $3.4 \mu \mathrm{m}$ is measured on a single-beam $\mathbb{R}$ spectrometer. Sets of oil-and-grease standards are prepared in the working range of 4 to $40 \mathrm{mg}$ in tetrachloroethylene using either GOM crude oil or a synthetic oil [37.5 (v/v) \% n-hexadecane, 37.5 (v/v) \% isooctane, and 25 (v/v) \% chlorobenzene). A three milliliter volume of oil standard is acidified; $2 \mathrm{~mL}$ of $100 \mathrm{~g} / \mathrm{L}$ $\mathrm{NaCl}$ is then added to match the salinity content of GOM brine simulant. After the shaking and phase separation steps, the solvent phase i's withdrawn as the working 'oil-and-grease standard.

\subsection{FRACTIONATION OF WSO IN SIMULATED PRODUCED WATER}

A more definitive approach to characterizing the WSO content in produced water samples is to fractionate compounds into primary classes of saturated hydrocarbon, aromatic hydrocarbon, and polar components. The TPH content of each fraction is then determined by GC/FID analysis. An open liquid chromatographic (LC) column was used to perform the fractionation of extractable TPH using a procedure similar to that described by Mills et al. In this procedure, a gross measurement of organic content is made by extracting total TPH from an aqueous sample with methylene chloride. The extract is then applied to a multi-sorbent column to separate the chemical fractions. The advantage of such an analytical approach is that the chemical character of WSO can be determined inexpensively as a function of general classes for a sample containing a myriad of organic constituents.

The procedure of Mills et al. was modified to accommodate the analytical requirements of the PERF 98-04 project. A primary change in the protocol was to replace the gravimetric analysis of column fractions with that of GC/FID analysis based on USEPA SW-846 Method 8015B. Gravimetric analysis did not provide the necessary detection limits and compositional information considered relevant to the project. A secondary procedural change was to estimate polar hydrocarbon content by eluting the bulk of the material from the open LC column with a 
final methanol wash. The distribution of carbon content within molecular size ranges could then be estimated for this fraction by GC/FID analysis. The GC/FID data for the polar fraction were then compared the method by Mills et al. The organic mass of the polar fraction can also be estimated by subtracting the combined mass of saturated and aromatic fractions from the total TPH content originally present in the methylene chloride extract. Finally, the solvent exchange procedure used to remove methylene chloride and transfer total TPH to a hexane matrix was altered midway through the study to minimize the loss of more volatile WSO components. Rather than evaporation at $65^{\circ} \mathrm{C}$ in Kudema-Danish glassware, the methylene chloride solvent was heated to $35^{\circ} \mathrm{C}$ under a light flow of nitrogen gas to reduce the sample volume. Two sequential additions of hexane were then added and concentrated in the same manner.

An outline of the modified procedure is reproduced in diagrammatic form in Fig. 6.1. Prior to TPH extraction, aliquots of produced water were withdrawn for analyses of inorganic constituents and low molecular weight organic acids. Surrogate recovery standards (n-hexanoic acid, ndodecane-d26, naphthalene- $d 8$, and n-phenol-d6 or tribromophenol) are then added to $1 \mathrm{~L}$ of produced water. Finally, WSOs were then serially extracted with three $30-\mathrm{mL}$ methylene chloride contacts.

The methylene chloride solvent was concentrated to $2 \mathrm{~mL}$ at $65^{\circ} \mathrm{C}$ using Kudema-Danish (K-D) evaporation glassware to yield the total extractable material (TEM) fraction. A 100- $\mu \mathrm{L}$ aliquot of the TEM fraction was dried on a tared glass-fiber filter to estimate the initial TPH mass in the fraction gravimetrically (generally a few milligrams). A second $100-\mu \mathrm{L}$ aliquot of the TEM fraction was placed'in a sealed ampoule for subsequent GC/FID analysis.

In the first $14 \mathrm{oil} /$ water contact experiments, $10 \mathrm{~mL}$ of hexane was added to $1-\mathrm{mL}$ TEM aliquot and evaporated at $65^{\circ} \mathrm{C}$ to a final volume of $2 \mathrm{~mL}$ in order to transfer TPH into a hexane matrix (HEX fraction). This step was repeated to ensure that all methylene chloride had been removed from the sample. Beginning with experiment PERF-15, solvent substitution was modified to reduce organic losses at elevated temperatures. Instead, $2 \mathrm{~mL}$ of hexane was added to a $1-\mathrm{mL}$ TEM fraction and evaporated to near dryness at $35^{\circ} \mathrm{C}$ under a light flow of nitrogen gas. This step was repeated twice for complete solvent substitution. The residue was then brought to a 2$\mathrm{mL}$ volume with hexane. The hexane fraction, denoted as HEX, was refrigerated overnight to precipitate asphaltenes. A 100- $\mu \mathrm{L}$ aliquot of the HEX fraction was dried on a tared glass-fiber filter to estimate the initial TPH mass in the fraction gravimetrically (generally a few milligrams). A second $100-\mu \mathrm{L}$ aliquot of the HEX fraction was placed in a sealed ampoule for subsequent GC/FID analysis.

The remainder of the clarified HEX fraction was added to the open LC column. The multilayered column was packed sequentially with $0.5 \mathrm{~cm}$ of fired glass wool, $5 \mathrm{~g}$ of fired sand prewashed with methanol, $7 \mathrm{~g}$ of fired activated alumina, $13.5 \mathrm{~g}$ of fired activated silica, $2 \mathrm{~g}$ of anhydrous sodium sulfate, and a final top layer of $0.5 \mathrm{~cm}$ of fired glass wool (Fig. 6.2). The packed column was prewashed with $50 \mathrm{~mL}$ of methanol, $200 \mathrm{~mL}$ of methylene chloride, and finally $40 \mathrm{~mL}$ of pentane before the HEX fraction was added. The saturated hydrocarbons from the applied HEX fraction were eluted with $40 \mathrm{~mL}$ of pentane. This fraction was concentrated to $1 \mathrm{~mL}$ by evaporation at $65^{\circ} \mathrm{C}$ in the K-D glassware, and is denoted as the TSAT fraction. The concentrated TSAT fraction was transferred to a sealed ampoule for GC/FID analysis.

A $200 \mathrm{~mL}$ volume of 1: 1 pentane:methylene chloride was used to elute the aromatic compounds from the LC column. This fraction, denoted as TARO, was also concentrated to $1 \mathrm{~mL}$ by 
evaporation at $65^{\circ} \mathrm{C}$. The concentrated TARO fraction was transferred to a sealed vial for GC/FID analysis.

The LC column was finally washed with 150 -mLof methanol to displace the majority of the polar compounds. This fraction, denoted as the TPOL, was then evaporated to $1 \mathrm{~mL}$ at $85^{\circ} \mathrm{C}$. Each $\mathrm{LC}$ fraction was analyzed for organic mass content by GC/FID.

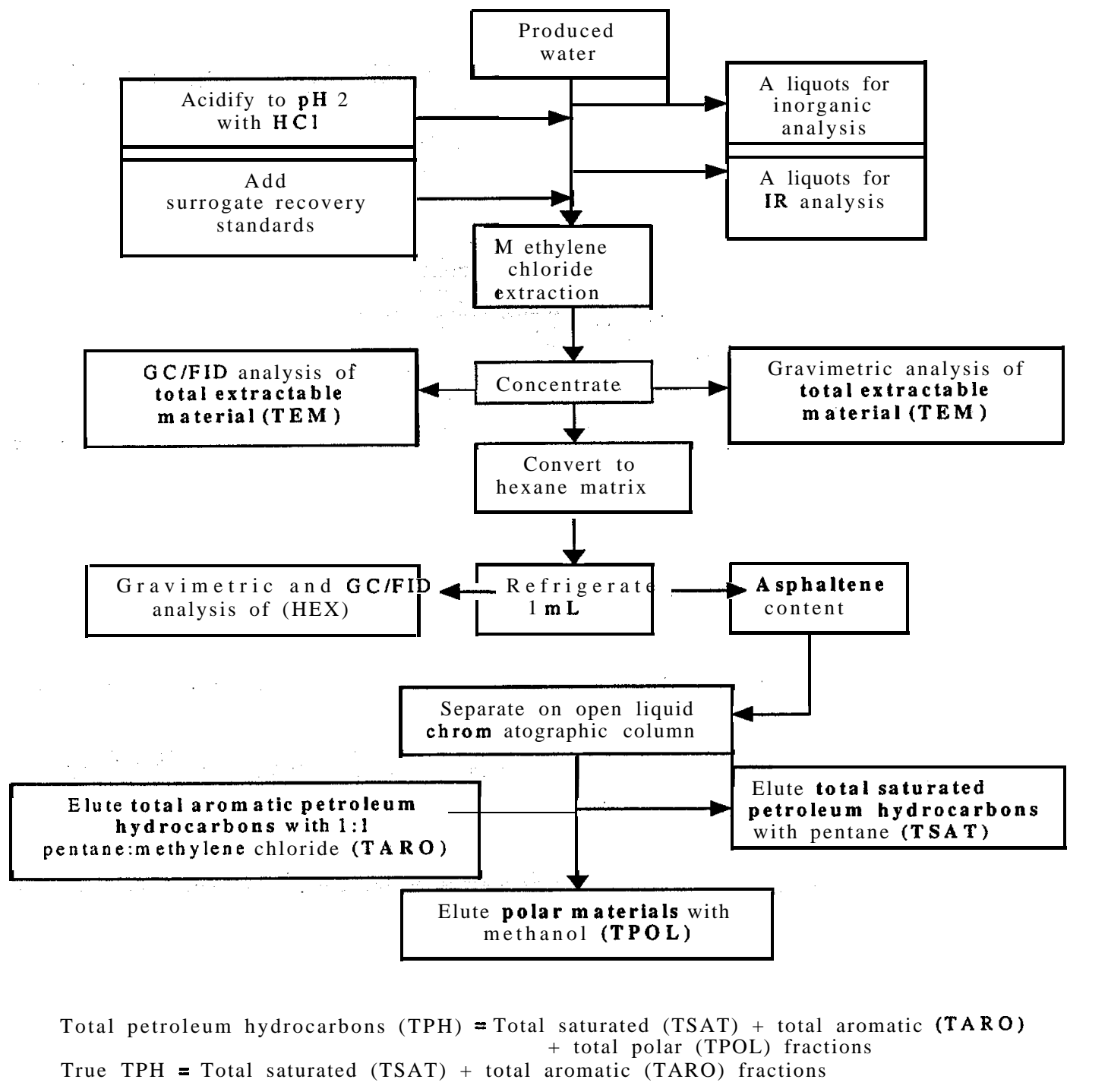

Fig. 6.1. Fractionation of WSO in simulated produced water.

Thus, the produced water sample is characterized'by total TPH content as determined from the TEM fraction. Again, it is important to recognize that total TPH mass in actuality is a summation of real petroleum hydrocarbons and water soluble organic constituents that are also extracted using methylene chloride solvent. The HEX fraction contains total TPH that was transferred from the methylene chloride matrix to the non-polar hexane fraction. Actual TPH is a combination of saturated hydrocarbon mass found in the TSAT fraction and the aromatic hydrocarbon mass found in the TARO fraction. The TPOL fraction contains the balance of organic mass from the produced water that is not petroleum hydrocarbons, but was coextracted when the water was extracted with methylene chloride. 


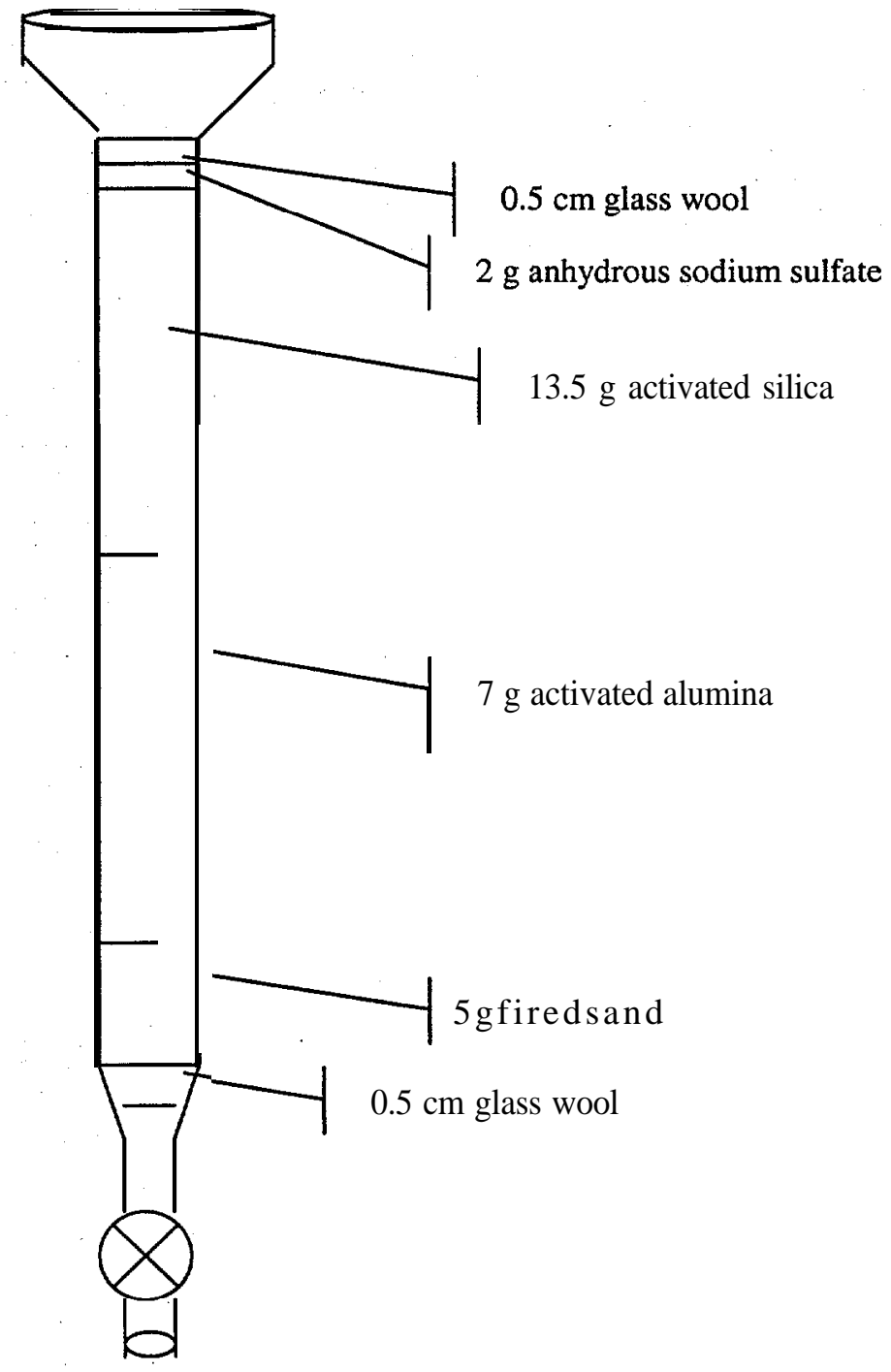

Fig. 6.2. Open liquid chromatography column for fractionation of TPH .

Column Preparation and Sample Elution

1. Pack the sorbents using a methanol solvent.

2. Once packed, elute the column successively with $50 \mathrm{~mL}$ of methanol, $200 \mathrm{~mL}$ of methylene chloride, and $40 \mathrm{~mL}$ of pentane.

3. Add the HEX sample to the top of the column. Rinse with several $1 \mathrm{~mL}$ pentane additions to transfer the sample to the head of the column.

4. Elute the TSAT fraction with $40 \mathrm{~mL}$ of pentane at $1 \mathrm{~mL} / \mathrm{min}$.

5. Rinse the K-D tube with 1: 1 methylene chloride:pentane and transfer rinsates to the head of the column. Elute the TARO fraction with $200 \mathrm{~mL}$ 1: 1 methylene chloride :pentane.

6. Rinse the K-D tube with methanol and transfer the rinsates to the head of the column. Elute the TPOL fraction with $150 \mathrm{~mL}$ of methanol. 


\subsection{DETERMINATION OF WATER CONTENT Iii CRUDE OIL}

The water content of as-received crude oil was determined by the standard Karl Fischer titration, using a Brinkman Model $652 \mathrm{KF}$-Coulometer. In this procedure, water reacts with iodine in the presence of an alkyl sulfurous acid and imidazole base to form the corresponding alkyl sulfuric acid. Iodine is generated at a constant rate by anodic oxidation of iodide present in the titration medium. When all the water present in the sample has reacted, excess iodine is indicated coulometrically. The total current multiplied by the time required to reach the titration end. point is proportional to the water content of the sample. The anode compartment of the coulometric cell was filled with AQUASTAR ${ }^{\circledR}$ Coulomat A (EM Science) anode generator solution. The cathode compartment was filled to a level of $2-3 \mathrm{~mm}$ below that of the anode generator solution with AQUASTAR ${ }^{\circledR}$ Coulomat C (EM Science) counter solution. The instrument was then turned on, and the cell matrix was conditioned to remove the trace water present in cell reagents. When the instrument response no longer drifted, $10-50 \mu \mathrm{L}$ of diluted oil was introduced into the coulometric cell. Equivalent water introduced to the cell from the diluted oil samples was 100 300 ug. Instrument response was calibrated using a $1 \mathrm{mg} / \mathrm{mL}$ water standard (HYDRANAL ${ }^{\circledR}$ Water Standard 1.00, Allied Signal).

\subsection{DETERMINATION OF pH AND BICARBONATE/CARBONATE CONTENT IN WATER}

A Metrohm 717 DMS Titrino automatic titrator was used to determine the $\mathrm{pH}$ and the hydroxide/bicarbonate/carbonate content of produced water samples (Franson, 1992). The instrument was standardized with two NIST-traceable buffer solutions $(\mathrm{pH} 7$ and $\mathrm{pH} 10$, respectively). The temperature of the solution was entered digitally before the $\mathrm{pH}$ of the sample was measured. The $\mathrm{OH}, \mathrm{CO}_{3}{ }^{2-}$, and $\mathrm{HCO}_{3}{ }^{-}$concentrations were determined by titrating $20 \mathrm{~mL}$ of produced water with standard $0.01 \mathrm{~N} \mathrm{HCl}$. End points measured at $\mathrm{pH} 8.3$ (i.e., volume end point A) and 3.7 (i.e., volume end point B) were then entered into the following calculations:

If $2 \mathrm{~A}>\mathrm{B}$, the solution contains $\mathrm{OH}$ and $\mathrm{CO}_{3}{ }^{2-}$,

$(2 \mathrm{~A}-\mathrm{B}) \times$ normality of $\mathrm{HCl} \times 17.0073 /($ sample volume $)=\mathrm{ppm} \mathrm{OH}$, 2(B - A) x normality of $\mathrm{HCl} \times 30.0046 /($ sample volume, $\mathrm{mL})=\mathrm{ppm}^{\mathrm{CO}_{3}}{ }^{2-}$.

If $\mathrm{B}>2 \mathrm{~A}$, the solution contains $\mathrm{CO}_{3}{ }^{2-}$ and $\mathrm{HCO}_{3}{ }^{-}$,

$2 \mathrm{~A} \times$ normality of $\mathrm{HCl} \times 30.0046 /($ sample volume, $\mathrm{mL})=\mathrm{ppm} \mathrm{CO}_{3}{ }^{2-}$,

$(\mathrm{B}-2 \mathrm{~A}) \times$ normality of $\mathrm{HCl} \times 61.0171 /($ sample volume, $\mathrm{mL})=\mathrm{ppm} \mathrm{HCO}_{3}{ }^{-}$.

Total alkalinity is determined from the total volume of acid required to achieve a $\mathrm{pH}$ of 3.7. It is calculated as:

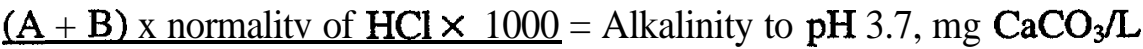
sample volume, $\mathrm{mL}$ 


\subsection{DETERMINATION OF CHLORIDE CONTENT IN PRODUCED WATER}

Ion chromatography (IC) and chloride ion-selective electrodes (ISE) were used to determine the salinity in produced water. Performance of IC protocol followed that of USEPA Method 9056 "Determination of Inorganic Anions in Ion Chromatography". Chloride analysis was performed by the sequential elution of 0.01 to $50 \mathrm{ppm}$ of anions from an IonPac AJ1 1 analytical column using a gradient elution. The eluting anion concentration was detected with a temperaturecompensated electrical conductivity cell. The instrument was calibrated by the introduction of standard anion solutions using IC operating conditions summarized in Table'6.7.

Table 6.7 IC operating conditions for anion analysis

\begin{tabular}{ll}
\hline Sample loop volume: & $4 \mathrm{mmID} ; 10 \mu \mathrm{L}$ \\
Trap column: & ATC-1 \\
Guard column: & IonPac ${ }^{\circledR} \mathrm{AG} 11$ \\
Analytical Column: & IonPac $^{\circledR} \mathrm{AJ} 11$ \\
Eluents: & El: Type I deionized water \\
& E2: $5.0 \mathrm{mM} \mathrm{NaOH}$ \\
& E3: $100 \mathrm{mM} \mathrm{NaOH}$ \\
Eluent flow rate: & $2.0 \mathrm{~mL} / \mathrm{min}$ \\
Suppressor: & Anion self-regenerating suppressor \\
& Autosuppression recycle mode \\
\hline
\end{tabular}

The majority of the sodium in brine samples had to be removed prior to anion analysis by IC. To accomplish this, a portion of the sample was passed through a hydrogen-form cation-exchange resin. The acidified sample was then introduced to the IC.

Determination of the chloride concentration was more commonly achieved using an Orion Model 94-17B chloride electrode and an Orion Model 90-02 Double-Junction Reference Electrode in combination with an Orion 520A pH/ISE meter. Response of the electrode system was calibrated using $\mathrm{NaCl}$ standards (100-3000 ppm Cl-) in which an Ionic Adjustor Solution (ISA) of $5 \mathrm{M}$ $\mathrm{NaNO}_{3}$ was added to modify the ionic strength of the solution. ISA was similarly added to a 1: 100 dilution of produced water to measure the chloride content.

\subsection{DETERMINATION OF METAL CONTENT IN PRODUCED WATER}

ICP-AES was used to determine the trace-element content of the GOM brine simulant and the produced water. All of the brine simulant samples were acidified to $10 \% \mathrm{HNO}_{3}$ concentration prior to analysis. In the case of both actual and simulated produced water samples, the dissolved organic constituents were first wet-ashed using microwave-assisted acid digestion (USEPA Method 3015). In this preparation technique, of $50 \mathrm{~mL}$ sample was digested in $5 \mathrm{~mL}$ concentrated $\mathrm{HNO}_{3}$ in a Teflon@ digestion vessel for 20 min using microwave heating. After the sample has cooled, it was filtered prior to analysis.

A Thermo-Jarrel Ash 61E ICP-AES system was used to measure trace metal concentration according to USEPA Method 6010B. Table 6.8 shows an example of instrument output for the analysis of GOM brine simulant, which lists the metals that are quantified by the equipment, as well as the instrument detection levels. Instrumental response and elemental emission correction factors were established by analyzing blanks and certified mixed-element standards. 
Table 6.8. ICP inorganic analysis of GOM brine simulant using ICP-AES

\begin{tabular}{|c|c|c|c|c|c|}
\hline Metal. & $\mathrm{DL}_{2}$ & $\begin{array}{l}\text { Quantification } \\
\text { limit } \\
(m \tilde{0} \pi \tilde{0})\end{array}$ & $\begin{array}{cc}\text { Raw } & \text { data } \\
\text { conc. } & S_{x} \\
(\mathrm{mg} / \mathrm{L}) & (\mathrm{mg} / \mathrm{L}) \\
-0.00086 & 0.00035\end{array}$ & $\begin{array}{l}\text { Sample } \\
\text { (mnch) } \\
8.00\end{array}$ & $\begin{array}{l}\text { Analytical error } \\
\text { (mg/L) }\end{array}$ \\
\hline Aluminum & 0.046404 & 0.06 & -0.01643 & 60.0 & \pm 25.4 \\
\hline Arsenic & 0.008304 & 0.02 & -0.006490 .00092 & 20.0 & \pm 2.3 \\
\hline Boron & 0.021937 & 0.05 & $\begin{array}{lll}-0.03 & 163 & 0.00094\end{array}$ & $50.0^{\prime}$ & \pm 2.3 \\
\hline Barium & $9.26842 \mathrm{E}$ & 0.003 & $0.04387 \quad 0.00125$ & 43.9 & \pm 3.1 \\
\hline Beryllium & $5.32885 \mathrm{E}$ & 0.002 & $-0.00046 \quad 0.00013$ & 2.00 & \pm 0.32 \\
\hline Calcium & 0.025085 & 0.075 & $3.3131 \quad 0.07225$ & 3313 & \pm 179 \\
\hline Cadmium & $6.34906 \mathrm{E}$ & 0.002 & -0.000040 .0001 & 2.00 & \pm 0.25 \\
\hline Chromium & 0.001673 & 0.005 & $-0.00051 \quad 0.00015$ & 5.00 & \pm 0.37 \\
\hline Cesium $^{a}$ & 17.10689 & 20 & -0.612373 .15486 & 20,000 & \pm 7838 \\
\hline Copper & 0.005883 & 0.02 & $-0.00186 \quad 0.00076$ & 20.0 & \pm 1.9 \\
\hline Iron & 0.113441 & 0.2 & $0.04355 \quad 0.01663$ & 200 & \pm 41 \\
\hline Potassium & 0.023321 & 0.04 & $-0.06447 \quad 0.00535$ & 40 & \pm 13 \\
\hline Magnesium & 0.040085 & 0.05 & $\begin{array}{lll}0.883 & 16 & 0.02262\end{array}$ & 883 & \pm 56 \\
\hline Manganese & 0.001003 & 0.003 & $\begin{array}{ll}-0.00038 & 0.00007\end{array}$ & 3.00 & \pm 0.17 \\
\hline Molybdenum & 0.004071 & 0.01 & $-0.00042 \quad 0.00078$ & 10.0 & \pm 1.9 \\
\hline Sodium & 0.092114 & 0.15 & $\begin{array}{lll}35.14379 & 0.84618\end{array}$ & 35,144 & \pm 2102 \\
\hline Niobium & 0.002731 & 0.008 & 0.00180 .00424 & 8.0 & \pm 10.5 \\
\hline Nickel & 0.006758 & 0.02 & $-0.00475 \quad 0.00034$ & 20.0 & \pm 0.8 \\
\hline Lead & 0.002946 & 0.009 & -0.001140 .00136 & 9.0 & \pm 3.4 \\
\hline Selenium & 0.010864 & 0.03 & -0.001890 .00169 & 30.0 & \pm 4.2 \\
\hline Antimony & 0.017710 & 0.04 & -0.003730 .00158 & 40.0 & \pm 3.9 \\
\hline Silicon & 0.029039 & 0.06 & -0.02790 .00489 & 60.0 & \pm 12.1 \\
\hline Strontium & $3.90035 \mathrm{E}$ & 0.001 & 0.134020 .00322 & , 134.0 & $\mathrm{f} 8.0$ \\
\hline Thorium & 0.553176 & 0.8 & 0.012490 .09979 & $800^{\cdots}$ & \pm 248 \\
\hline Titanium & $6.18243 \mathrm{E}$ & 0.002 & -0.00130 .00002 & 2.00 & \pm 0.05 \\
\hline Thallium & 0.008663 & 0.025 & $0.0002: 0.00337$ & 25.0 & $\mathrm{f} 8.4$ \\
\hline Uranium & 0.073958 & 0.18 & $0.12958 \quad 0.06027$ & 180 & \pm 150 \\
\hline Vanadium & 0.007891 & 0.02 & $-0.00026 \quad 0.00013$ & 20.00 & \pm 0.32 \\
\hline Zinc & 0.004324 & 0.01 & $-0.00797 \quad 0.00016$ & 10.00 & \pm 0.40 \\
\hline Zirconium & 0.031518 & 0.07 & $0.00154 \quad 0.00561$ & 7.900 & \pm 13.9 \\
\hline
\end{tabular}

${ }^{a}$ Cesium concentration overestimated due to the interference of large quantities of sodium ion in the sample. 


\subsection{ANALYSIS OF $\mathrm{C}_{1}-\mathrm{C}_{6}$ ORGANIC ACIDS}

Concentrations of organic acids were determined by injecting produced water directly into a Dionex LC20 ion chromatograph fitted with an IonPac ${ }^{\circledR}$ ICE-AS6 (Dionex Corp.) separation column. The acids were separated from the high chloride sample matrix using a $0.4 \mathrm{mM}$ heptafluorobutyric acid eluent; a 1-ppm detection limit was typical. Instrument response was calibrated using formic, acetic, propionic, malonic, and oxalic acids in the concentration range of 10-50 ppm. Specific operating conditions are listed below.

Table 6.9 IC operating conditions for $\mathbf{C}_{1}-\mathbf{C}_{6}$ organic acid analysis

\begin{tabular}{ll}
\hline Sample loop volume: & $0.037-\mathrm{mm}$ ID X 9.75 in length; $50 \mu \mathrm{L}$ \\
Analytical Column: & IonPac ${ }^{\circledR}$ ICE-AS6 \\
Eluents: & E1: $1.8 \mathrm{~m} M$ carbonate/1.7 mM bicarbonate \\
& E2: $0.1 \mathrm{M}$ sodium hydroxide \\
& E3: $0.4 \mathrm{mM}$ heptafluorobutyric acid \\
& E4: dionized water \\
Eluent flow rate: & 1.OmL/min \\
Suppressor: & Anion micromembrane self- \\
& regenerating suppressor-ICE II \\
& Autosuppression regenerant mode \\
\hline
\end{tabular}

\section{ASSESSMENT OF DATA QUALITY}

\subsection{CORRESPONDENCE BETWEEN ANALYTICAL METHODS FOR WSO CONSTITUENTS}

Correspondence testing of chemical procedures used to analyze the chemical contents of neat oil and produced water was performed to establish equivalency in data derived through various analytical protocols within the PERF 98-04 project. Statoil provided characterization data derived from North Sea samples. Their protocol relied on the analysis of individual semi-volatile compounds, as defined by USEPA Method SW-846 8270C, and total petroleum hydrocarbon content, as defined by USEPA Method SW-846 8015B. ORNL supplied data derived from GOM crude oil and brine. Rather than identifying individual chemical compounds, ORNL characterized samples based on carbon-range content and general chemical classes. It will be important to understand the equivalency of the North Sea and GOM data when all the information is combined into a single mathematical model that will predict organic contamination in produced water.

ORNL submitted samples of GOM crude and synthetic produced water to Mountain States Analytical, Inc. (1645 West 2200 South, Salt Lake City, Utah 84119) for standard USEPA Methods testing. These samples were also analyzed at ORNL, using open-column LC separation to fractionate WSO into general chemical classes. The resulting fractions were then analyzed by GC/FID to determine the relative distribution of carbon content in each of these classes. Comparative results of deep-well crude by various protocols are summarized in Table 7.1. The TPH content in the GOM crude, as defined by USEPA Method SW-846 8015B, was $300 \mathrm{~g} / \mathrm{kg}$ TPH-DRO $\mathrm{C}_{10}-\mathrm{C}_{28} ; 180 \mathrm{~g} / \mathrm{kg}$ TPH-GRO $\mathrm{C}_{6}-\mathrm{C}_{10}$; and $200 \mathrm{~g} / \mathrm{kg} \mathrm{TPH}-O i l \mathrm{C}_{20}-\mathrm{C}_{28}$. Approximate ratios of carbon size by the USEPA method were 37,21 , and $42 \%$ for $C_{6}-C_{10}, C_{10}-C_{20}$, and $\mathrm{C}_{20}-\mathrm{C}_{28}$ ranges, respectively. The relative distribution using a similar GC/FID procedure at 
ORNL was found to be 50,42 , and $8 \%$ in the carbon series. Differences in relative distribution of. carbon content may reflect error introduced by variances in sampling time and frequency of sampling. . Off-site data were the result of duplicate analyses from a single grab sample taken on arrival of Deep1 crude. ORNL data were derived from the average results of five grab samples taken over a several month time frame.

The principal semi-volatile compounds in the deep-well oil, as identified by USEPA Method SW$8468270 \mathrm{C}$, included acetophenone $(0.6 \mathrm{~g} / \mathrm{kg})$ and methylnapthalene $(0.4 \mathrm{~g} / \mathrm{kg})$. These particular constituents represented less than $2 \%$ of the total organic content in either GOM or North Sea sources of crude oil. Chemical classification by open LC protocol helps to accounted for the remaining $98 \%$ of the organic character in either oil orproduced water samples. Methylene chloride-extractable material (TEM) in deep-well oil was $200-400 \mathrm{~g} / \mathrm{kg}$. Approximately $35 \%$ of this material could be exchanged into a hexane "matrix. The relative composition of the hexane matrix is $35 \%$ saturated hydrocarbons, $15 \%$ aromatic components, and $50 \%$ polar material. The visibly colored red-brown material was primarily present in the polar fraction.

Table 7.1 Correspondence of analytical methods in the characterization of deep-well crude

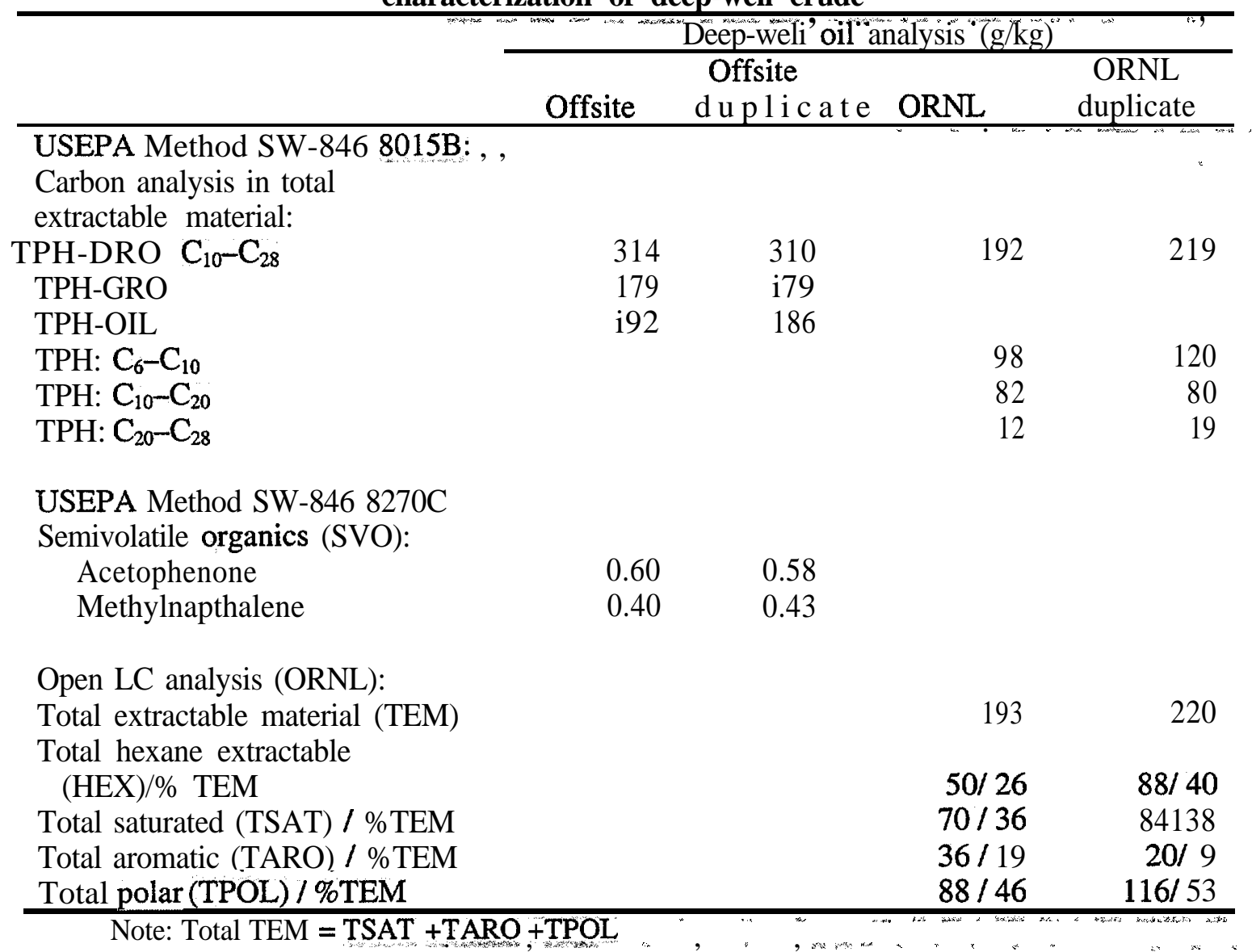

The total concentration of WSO in produced water derived from oil/brine simulant contacts was 20-30 ppm, using either USEPA Method SW-846 8015B or ORNL GC/FID procedures. Identified semi-volatile compounds were 1-methylnaphthalene (10 ppb), 2-methylnaphthalene (9 $\mathrm{ppb}$ ), naphthalene (14 ppb), and phenol (30 ppb). Again, compounds identified by USEPA Method SW-846 (8270C) accounted for very little of the total WSO content. Chemical 
fractionation of the total extractable materials suggested that $80-90 \%$ of WSO is present as polar compounds; the next largest fraction is that of aromatic materials. The colored material was primarily present in the lightly yellow aromatic fraction.

In combining data from the North Sea and GOM samples, it appears that data generated by USEPA Method SW-846 8015B or ORNL GC/FID procedures correlate well to indicate the total organic content and relative carbon ranges from these two drilling sites. The toxicity of the WSO can be estimated using data generated by USEPA Method SW-846 8270C from North Sea samples and the chemical nature of the material can be estimated using the open LC method derived from GOM samples.

\subsection{SURROGATE RECOVERY AND BLANK LEVELS FOR OPEN LC FRACTIONATION AND GC/FID ANALYSIS}

The analysis of produced water generated by contacting shipped oil samples with simulant GOM brine probably reflects a negative bias in total WSO content. The oil had been contacted with injection water during its collection onsite; therefore, a portion of the TPH had already been stripped from the sample of crude prior to testing in this project. An estimate of the analytical bias might be achieved by analyzing WSO in actual produced water from this particular site.

The gravimetric analysis of evaporate residue provided a gross estimate of TPH content. This analysis was usually performed on either crude oil dissolved directly in methylene chloride or WSO present in the concentrated methylene chloride extracts (TEM fractions) of produced water. The lower limit of detection for gravimetric analysis was dictated by the $0.2-\mathrm{mg}$ weight limit of an electronic balance. This measurement corresponded to a gravimetric limit of detection of 0.2 $\mathrm{g} / \mathrm{L}$ in $650 \mathrm{~g} / \mathrm{L}$ WSO found in crude. The WSO content in produced water was significantly lower $(20-30 \mathrm{ppm})$. Since the TEM fraction is derived from the extraction of one liter of produced water, the balance weight limit corresponded to a gravimetric limit of detection of 12 ppm in aqueous samples.

GC/FID provided a much more sensitive estimate for WSO present in oil or produced water. Quantitation was based on instrument response relative to that of a series of certified $n$-alkane standards. Identification of mass within carbon size ranges is dependent on retention times of the various alkane standard components (Fig. 7.1). Both $\mathrm{C}_{6}-\mathrm{C}_{10}$ and $\mathrm{C}_{10}-\mathrm{C}_{20}$ ranges had similar FID response factors; FID response over the $\mathrm{C}_{20}-\mathrm{C}_{28}$ range was slightly lower due to column bleed at the elevated GC temperatures in this portion of the chromatogram. The relatively constant FID response factor over all carbon ranges indicated that GC/FID analysis provided a relatively accurate estimate of true TPH mass in the LC fractions. The material present in the TPOL fraction is made up of compounds containing nitrogen, oxygen and sulfur atoms. FID response to non-hydrocarbon components is more variable. Therefore, GC/FID analysis of this fraction in particular provides an estimate of organic mass.

The successive solvent extractions and multiple concentration steps in either the USEPA protocol or the LC fraction protocol contributed to losses of WSO material. Although negative bias is inherent to the WSO analysis, discharge permitting is based on the same USEPA method. Therefore, data derived from such procedures will still reflect a value for WSO content that can be used for modeling and subsequent development of engineering practices that will reduce the generation of WSO. The extraction recovery of WSO were typically estimated by the introduction of surrogate recovery standards to the produced water prior to manipulating the sample. Deuterated forms of the spike standards were selected to provide the option for future 
sample analysis by GC-MS if the latter was considered necessary. These compounds are listed in Table 7.2, together with the recovery found for each LC fraction. Tribromophenol was substituted for phenol midway through the experimental campaign. Phenol identification was difficult due to the proximity of its retention peak to the peaks of the majority of WSO compounds found in the TEM and HEX fractions.

Table 7.2. Surrogate spike recovery compounds for $L C$ fractionation protocol

\begin{tabular}{lccccccc}
\hline Recovery & Constituent & \multicolumn{2}{c}{ Spike } & \multicolumn{5}{c}{ Recovery in each LC fraction (\%) } \\
\cline { 3 - 8 } standard & surrogate & level $(\mu \mathrm{g})$ & TE M & H E X & TSAT & TARO & TPOL \\
\hline n-Hexanoic acid Organic-acids & 4,635 & 100 & 55 & 0 & 0 & $1-10$ \\
n-Dodecane- $d_{26}$ & Saturated TPH & 115 & 100 & 60 & $5-30$ & 0 & 0 \\
Naphthalene- $d_{8}$ & Aromatic TPH & 100 & 100 & 55 & 0 & $20-60$ & $5-40$ \\
N-phenol\& & Polar TPH & 70 & $\cdots$ & --- & 0 & 0 & $0-40$ \\
tribromophenol polar TPH & 196 & 100 & 75 & 0 & 0 & $50-90$ \\
\hline
\end{tabular}

Positive bias can be introduced into the analytical procedure through the contamination present in solvents and labware. Therefore, a procedural blank containing all surrogate recovery standards was run to determine the WSO blank level for each LC fraction. Figure 7.2 presents a chromatogram of the blank levels and recovery standards associated with the TEM fraction derived from the methylene chloride extraction of $1 \mathrm{~L}$ simulant brine spiked with recovery standards. The solvent front completely eluted after $2 \mathrm{~min}$. After solvent and recovery surrogate data was stripped from the chromatogram, regression analysis of the resulting peak area for this fraction yielded a calculated blank level of $-0.2 \mu \mathrm{g}$ TPH. This level compares with a $0.2-\mu \mathrm{g}$ TPH detection limit for the GC/FID. Complete processing through the LC protocol yielded the blank levels shown in Table 7.3. Comparable WSO blank levels were calculated for $1 \mathrm{~L}$ of produced water. A positive blank was associated with the TPOL fraction:. A low level of apparent WSO resulted from methanol extraction of the organic matter from fired sand. This necessitated an additional wash of fired sand before a packed LC column was loaded with sample.

Table 7.3 Calculated blank levels associated with each LC fraction

\begin{tabular}{lccc}
\hline LC fraction & TPH $(\mu \mathrm{g})$ & $\begin{array}{c}\text { Equivalent WSO in } \\
\text { produced water }(\mathrm{ppm})\end{array}$ \\
\hline TEM & -0.2 & -0.02 \\
'HEX & -0.3 & -0.02 \\
TSAT & & 0.0 & 0.0 \\
TARO & 0.08 & 0.08 \\
TPOL & 0.2 & 0.02 \\
\hline
\end{tabular}

\subsection{BIASES ASSOCIATED WITH LC FRACTIONATION PROTOCOL}

A series of chromatograms were prepared to illustrate the typical quantities of TPH found in individual LC fractions, as well as the relative losses encountered with the fractionation protocol. These chromatograms followed the processing of produced water generated from contacting 750 $\mathrm{mL}$ of deep-well crude with $3000 \mathrm{~mL}$ of GOM brine simulant at $\mathrm{pH} 7,65,000 \mathrm{TDS}, 25^{\circ} \mathrm{C}$, and ambient pressure (denoted as experiment "PERF-20" in appendix data tables). As in chromatograms of diluted oils, the WSO in produced water contained a multitude of organic components. Figure 7.3 presents the WSO contained in the concentrated methylene chloride extract of produced water (i.e., the TEM fraction). Because of the complexity of the composition, 
it is evident that a general classification, rather than specific component identification, should be used to characterize WSO in produced water economically. The majority of WSO elute at retention times comparable to $\mathrm{C}_{6}-\mathrm{C}_{10}$ and $\mathrm{C}_{10}-\mathrm{C}_{20}$ n-alkanes. Because of the quantity of material present in TEM fractions, manual baseline construction was performed to determine the organic mass in these fractions.

Most of the TEM fraction concentrate was converted to a hexane (HEX) matrix prior to its addition to the LC column. This procedural step accomplished two objectives. The first was to acquire TPH data equivalent to data obtained from extractions with hexane, a typical solvent used to determine WSO in field testing. Second, the LC protocol required an initial nonpolar matrix. Organic fractionation was then accomplished by serially increasing the polarity of the eluent. Figure 7.4 presents the chromatogram of WSO in the hexane matrix. Concentration of hexane requires a heating temperature of $85^{\circ} \mathrm{C}$, which is $20^{\circ} \mathrm{C}$ higher than that needed for methylene chloride evaporation. Therefore, some of the more volatile WSO constituents in the $\mathrm{C}_{6}-\mathrm{C}_{10}$ range were less prevalent in the chromatogram of HEX extracts, yielding a carbon range distribution observed using USEPA methods based on hexane extractions. Approximately 50\% of the surrogate recovery standards are lost in the solvent exchange. Beginning with experiment PERF15 , solvent substitution was modified to reduce organic losses as a result of elevated temperatures. The volume of hexane was reduced by evaporation at $35^{\circ} \mathrm{C}$ under a flow of nitrogen gas. Again, the quantity of material present in TEM fraction was such that the chromatograms were typically not baseline resolved. This may have contributed to a slight negative bias in the calculation of percent TPH transferred to the HEX fraction.

Pentane was used to elute saturated organic compounds from the LC column. Typically, the TSAT chromatogram (Fig.7.5) contained only the n-decane surrogate standard at a recovery of approximately $25 \%$. Aromatic compounds were present in the produced water as indicated in the number of peaks found in the chromatogram of the TARO fraction. Naphthalene was usually recovered at $40 \%$ of initial spike levels. The TARO chromatogram (Fig. 7.6) contained column contaminants in the $\mathrm{C}_{6}-\mathrm{C}_{10}$ carbon range equivalent to about $0.1 \mathrm{ppm}$ WSO in produced water. This contaminant level was subtracted from all TARO fraction data.

The LC protocol developed by Mills et al. was used to calculate the quantity of polar constituents in produced water by subtracting the combined WSO mass found in TARO and TSAT fractions from that found in the TEM fraction. This type of calculation was made for each contact experiment performed in the study reported here. These values are denoted as TPOL(subtract) in the appendix data tables. This form of calculation may have overestimated the contribution of polar material, considering that only $40 \%$ of TEM material was actually transferred to the LC column in the form of the HEX extract. If it is assumed that losses in the solvent exchange from methylene chloride to hexane were primarily due to the evaporation of low molecular weight organic acids, then the TPOL(subtract) data might adequately compensate for this loss and thus would not significantly bias the calculation of total WSO found in this fraction.

The polar material in produced water was also estimated by adding a final elution step to the LC protocol defined by Mills et al. After the TARO fraction had been collected, a polar solvent was employed to elute the polar WSO from the column. Initially, methylene chloride was used as the eluent; however, methanol was found to be more effective in removing polar constituents and was used in experiment PERF-11 and all experiments thereafter. Even with a methanol solvent, the presence of colored material remaining on the fired sand at the head of the column from the LC separation of diluted crude indicated that some polar constituents were irreversibly adsorbed to the column. Nonetheless, the chromatogram (Fig. 7.7) of the eluted TPOL fraction, denoted as 
TPOL (gc) in the appendix data tables, implies that most of the WSO compounds were present as polar constituents in the $\mathrm{C}_{10}-\mathrm{C}_{20}$ carbon range. The hexanoic acid and tribromophenol recovery standards in this fraction were present at 5 and $70 \%$, respectively.

\subsection{COMPARISON OF LC FRACTIONATION PROTOCOL WITH INFRARED SPECTROMETRIC A NAL Y IS,}

A secondary comparison of methods is presented below. The TPH content of a portion of produced-water samples was determined by the GC/FID analysis of TEM fractions and, secondarily, by the $\mathbb{R}$ analysis of their tetrachloroethylene extracts. Results based on IR data tended to underestimated the TPH content; the salinity present in the produced water depressed IR absorbance readings in the samples (see Table 7.4).

Table 7.4. Correspondence of TPH results from LC fractionation and IR spectroscopy

\begin{tabular}{|c|c|c|c|c|}
\hline \multirow[b]{2}{*}{ Experiment } & \multicolumn{3}{|c|}{ "TPH $(\mathrm{mg} / \mathrm{L})$} & \multirow[b]{2}{*}{$\sim$} \\
\hline & $\begin{array}{l}\text { LC fractionation } \\
\text { TEM fraction }\end{array}$ & IF & spectroscopy & \\
\hline PERF-6 & 12 & & I- & tis - \\
\hline PERP-7 & 37 & & & \\
\hline PERF-8 & 25 & & 6 & \\
\hline PERF-9 & 30 & & 13 & \\
\hline PERF-10 & 22 & & 13 & \\
\hline PERF-11 & 2 & 6 & 25 & \\
\hline PERF-12 & 11 & & & \\
\hline PERF-13 & 21 & & 16 & \\
\hline PERF-14 & 10 & & 49.8 & \\
\hline PERF-15 & 12 & & 12.3 & \\
\hline PERP-16 & 14 & & 10.5 & \\
\hline PERP-17 & 18 & & 17.6 & \\
\hline PERF-18 & 2 & & 23.1 & \\
\hline PERP-19 & 10 & & 8.7 & \\
\hline PERF-20 & 21 & & 10.6 & \\
\hline
\end{tabular}

\section{RESULTS}

\subsection{CHEMICAL CHARACTERIZATION OF DEEP-WELL CRUDE}

The LC column fractionation procedure was used to characterize deep-well crude according to the quantity of organic matter in each chemical class, as well as carbon size distribution. Results presented in Table 8.1 summarize the data for three to five deep crude analyses, in which $\lg$ of mixed oil was diluted 25-fold with methylene chloride. Data were calculated in units of grams organic mass per liter of oil but can be converted to a weight basis using a density value of 0.8432 $\mathrm{g} / \mathrm{L}$ at $25^{\circ} \mathrm{C}$. The TEM fraction was made up of $45 \%$ each of $\mathrm{C}_{6}-\mathrm{C}_{10}$ and $\mathrm{C}_{10}-\mathrm{C}_{20}$ material. The $\mathrm{C}_{6}-\mathrm{C}_{28}$ data indicate that $35 \%$ of the organic mass was transferred to the HEX fraction; the major loss of material was from the $\mathrm{C}_{6}-\mathrm{C}_{10}$ carbon range. Of the organic material transferred to the HEX fraction roughly $75 \%$ of the mass was contained in the saturated hydrocarbon class. The remaining mass was equally divided between aromatic and polar constituents. The standard 
deviation in the data reflects a combination of error introduced in sampling the mixed oil and in preparing the LC fractions.

Table 8.1. Chemical fraction data for GOM deep-well crude samples

\begin{tabular}{lcccc}
\hline LC fraction & $\mathrm{C}_{6}-\mathrm{C}_{28}(\mathrm{~g} / \mathrm{L})$ & $\mathrm{C}_{6}-\mathrm{C}_{10}(\mathrm{~g} / \mathrm{L})$ & $\mathrm{C}_{10}-\mathrm{C}_{20}(\mathrm{~g} / \mathrm{L})$ & $\mathrm{C}_{20}-\mathrm{C}_{28}(\mathrm{~g} / \mathrm{L})$ \\
\hline TEM & $201 \pm 26$ & $114 \pm 21$ & $90 . \pm 14$ & $9.7 \pm 6.1$ \\
HEX & $70 . \pm 19$ & $5.3 \pm 3.5$ & $54 \pm 19$ & $10 . \pm 4.7$ \\
TSAT & $74 \pm 9.1$ & $8.3 \pm 4.0$ & $61 \pm 11$ & $3.5 \pm 0.7$ \\
TARO & $21 \pm 14$ & $4.0 \pm 3.4$ & $15 \pm 9.6$ & $4.0 \pm 3.0$ \\
TPOL $(\mathrm{gc})$ & $16 \pm 3.6$ & $14 \pm 4.2$ & $0.57 \pm 0.06$ & $0.67 \pm 0.57$ \\
\hline
\end{tabular}

\subsection{WSO AS A FUNCTION OF PERCENT WATER CUT}

Methylene chloride-extractable material in the equilibrated produced water was typically present at 20-30 ppm. Its chemical character differed significantly from that of the deep crude. The values listed in Table 8.2 reflect the average of three oil/brine contacts in which the experimental baseline conditions were set at $80 \%$ GOM synthetic brine/oil, equilibration for 4 days at $25^{\circ} \mathrm{C}, \mathrm{pH}$ 7 brine, and 65,000 TDS. The brine volumes added to the WAF vessel varied from 1 to $3 \mathrm{~L}$, while the oil volume varied from 0.25 to $0.75 \mathrm{~L}$. TEM organic matter was distributed between the low and midrange carbon masses, similar to the oil data. However, the WSO eluted from the LC column are primarily polar compounds with a minor contribution by aromatic constituents. The slight yellow coloration of produced water appears to be associated with the aromatic fraction. As would be expected, saturated compounds were not noticeably extracted into the produced water.

Table 8.2. Chemical fraction data for GOM synthetic produced water*

\begin{tabular}{lcccc}
\hline LC Fraction & $\mathrm{C}_{6}-\mathrm{C}_{28}(\mathrm{mg} / \mathrm{L})$ & $\mathrm{C}_{6}-\mathrm{C}_{10}(\mathrm{mg} / \mathrm{L})$ & $\mathrm{C}_{10}-\mathrm{C}_{20}(\mathrm{mg} / \mathrm{L})$ & $\mathrm{C}_{20}-\mathrm{C}_{28}(\mathrm{mg} / \mathrm{L})$ \\
\hline TEM & $21 \pm 4$ & $7 \pm 0.4$ & $13 \pm 3$ & $0.8 \pm 1.3$ \\
HEX & $11 \pm 5$ & $0.4 \pm 0.4$ & $10 \pm 4$ & $0.01 \pm 0.01$ \\
TSAT & $0.02 \pm 0.02$ & $0.02 \pm 0.01$ & $0.00 \pm 0.00$ & $0.00 \pm 0.00$ \\
TARO & $0.2 \pm 0.2$ & $0.07 \pm 0.08$ & $0.04 \pm 0.02$ & $0.00 \pm 0.00$ \\
TPOL $(\mathrm{gc})$ & $2.4 \pm 1.7$ & $0.00 \pm 0.00$ & $2.4 \pm 1.7$ & $0.00 \pm 0.00$ \\
\hline
\end{tabular}

$* 80 \%$ GOM synthetic brine/oil, 4 days at $25^{\circ} \mathrm{C}$, pH 7 brine, 65,000 TDS WAF vessel

Figures 8.1 and 8.2 summarize the data trends for various water/oil ratios. There was a slight negative trend in WSO content in all chemical fractions as the water cut increased. This effect was a combination of decreasing solubility of the $\mathrm{C}_{10}-\mathrm{C}_{20}$ mass and increasing solubility of the $\mathrm{C}_{6}-\mathrm{C}_{10}$ carbonaceous material.

\subsection{WSO DISTRIBUTION COEFFICIENTS AS A FUNCTION OF PERCENT WATER CUT}

The analytical results obtained in the characterization of crude oil were used to determine values of the approximate distribution coefficients $\left(\mathrm{K}_{\mathbf{d}} \mathbf{s}\right)$ of WSO in GOM brine as a function of percent water cut and brine volume. The $\mathrm{K}_{\mathrm{d}} \mathrm{s}$ were calculated for brine simulant at baseline conditions of $65,000 \mathrm{TDS}, \mathrm{pH} 7$ brine, ambient pressure, and $25^{\circ} \mathrm{C}$. Equilibrium conditions were assumed after 
a 4day contact time. Calculations based on the following equation were performed for each chemical class:

$$
\mathrm{K}_{\mathrm{d}}=\frac{\text { (initial oil concentration }) \times(\text { oil volume })-(\text { WSO in brine }) \times \text { (brine volume })}{(\text { WSO in brine }) \times(\text { oil volume })^{\prime}}
$$

The data presented in Fig. 8.3 imply that the value for $\log K_{d}$ of each chemical fraction remained constant with water cut. Average values for $\log \mathrm{K}_{\mathrm{d}}$ were 4.0, 3.8, 5.0, 5.1, and 6.3 for TEM, HEX, TPOL, TARO and TSAT fractions, respectively. The value of Log $\mathbf{K}_{\mathbf{d}}$ for each carbon range was also independent of water cut, as borne out in Fig. 8.4 as well as in the data summarized in Tables 8.3 and 8.4. The only deviation from this trend was observed with slightly higher values for the data set obtained for a $73 \%$ water, cut. These data were generated using the small pressure vessel. Although all data acquired with the pressure vessel were consistent in the subset, WSO values in the produced water were lower than those obtained with the WAF vessel.

\subsection{WSO AS A FUNCTION OF SALINITY}

The variation of TDS (as salinity) did not significantly alter the WSO content of the produced water. As seen in Fig. 8.5, the total WSO remained at $10-15$ ppm over the chloride concentration range of 40,000 to $115,000 \mathrm{ppm}$. Neither the chemical character nor the carbon content (Fig. 8.6) varied with TDS.

\subsection{WSO AS A FUNCTION OF pH}

The $\mathrm{pH}$ of the GOM brine simulant. was-buffered to $7-7.5$ by the presence of an oil layer. In order for the oil/water contact to be performed at a $\mathrm{pH}$ outside this range, $\mathrm{NaOH}$ or $\mathrm{HCl}$ had to be added continuously to maintain the desired $\mathrm{pH}$ level. The use of a $0.25 \mathrm{M}$ borate buffer was not sufficient to maintain the $\mathrm{pH}$ of the aqueous phase at more alkaline values. The required $\mathrm{pH}$ adjustment was reduced with each contact day, such that no further adjustment was required on

the fourth day. Thus, equilibrium was assumed to have been reached at this point. As expected, the $\mathrm{pH}$ of the brine simulant affected the concentrations of $\mathrm{CO}_{3}{ }^{2-}$ and $\mathrm{HCO}_{3}^{-}$. Acidic solutions reacted with $\mathrm{HCO}_{3}^{-}$anion. Basic solutions increased the initial carbonate concentration sufficiently to precipitate alkaline earth metals, thereby reducing the equilibrium concentration of both $\mathrm{CO}_{3}^{2-}$ and $\mathrm{HCO}_{3}^{-}$.

The WSO content almost doubled for $\mathrm{pH}$ values above 7 (Fig. 8.7). This was primarily due to the enhanced solubility of polar organic compounds that ionize at higher $\mathrm{pH}$ levels. An enhanced solubility of the $\mathrm{C}_{10}-\mathrm{C}_{20}$ carbon-range material and a decline in $\mathrm{C}_{6}-\mathrm{C}_{10}$ mass for $\mathrm{pH}$ values greater than 7 were also observed (Fig. 8.8).

\subsection{WSO AS A FUNCTION OF TEMPERATURE}

The chemical character of the WSO did not. appear to be dependent on brine temperature (Fig. 8.9). However, the percentage mass in each carbon range was altered; the mass of WSO in the $\mathrm{C}_{6}-\mathrm{C}_{10}$ carbon range decreased while that in the $\mathrm{C}_{10}-\mathrm{C}_{20}$ range increased (Fig. 8.10). Thus, the net quantity of organics in the produced water increased by only $5 \mathrm{ppm}$ for a $60^{\circ} \mathrm{C}$ elevation in solution temperature. 


\subsection{WSO AS A FUNCTION OF PRESSURE}

The distribution of organic compounds in GOM brine was studied as a function of pressure over the range of 1 to 58 bar. The results are presented in Fig. 8.11 and 8.12. It was found that WSO content in the TEM fraction increased by less than ten percent over the pressure range. The total WSO content for this subset of experiments were less than expected, based on pervious data obtained with the WAF vessel. Experiments performed with the WAF vessel were typically conducted with $300 \mathrm{~mL}$ oil in contact with $1 \mathrm{~L}$ of brine. The total WSO levels were generally 16$20 \mathrm{ppm}$ for WAF experiments. The WSO of the $200 \mathrm{~mL}$ brine drawn from the pressure vessel consistently averaged only 4-6 ppm. At this point, the reason for this variance is unknown. Pressure data presented in these graphs also exhibit a fair amount of scatter, attributed to both the low level of WSO in the pressurized samples and tie difficulty in separating the phases after contact in the opaque pressure vessel.

The slight increase observed in total WSO as a function of pressure appears to be associated with the polar fraction. The influence of pressure on the measured fractions of saturated hydrocarbons (TSAT) and aromatic hydrocarbons (TARO) were investigated, but no trends were observed. The enhanced quantity of WSO observed in the polar fraction was the result of additional dissolved $\mathrm{C}_{6}-\mathrm{C}_{10}$ material (Fig. 8.12). A slight decrease in quantities in the $\mathrm{C}_{20}-\mathrm{C}_{28}$ range was also evident.

\subsection{COMPOSITION OF $\mathrm{C}_{1}-\mathrm{C}_{6}$ ORGANIC ACIDS IN PRODUCED WATER}

Three organic acids were typically found in the produced-water samples: formic, acetic, and propionic acids. No higher-carbon acids were found. Acetic acid, which made up the bulk of the acid mass, was present at levels similar to that of TPH (10-30 ppm). Propionic and formic acids were present at approximately 60 and 20\%, respectively, of the acetic acid concentration.

It is important to understand the extent to which low-molecular-weight acids might elevate the apparent TPH concentration found in methylene chloride and HEX extracts. The NPDES limit set for the oceanic discharge of GOM produced water is $42 \mathrm{ppm}$ TPH. If the acid and TPH concentrations in produced water were roughly equivalent, the TPH analysis might be artificially overstated by the presence of high levels of organic acids. To estimate the proportion of acids extracted by methylene chloride and hexane, $1 \mathrm{~L}$ of GOM brine simulant was spiked with 1000 $\mu \mathrm{g}$ each of formic, acetic, propionic, and n-butyric acids. Both a TEM fraction and a HEX fraction were generated from the spiked brine using the standard extraction protocol for produced water. The fractions were analyzed by GC/FID and IC. Only propionic and n-butyric acids were sufficiently resolved from the solvent fronts to quantitate these particular acids by GC/FID. These acids fell within $\mathrm{GC}$ retention times of $\mathrm{C}_{7}$ and $\mathrm{C}_{8}$ n-alkanes. Less than $5 \%$ total acid was recovered in the TEM fraction, corresponding to an equivalent TPH content of $51 \mathrm{ppm}$ in a produced water sample. Less than $1 \%$ organic acids were recovered in the HEX fraction, corresponding to a value of $23 \mathrm{ppm}$ TPH in produced water. The organic acid concentration observed in PERF oil/water contacts indicates that no more than $30 \mathrm{ppm}$ organic acids were typically present. Estimating that no more than 5\% of the acids are recovered in the TEM fraction, TPH would typically be overestimated by less than $2 \mathrm{ppm}$.

The TEM and HEX fractions were analyzed by IC by first diluting the samples by a factor of 20 with acetonitrile. Relative ratios for formic, acetic, propionic, and n-butyric acids were 1: 100:500:2500, respectively. The total acid concentration found in the TEM fraction was approximately four times that determined by GC/FID, due to the ability to the ability of the 
method to resolve the formic and acetic acid peaks from the solvent front. Only propionic and butyric acids were observed in the HEX fraction at a concentration ratio of 1: 10, respectively. Eight percent of the total acid mass found in TEM was transferred into the HEX fraction. Losses of formic and acetic acids from this fraction are attributed to volatilization in the solvent exchange necessary to produce the HEX fraction. Assuming that the typical TPH concentration in HEX fractions derived from the processing of produced water samples was approximately 12 $\mathrm{ppm}$ and that $30 \mathrm{ppm}$ of organic acids was present in the water, the TPH concentration would be elevated by no more than $0.5 \mathrm{ppm}$ in the HEX fraction.

Several experimental parameters were found to affect the concentrations of organic acids found in produced water. The oil/water ratio did not consistently affect the levels of organic acids in produced water (Fig. 8.13). However, the acid levels decreased as the brine simulant became more alkaline, a trend opposite to that observed for hydrocarbon content in the TEM fraction (Fig. 8.14). The organic acid concentration was near zero at $42,000 \mathrm{ppm}$ chloride; acetic and propionic acids were consistently present at about $10 \mathrm{ppm}$ at the higher salinity levels (Fig. 8.15). Concentrations, of both acetic acid and TPH were elevated at temperatures greater than $50^{\circ} \mathrm{C}$ (Fig. 8.16). Elevating pressure did not significantly affect organic acid content in produced water.

In addition to organic acids, the chromatograms of produced water included elution peaks for the primary anion, chloride, as well as a minor phosphate constituent (Fig. 8.17). Phosphate was present at slightly greater than $1200 \mathrm{ppm}$ at room temperature; however it was lost as the temperature increased. Only $300 \mathrm{ppm}$ of phosphate was contained in the produced water of a $75^{\circ} \mathrm{C}$ oil/water contact experiment. Phosphate was most prevalent at near-neutral $\mathrm{pH}$ levels and was rapidly lost when the $\mathrm{pH}$ was increased or decreased. Phosphate concentration showed no consistent trends with either the salinity or the water cut.

\subsection{PRESENCE OF INORGANIC CONSTITUENTS IN CRUDE AND PRODUCED WATER}

Alkaline and alkaline-earth metals were the primary metal components in the deep-well crude according to results of ICP-AES analyses; their total concentration was about $7 \mathrm{~g} / \mathrm{kg}$. The primary transition metals are nickel $(25 \mathrm{mg} / \mathrm{kg})$; silicon $(248 \mathrm{mg} / \mathrm{kg})$; iron $(22 \mathrm{mg} / \mathrm{kg})$; vanadium $(67 \mathrm{mg} / \mathrm{kg})$ and zinc $(6 \mathrm{mg} / \mathrm{kg})$. Only selenium $(3.5 \mathrm{mg} / \mathrm{kg})$ approached the level to be considered a toxicity characteristic of the oil.

Results of inorganic chemical analysis of produced water samples indicated that only cadmium and antimony were occasionally extracted into the water phase at the level of $0.1 \mathrm{ppm}$. The concentrations of these metals did not appear to be affected by variations in $\mathrm{pH}$ or water/oil cut. The alkaline and alkaline-ear@ metal concentrations in produced water were equivalent to those found in the starting brine simulant. 
Table 8.3. WSO distribution coefficients within chemical classes

\begin{tabular}{|c|c|c|c|c|c|c|c|c|}
\hline \multirow[b]{2}{*}{ Experiment } & \multirow[b]{2}{*}{$\begin{array}{c}\text { Water cut } \\
(\%)\end{array}$} & \multirow{2}{*}{$\begin{array}{l}\text { Simulant } \\
\text { volume } \\
(\mathrm{mL})\end{array}$} & \multirow{2}{*}{$\begin{array}{c}\text { Oil } \\
\text { volume } \\
\text { (mL) }\end{array}$} & \multicolumn{5}{|c|}{ Distribution coefficients, $K_{d}$} \\
\hline & & & & TEM & HEX & TSAT & TARO & TPOL (GC) \\
\hline PERF-9 & 20 & 1000 & 4000 & 6,719 & 5,095 & $1,457,002$ & 88,523 & $N A^{a-}$ \\
\hline PERF-7 & 50 & 1000 & 1000 & 5,471 & 3,208 & $1,746,309$ & 46,785 & 2,953 \\
\hline PERF-10 & 50 & 1100 & 1100 & 8,257 & 7,339 & $1,267,370$ & 144,889 & 2,560 \\
\hline PERF-6 & 67 & 1000 & 500 & 17,291 & 6,671 & $1,188,170$ & 627,449 & NA \\
\hline PERF-8 & 80 & 1000 & 250 & 8,132 & 4,522 & $2,156,409$ & 139,427 & NA \\
\hline PERF-16 & 80 & 2400 & 600 & 12,097 & 6,606 & $4,794,989$ & 128,948 & 4,468 \\
\hline PERFPO & 80 & 3000 & 750 & 9,698 & 12,009 & no extraction & no extraction & 14,358 \\
\hline PERF-25 & 73 & 200 & 73 & 52,006 & 20,220 & 4648566 & 128,756 & 3,927 \\
\hline
\end{tabular}

${ }^{\mathrm{a}} \mathrm{NA}=$ not analyzed.

Table 8.4. WSO distribution coefficients within carbon ranges for TEM fractions

\begin{tabular}{lcccccc}
\hline Experiment & $\begin{array}{c}\text { Water cut } \\
\text { (\%) }\end{array}$ & $\begin{array}{c}\text { Simulant } \\
\text { volume }\end{array}$ & $\begin{array}{c}\text { Oil } \\
\text { volume }\end{array}$ & \multicolumn{3}{c}{$\mathrm{K}_{\mathbf{d}}$ in TEM Fractions } \\
\cline { 6 - 7 } & & $(\mathrm{mL})$ & $\mathrm{C}_{6}-\mathrm{C}_{10}$ & $\mathrm{C}_{10}-\mathrm{C}_{20}$ & $\mathrm{C}_{20}-\mathrm{C}_{\mathbf{2}}$ \\
\hline PERF-9 & 20 & 1000 & 4000 & 12,195 & 4,375 & No extraction \\
PERF-7 & 50 & 1000 & 1000 & 9,525 & 3,637 & No extraction \\
PERF-10 & 50 & 1100 & 1100 & 18,654 & 4,937 & No extraction \\
PERF-6 & 67 & 1000 & 500 & 21,306 & 14,346 & No extraction \\
PERF-8 & 80 & 1000 & 250 & 16,025 & 5,876 & No extraction \\
PERF-16 & 80 & 2400 & 600 & 16,792 & 9,153 & No extraction. \\
PERF-20 & 80 & 3000 & 750 & 14,941 & 6,873 & No extraction \\
PERF-25 & 73 & 200 & 73 & 51.388 & 54.557 & No extraction \\
\hline
\end{tabular}




\section{CONCLUSIONS}

Quantitative characterization data were collected for the WSO content of produced water as a function of several experimental parameters-The WSO content was defined on the basis of an open LC column procedure in which the total organic material was fractionated into methylene chloride-soluble, hexane-soluble, saturated hydrocarbon, aromatic hydrocarbon, and polar hydrocarbon classes. The proportions of gas-, diesel- and oil-TPH within each fraction were then determined by GC/FD analysis. Data from this protocol were supported by the results using USEPA SW-846 Method $8270 \mathrm{C}$ for semi-volatile organic analytes and infrared spectroscopy for TPH content. Analyses were also performed for a number of in-organic constituents .

The GOM crude was obtainedfrom a single deep-well site. The TPH contents in this sample were 50,42 , and $8 \%$ for the $\mathrm{C}_{6}-\mathrm{C}_{10}, \mathrm{C}_{10}-\mathrm{C}_{20}$, and $\mathrm{C}_{20}-\mathrm{C}_{28}$ ranges, respectively. The principal SVOCs in the deep-well oil were acetophenone $(0.6 \mathrm{~g} / \mathrm{kg})$ and methylnaphthalene

$(0.4 \mathrm{~g} / \mathrm{kg})$, which represent less than $2 \%$ of the total organic content. Chemical classification by the open LC protocol was used to account for the remaining $98 \%$ of the organic character of the oil. Methylene chloride-extractable material (TEM) in the deep-well oil was present at $200-400 \mathrm{~g} / \mathrm{kg}$. Approximately $35 \%$ of this material could be, exchanged-into a hexane matrix. The relative composition of the hexane matrix was $35 \%$ saturated hydrocarbons, $15 \%$ aromatic components, and $50 \%$ polar material. The visibly colored red-brown material was primarily present in the polar fraction. Alkaline and alkaline-earth metals were the primary ICP metal components in the deep-well crude; their total concentration was about $17 \mathrm{~g} / \mathrm{kg}$. Several RCRA metals were detected-slightly above the ICP detection limit; however, they were not present above the USEPA-defined toxicity limits.

The sample of GOM crude described above was contacted with a GOM brine simulant in a WAF vessel to generate produced water samples. The total concentration of WSO observed in the oil/brine simulant contacts ranged from 20-30 ppm. Four SVOCs were identified: 1-methylnaphthalene (10 ppb), 2-methylnaphthalene (9 ppb), naphthalene (14 ppb), and phenol $(30 \mathrm{ppb})$. The distribution within the chemical fractions differed significantly from that of the deep crude. Chemical fractionation of the total extractable materials suggested that 80 to $90 \%$ of the WSO was present as polar compounds; the next largest fraction was that of aromatic materials. The visibly colored material was primarily present in the light-yellow aromatic fraction. TEM organic matter was distributed between the low and midrange carbon masses, similar to oil data.

Variation in the water/oil ratio indicated that there was a slight negative trend in the WSO content in all chemical fractions as the water cut increased, This, effect was a combination of, the decreasing solubility of the $C_{10}-C_{20}$ mass and the increasing' solubility of the $C_{6}-C_{10}$ carbon material. Analytical results obtained in the characterization of crude oil were used in combination with data from water cut experiments to determine approximate distribution coefficients $\left(\mathrm{K}_{\mathbf{d}}\right.$ values) of WSO in GOM brine as a function of percent water cut and brine volume. Distribution data imply that that brine was saturated with WSO for water cuts of less than $50 \%$.

The variation of TDS with salinity did not significantly alter the WSO content in produced water; however, the $\mathrm{pH}$ of the brine did affect TPH content, Normally, the $\mathrm{pH}$ of the GOM brine simulant was buffered to 7-7.5 by the presence of an oil layer. When the buffering capacity of oil was exhausted with base, the WSO content almost doubled for $\mathrm{pH}$ values above 7 . This was primarily due to the enhanced solubility of polar organic compounds that deprotonate at higher 
$\mathrm{pH}$ values. There was an enhanced solubility of the $\mathrm{C}_{10}-\mathrm{C}_{20}$ carbon range material and a decline in $\mathrm{C}_{6}-\mathrm{C}_{10}$ mass for $\mathrm{pH}$ values greater than 7 .

The chemical character of WSO did not appear to be significantly dependent upon solution temperature, although the percentage mass in each carbon range was altered. The mass of WSO in the $C_{6}-C_{10}$ carbon range decreased while that in the $C_{10}-C_{20}$ range increased. Thus, the net quantity of organics in the produced water increased by $5 \mathrm{ppm}$ for a $60^{\circ} \mathrm{C}$ elevation in solution temperature.

Over the pressure range of 1-60 bar, total WSO content increased by less than $10 \%$. The additional quantity of WSO was primarily associated with the polar fraction. The most notable difference in the content of produced water derived from high pressure contacts was the increased amounts of $\mathrm{C}_{6}-\mathrm{C}_{10}$ range material, particularly in the polar fraction and to a lesser extent in the aromatic fraction. There was considerable scatter in pressure data due to the low volumes of oil and water used in this series of experiments. The low quantities of saturated hydrocarbon fractions made it difficult to discern any trends for this chemical fraction.

Three organic acids were typically found in the produced-water samples: formic, acetic, and propionic. Acetic acid, which was present at 10-30 ppm (similar to that of TPH), made up the bulk of the acid mass. However, acid levels decreased as the brine simulant became more alkaline, a trend opposite from that observed for the hydrocarbon content in the TEM fraction. Both salinity and temperature slightly elevated the organic acid concentration, particularly that of acetic acid. Less than 5\% total acid in produced water was recovered in the TEM fraction; less than $1 \%$ organic acids was recovered in the HEX fraction. For $30 \mathrm{ppm}$ of total acid present in produced water, it was estimated that the TPH content would be overestimated by less than $2 \mathrm{ppm}$ if methylene chloride were used to extract WSO from produced water. The TPH content would be overestimated by $0.5 \mathrm{ppm}$ if hexane were used for solvent extraction. Assuming a constant distribution coefficient, overestimation would then increase in a linear fashion relative to total acid concentration in the produced water.

Of the five experimental parameters tested (percent water cut, $\mathrm{pH}$, salinity, temperature, and pressure), the factor that most controlled the total WSO in produced water was that of aqueous phase $\mathrm{pH}$. Beyond a value of $\mathrm{pH} 7$ significant quantities of $\mathrm{C}_{10}-\mathrm{C}_{20}$ range material became markedly soluble at they deprotonated in basic GOM brine. Both the absolute and relative volumes of GOM brine and crude additionally affected total WSO. Produced water appeared to reach a saturation level of WSO at a 50\% water/oil ratio. Pressure slightly enhanced WSO by increasing the relative quantity of $\mathrm{C}_{6}-\mathrm{C}_{10}$ range material. Temperature primarily altered the relative ratio of the carbon ranges within the WSO without significantly elevating the total WSO in the GOM brine. Salinity had the least affect on the chemical character or the carbon size of WSO in produced water.

\section{REFERENCES}

M. A. Mills, T. J. McDonald, J. S. Bonner, M. A. Simon, and R. L. Autenrieth, "Method for Quantifying the Fate of Petroleum in the Environment," Chemosphere 39, 2563-82 (1999).

M. A. Franson, (ed.), Standard Methods for the Examination of Water and Wastewater, 18th ed., American Public Health Association, Washington, D.C., 1992, pp. 2-23 to 2-28. 
Figures for Text of Report 
: 


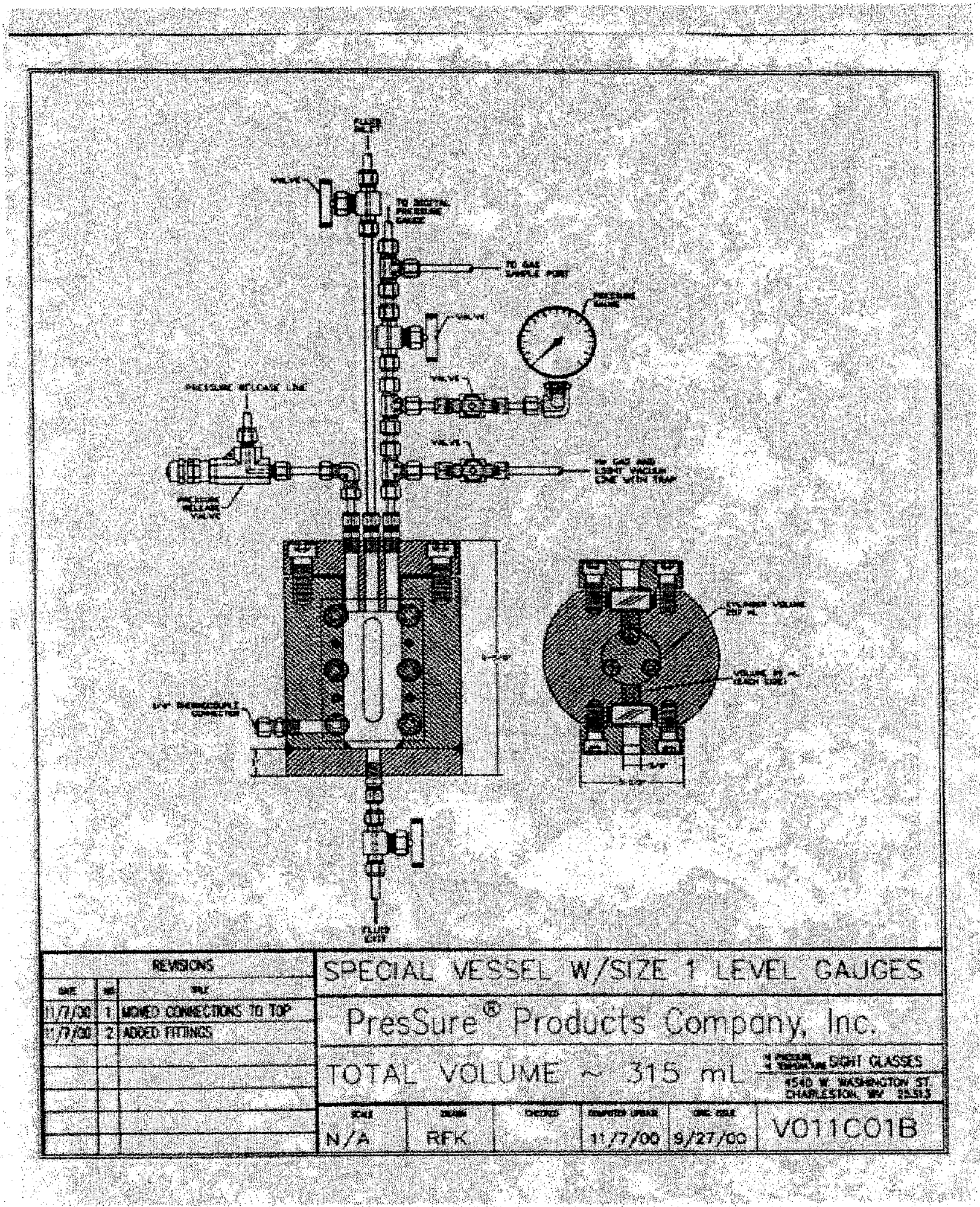

Fig. 4.1. Schematic'diagram of oil/water contact pressure vessel. 



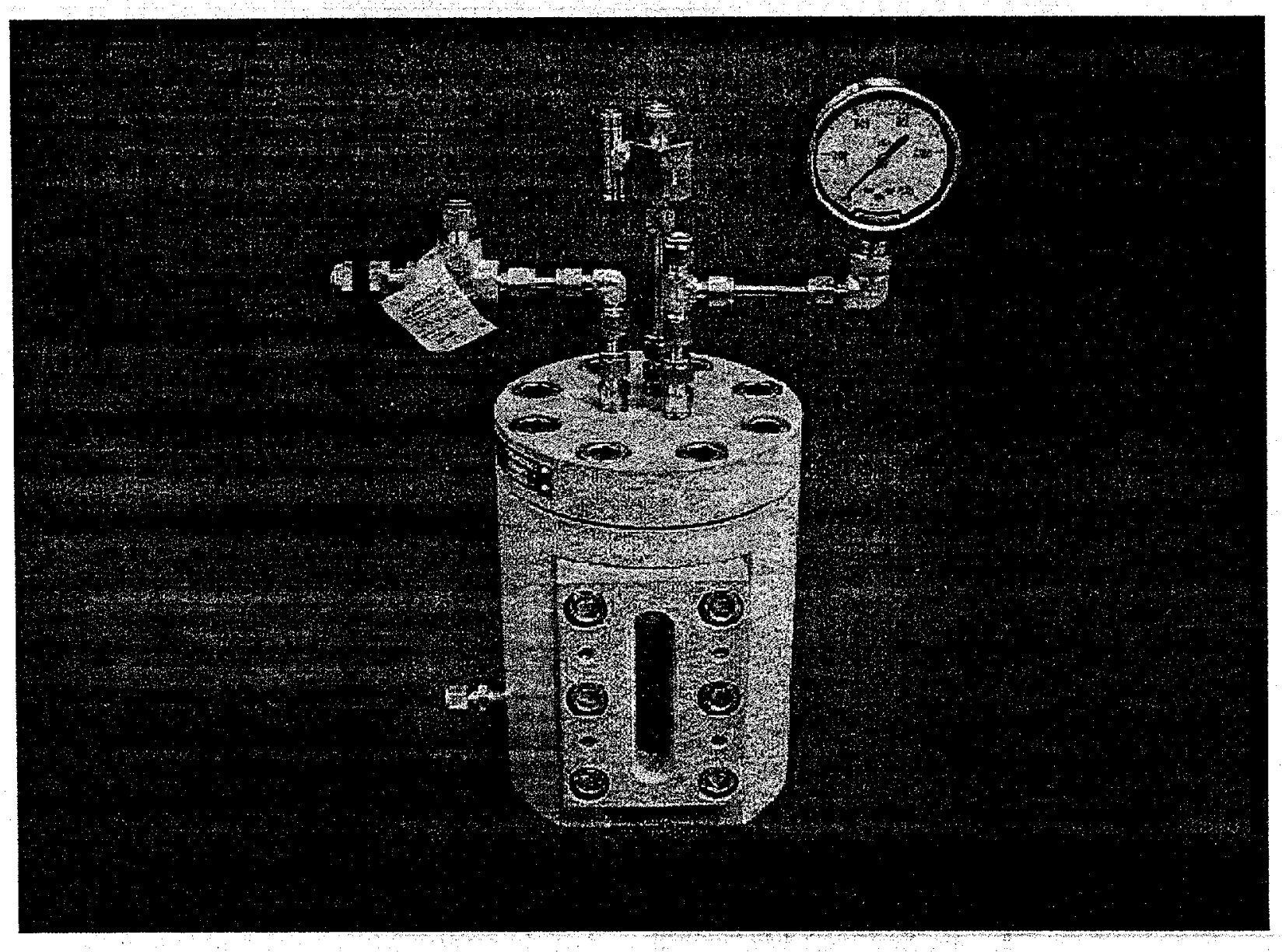

Fig. 4.2. Oil/brine contact pressure vessel. I' 


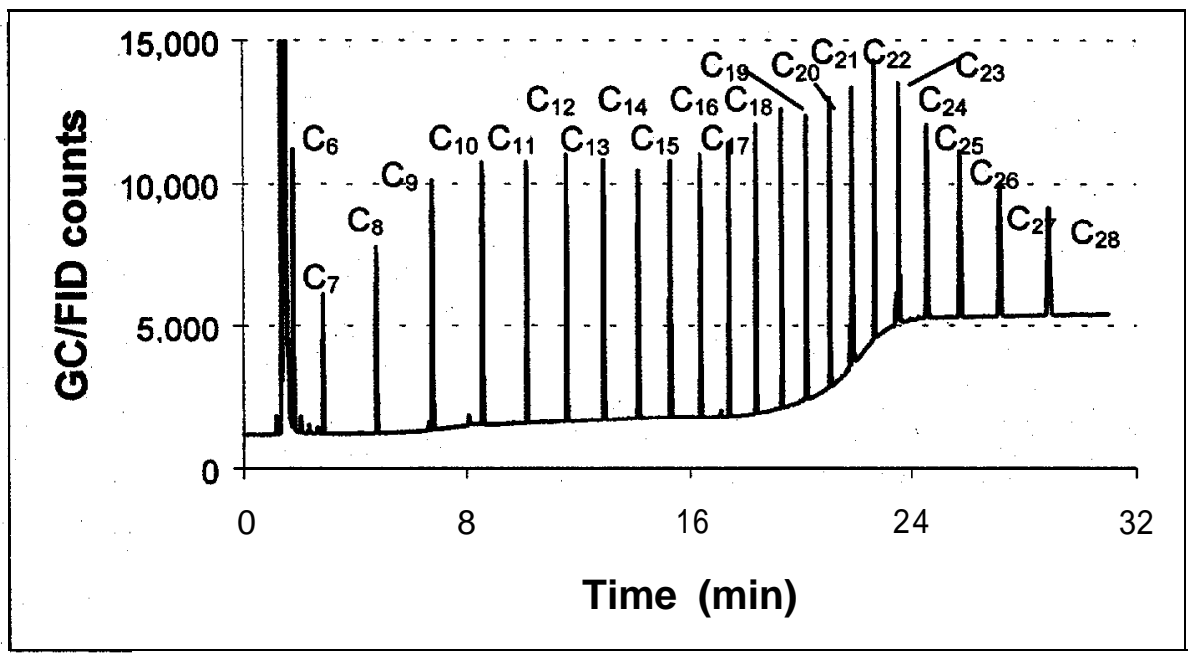

Fig. 7.i. GC/FID chromatogram of $\boldsymbol{n}$-alkane standards. (2- $\mu \mathrm{L}$ injection of $15 \mathrm{ppm}$ of each alkane)

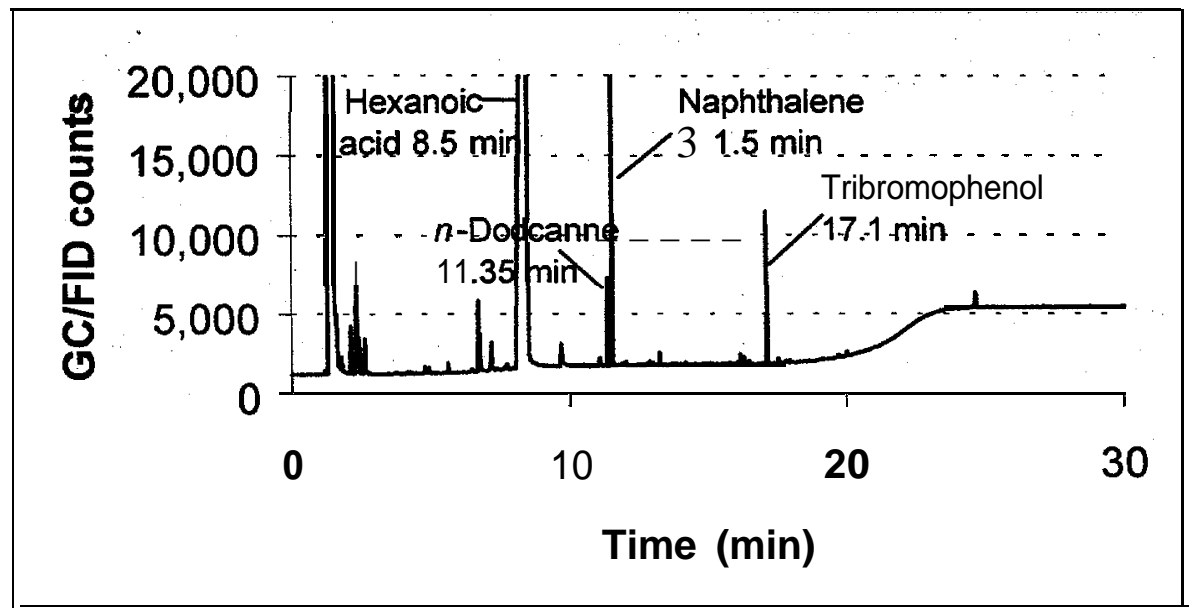

Fig. 7.2. GC/FID chromatogram of surrogate recovery standards. (2- $\mu \mathrm{L}$ injection of methylene chloride (TEM) extract) 


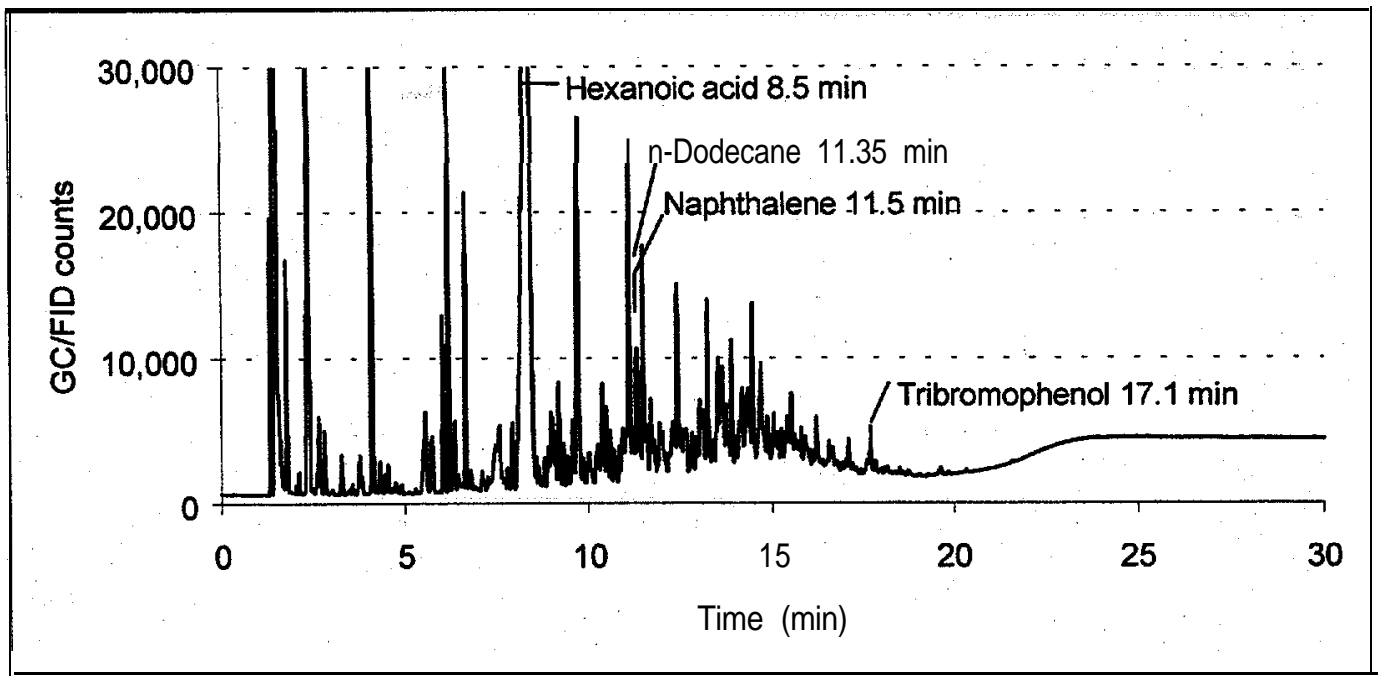

Fig. 7.3. GC/FID chromatogram of TEM fraction. (0.5- $\mu \mathrm{L}$ injection of $1.2 \mathrm{~mL}$ of TEM-20 fraction)

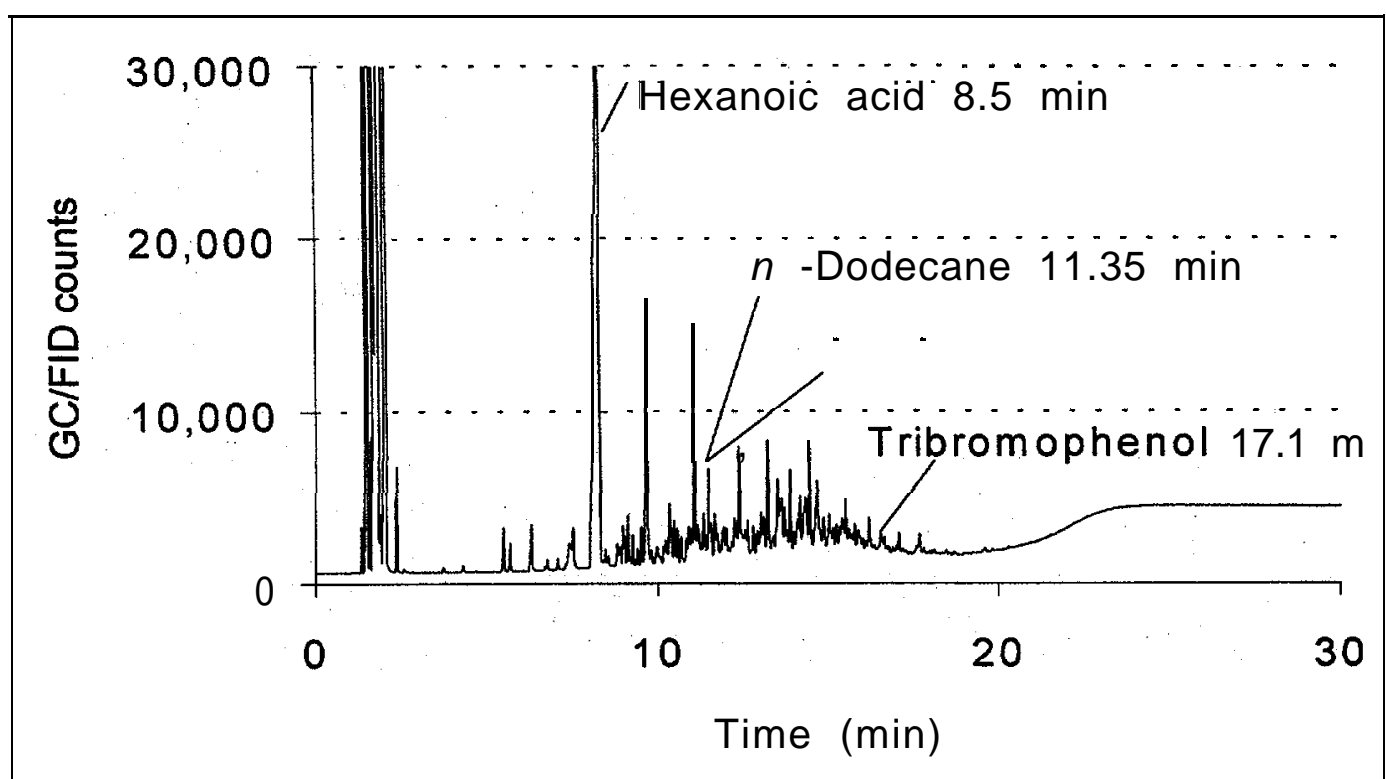

Fig. 7.4. GC/FID chromatogram of HEX fraction. (0.5- $\mu \mathrm{L}$ injection of $1.0 \mathrm{~mL}$ of HEX-20 Fraction) 


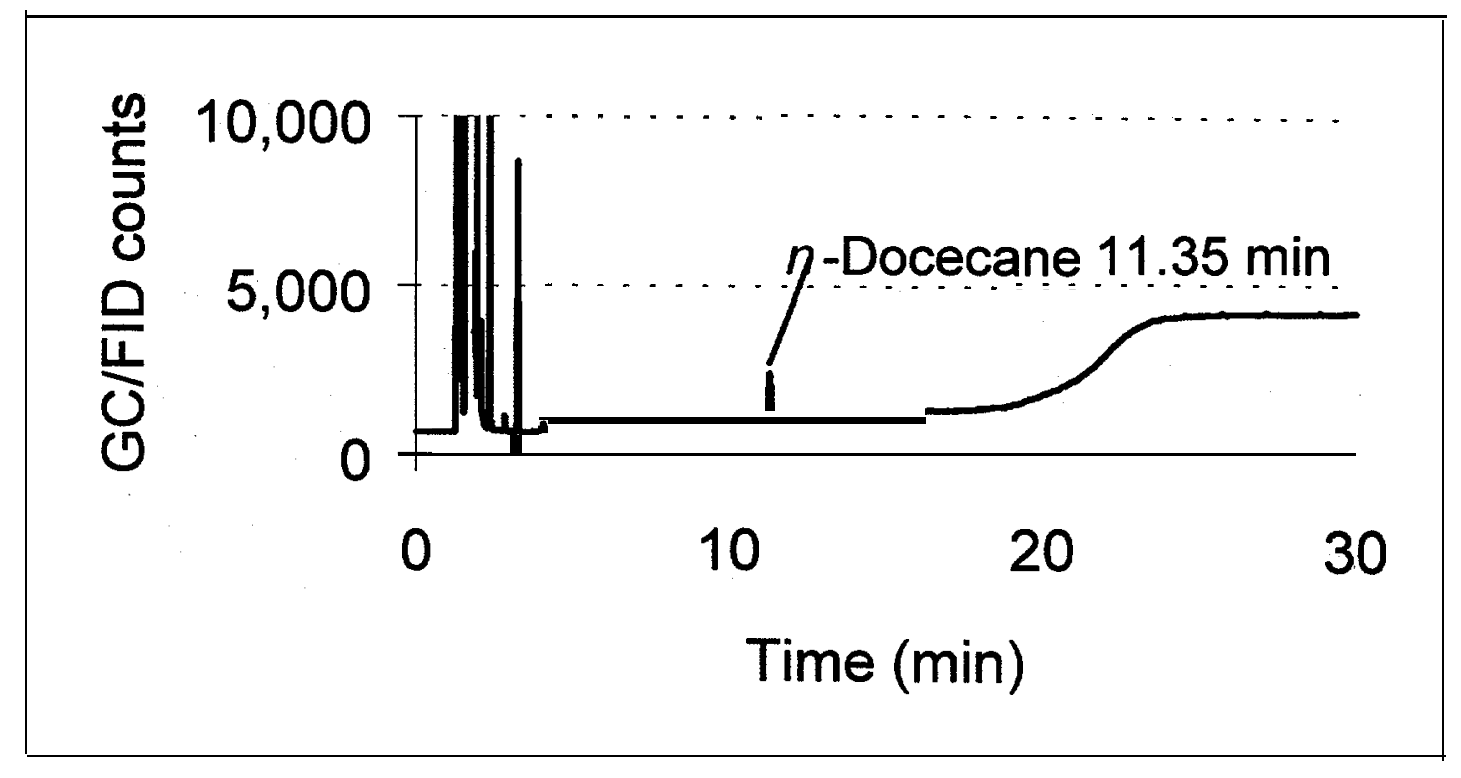

Fig. 7.5. GC/FID chromatogram of TSAT fraction.

(3- $\mu \mathrm{L}$ injection of $1.1 \mathrm{~mL}$ of TSAT-20 fraction)

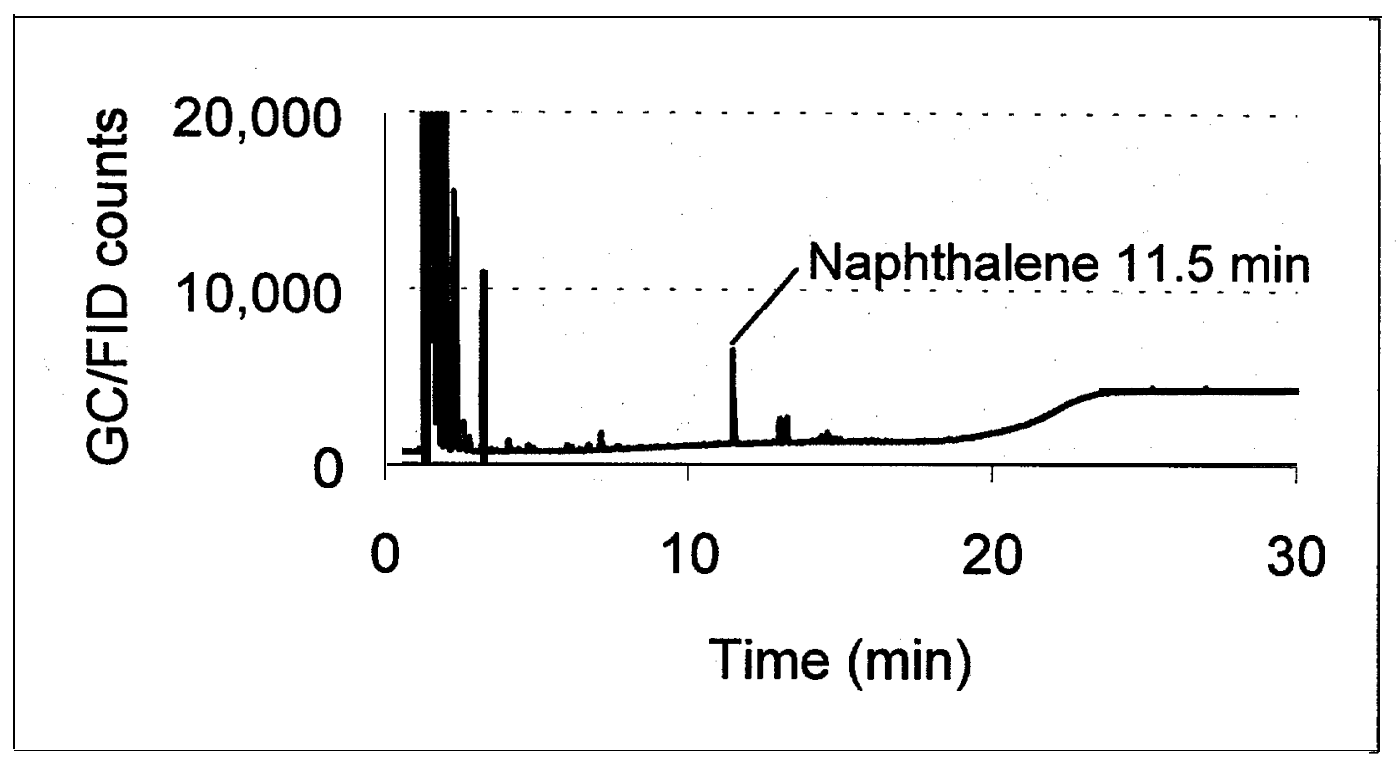

Fig. 7.6. GC/FID chromatogram of TARO fraction.

(3- $\mu \mathrm{L}$ injection of $0.95 \mathrm{~mL}$ of TARO-20 fraction) 


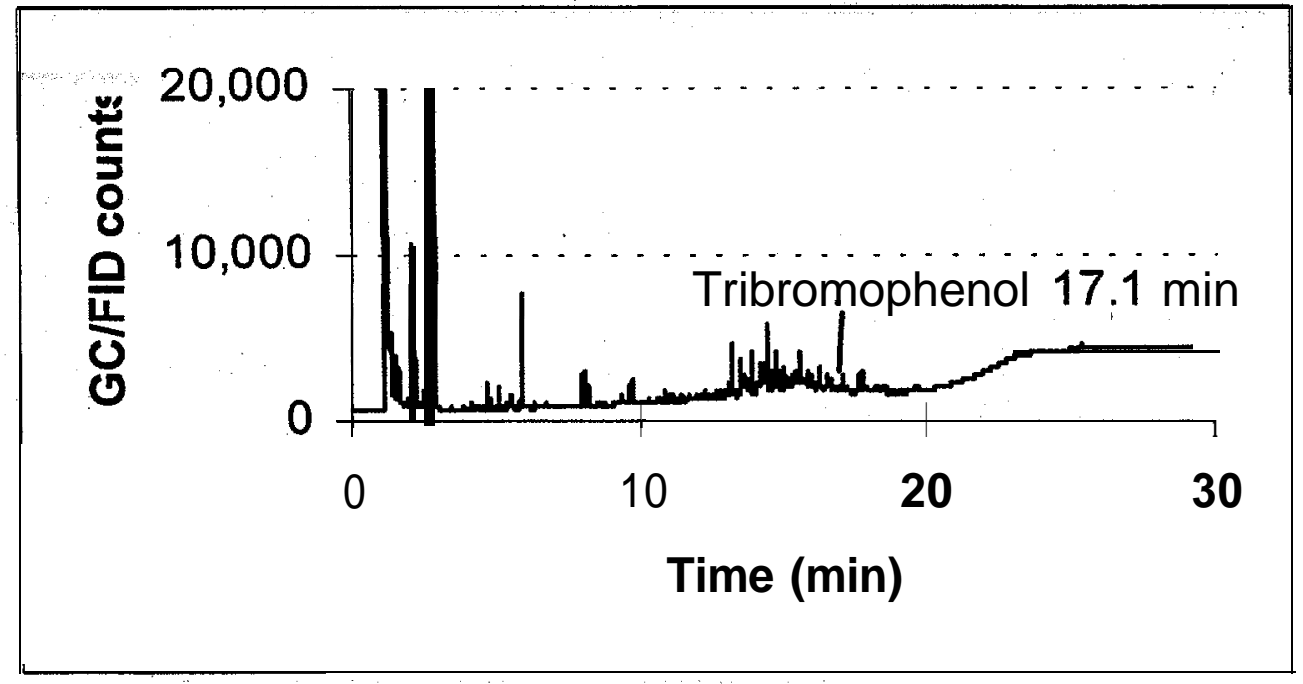

Fig. 7.7. GC/FID chromatogram of TPOL fraction.

(1- $\mu \mathrm{L}$ injection of $1.0 \mathrm{~mL}$ of TPOL-20 fraction) 


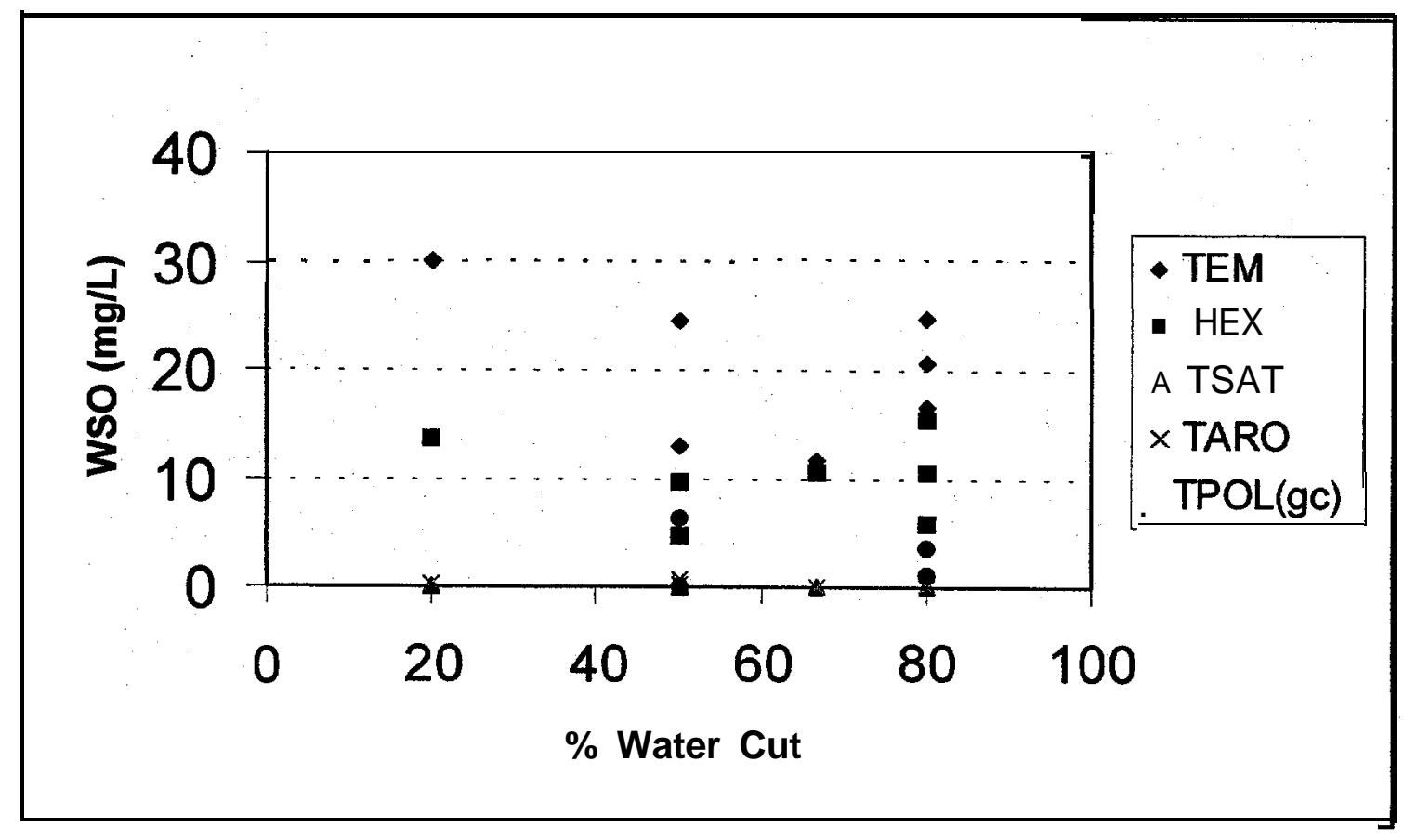

Fig. 8.1. WSO chemical character versus percent water cut.

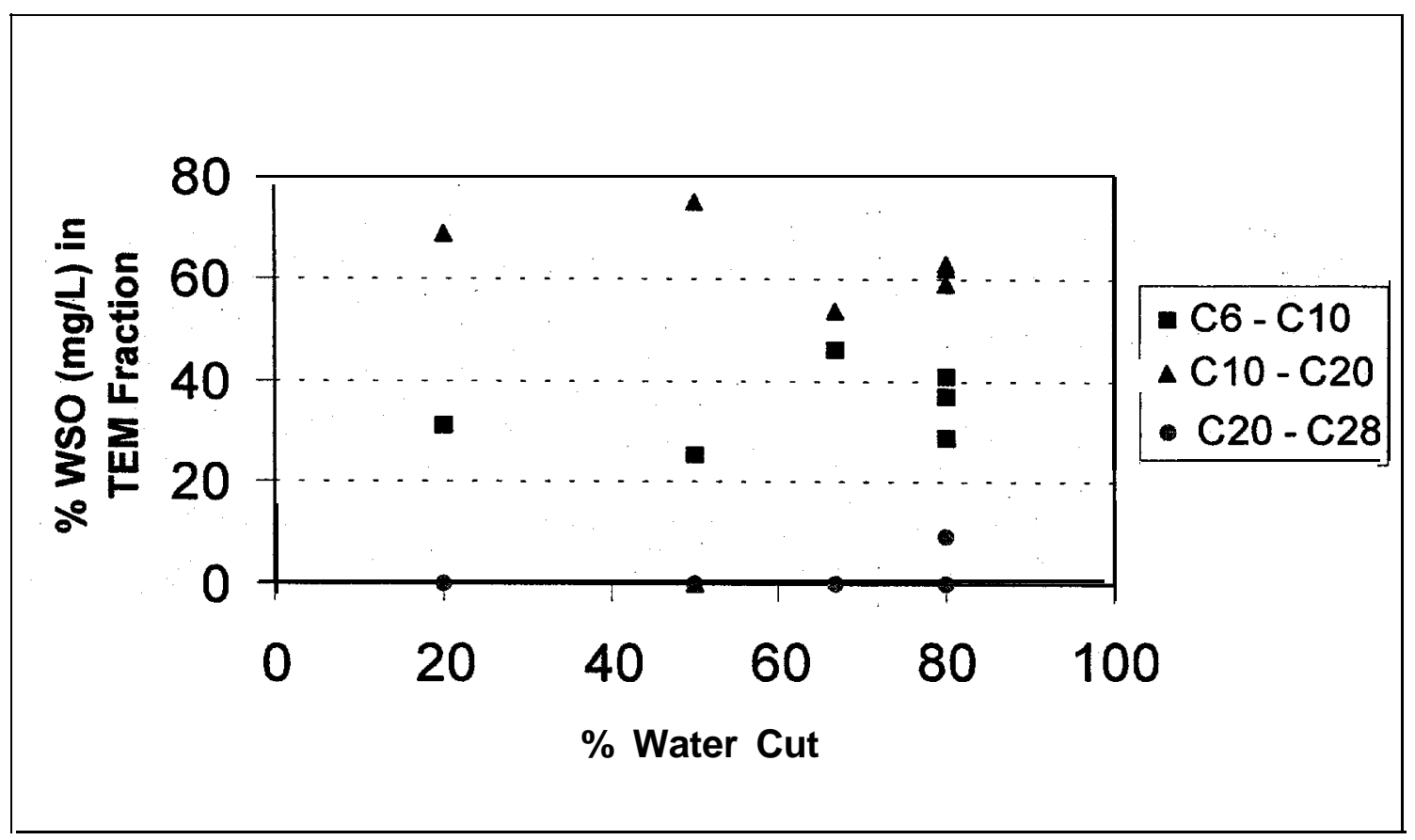

Fig. 8.2. WSO carbon content versus percent water cut. 


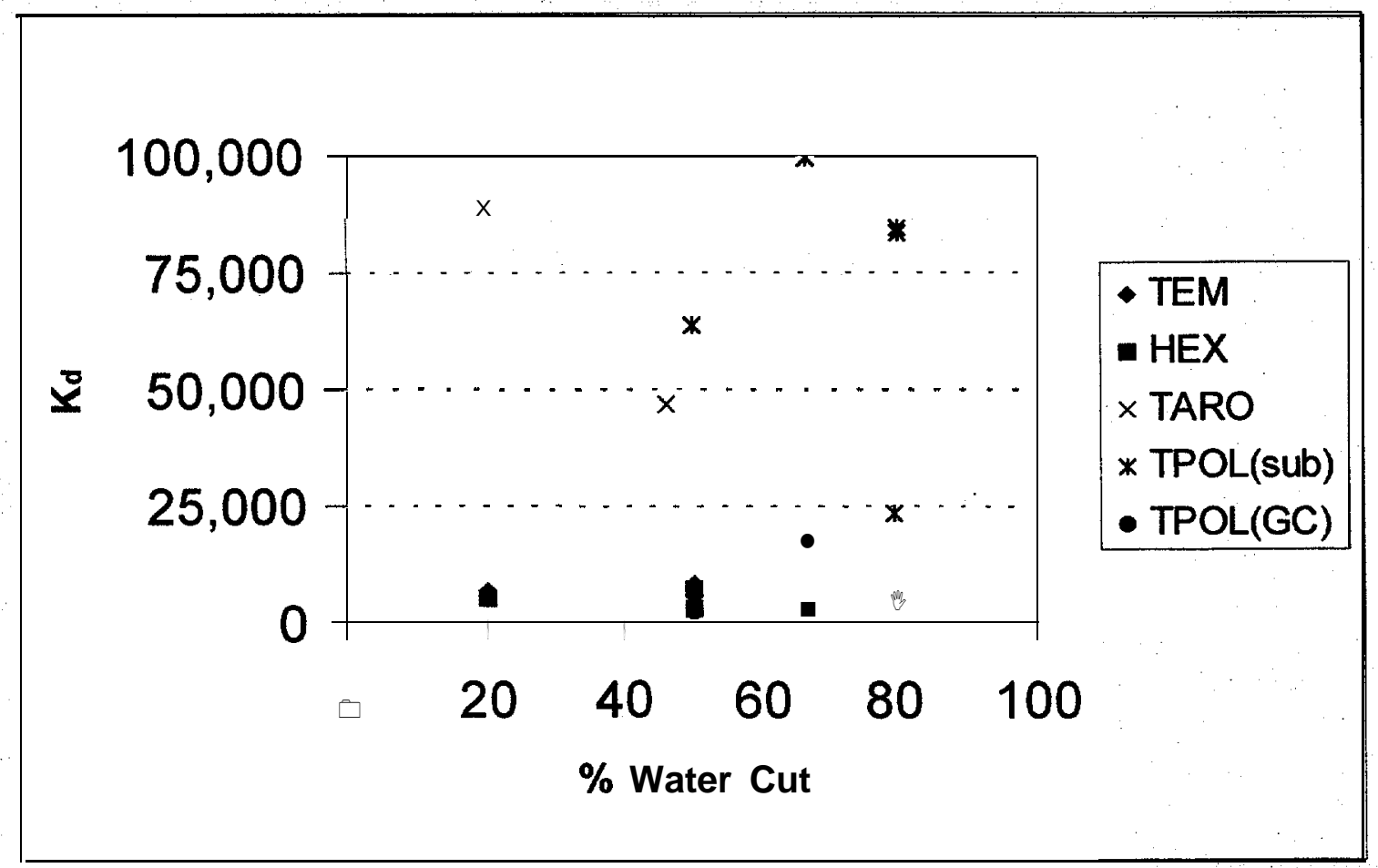

-Fig. 8.3. WSO $K_{d}$ versus percent water cut.

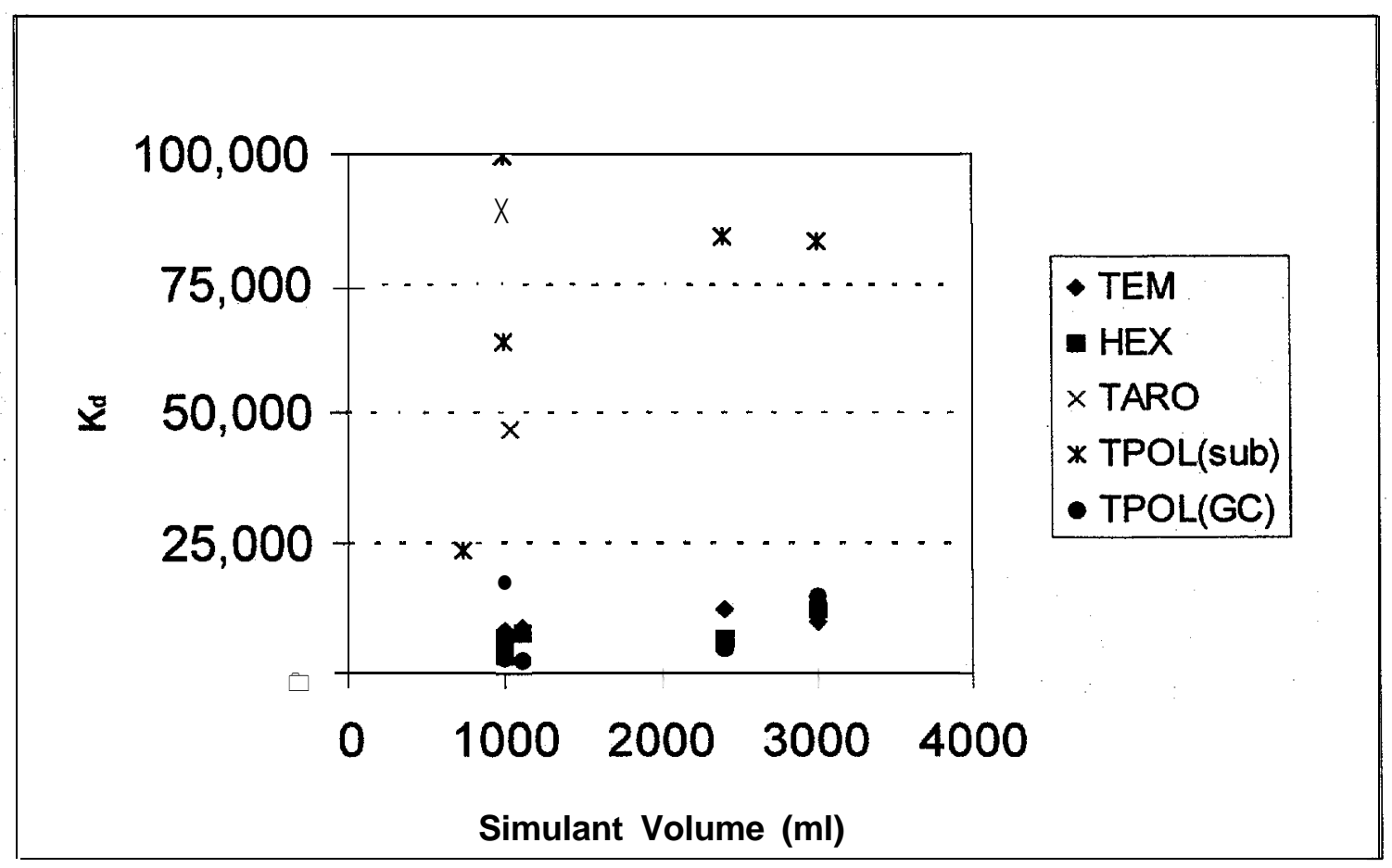

Fig. 8.4. WSO $\mathbf{K}_{\mathbf{d}}$ versus GOM simulant volume. 


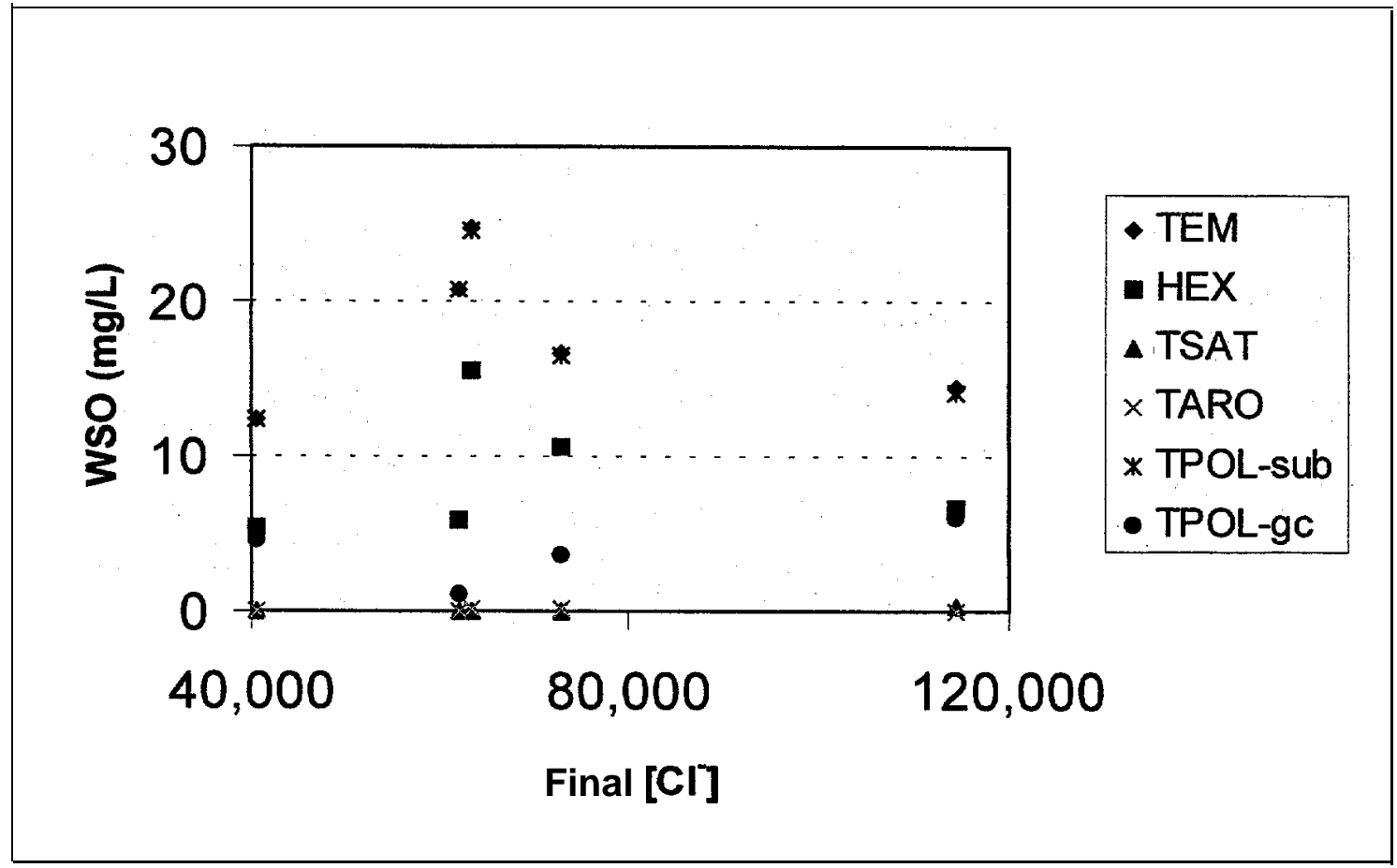

Fig. 8.5. Chemical fraction as a function of total dissolved solids (as $\left.\mathrm{Cl}^{7}\right)$.

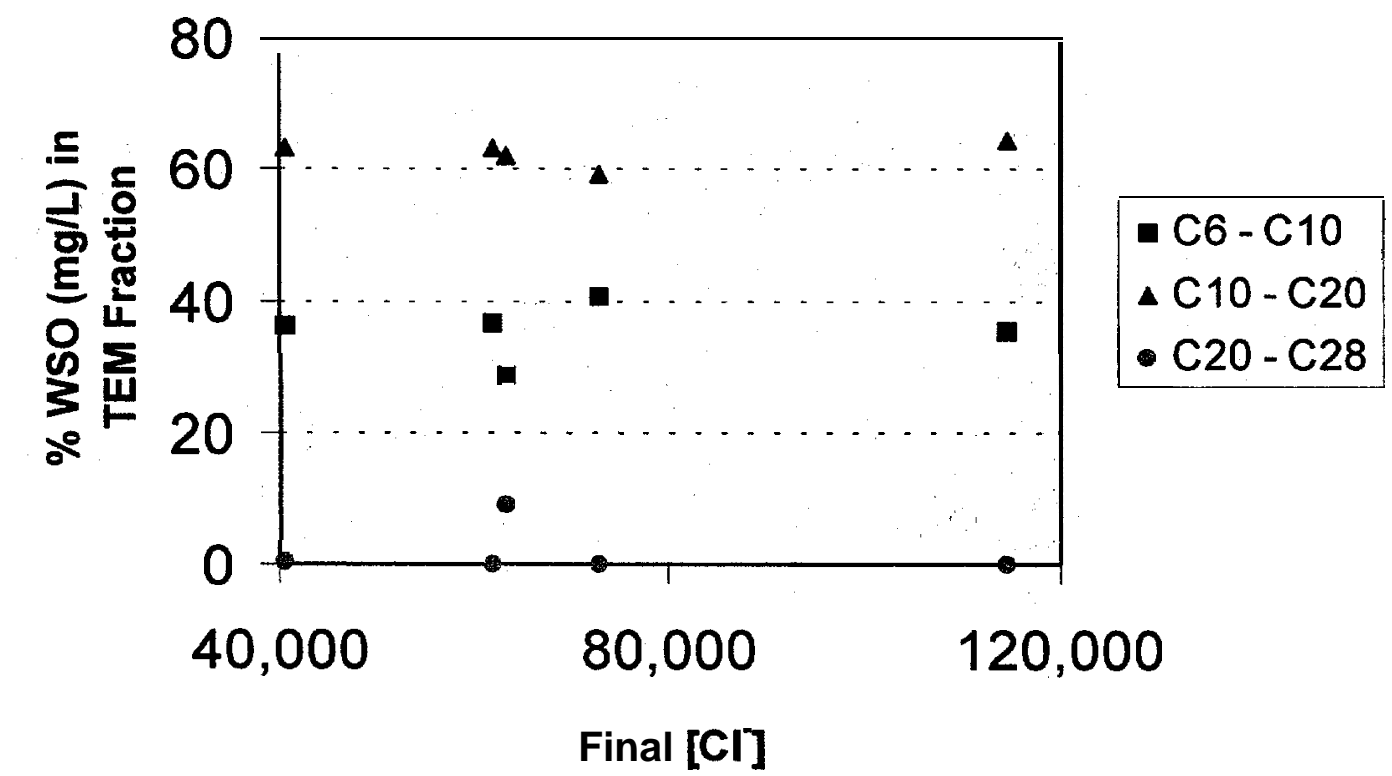

Fig. 8.6. Carbon content in TEM fractions as a function of total dissolved solids (Cl-). 


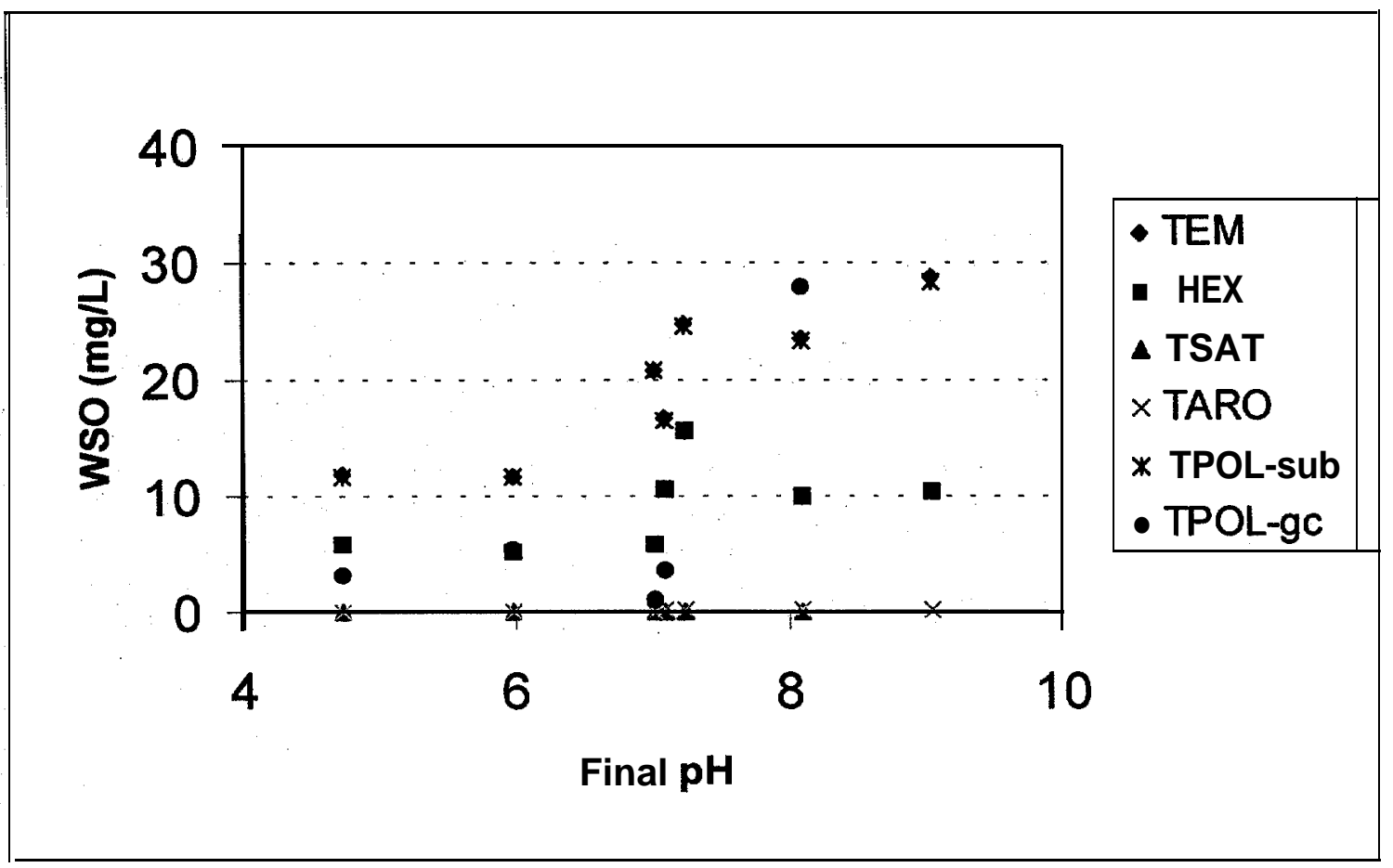

Fig. 8.7. Chemical character as a function of GOM brine pH.

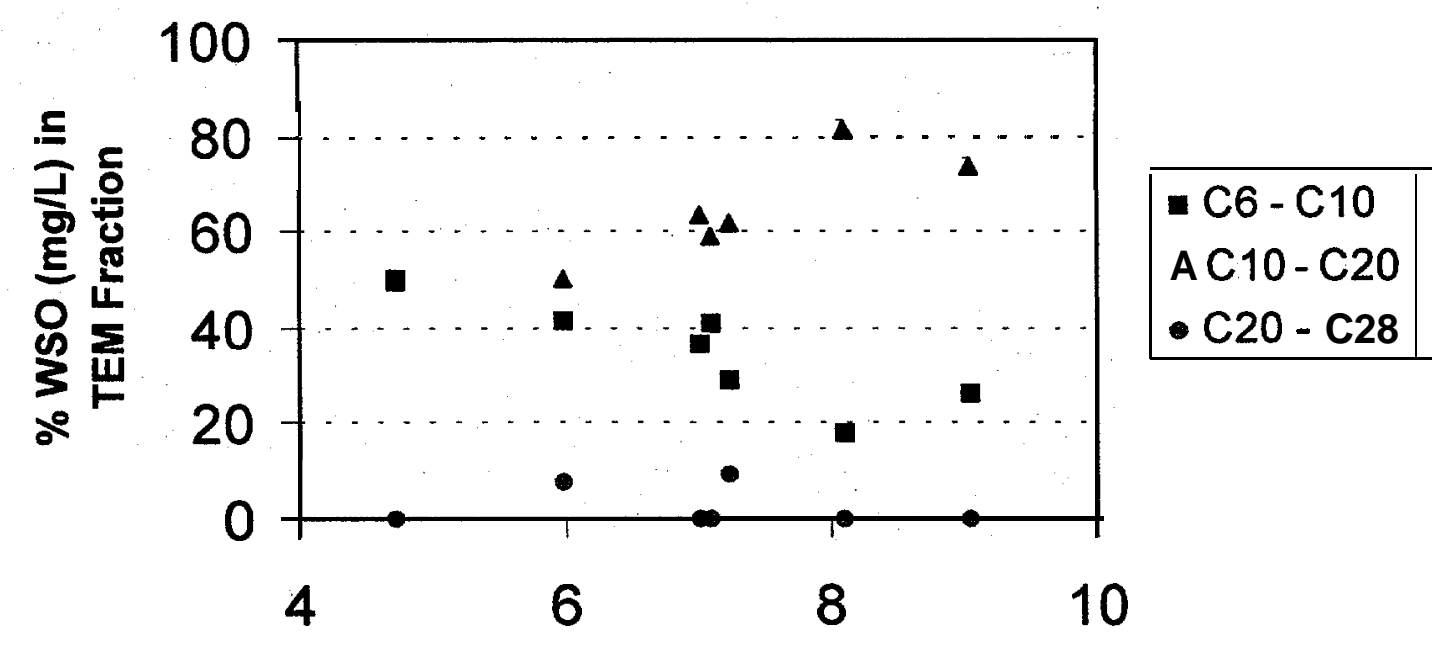

Final pH

Fig. 8.8. Carbon content in TEM fractions versus GOM brine $\mathbf{p H}$. 


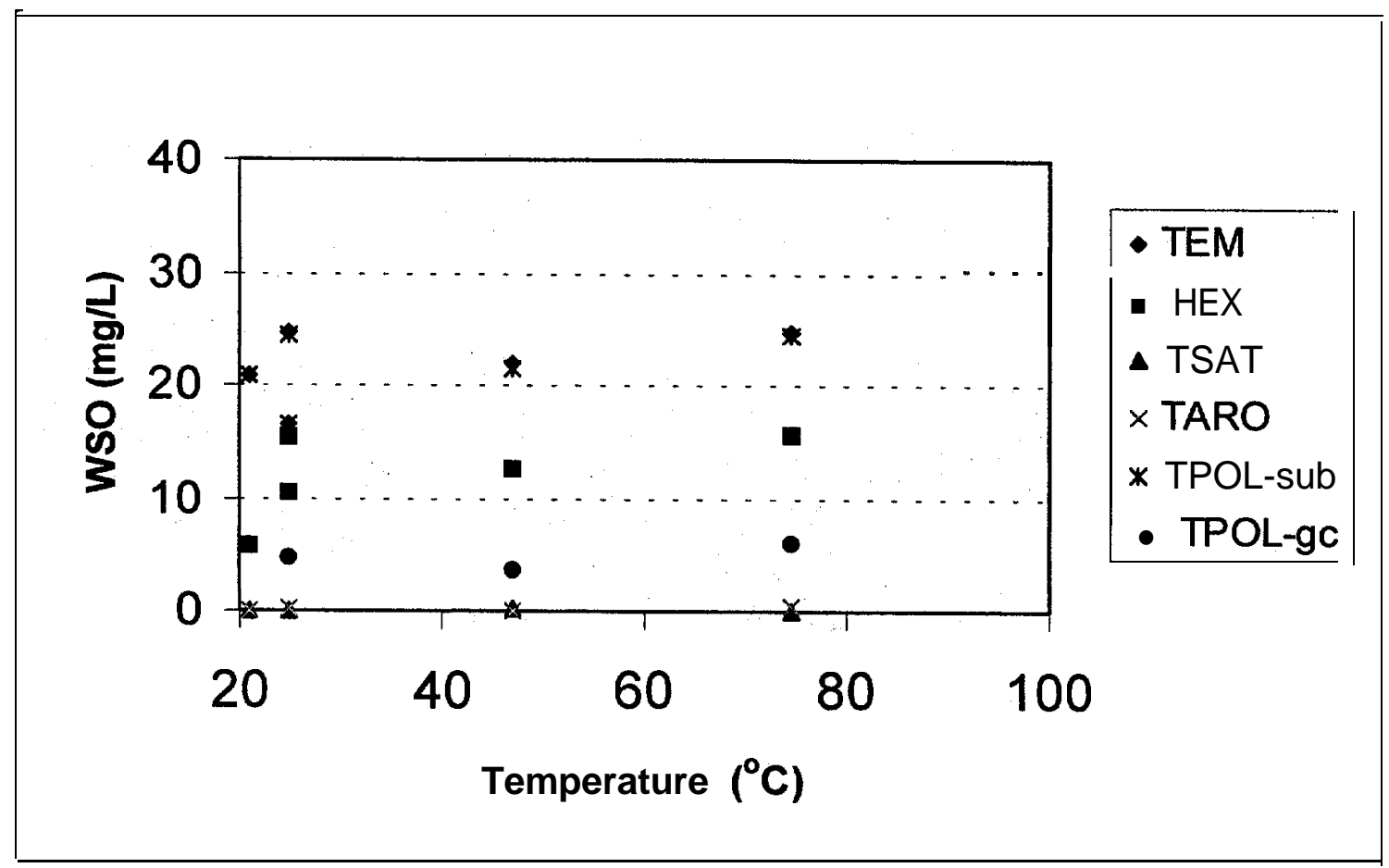

Fig. 8.9. Chemical character as a function of GOM brine temperature.

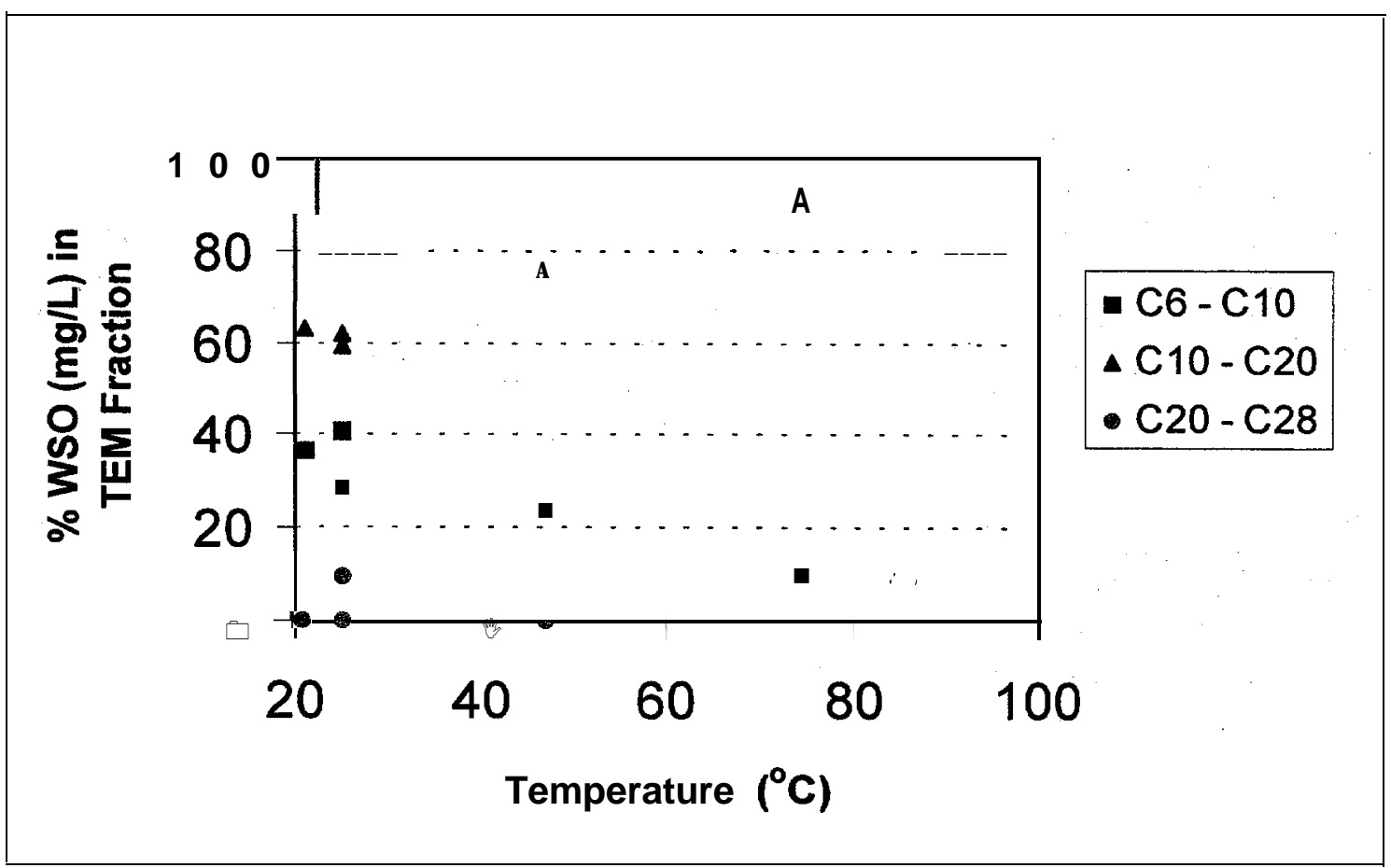

Fig. 8.10. Carbon content in TEM fractions as GOM brine temperature. 


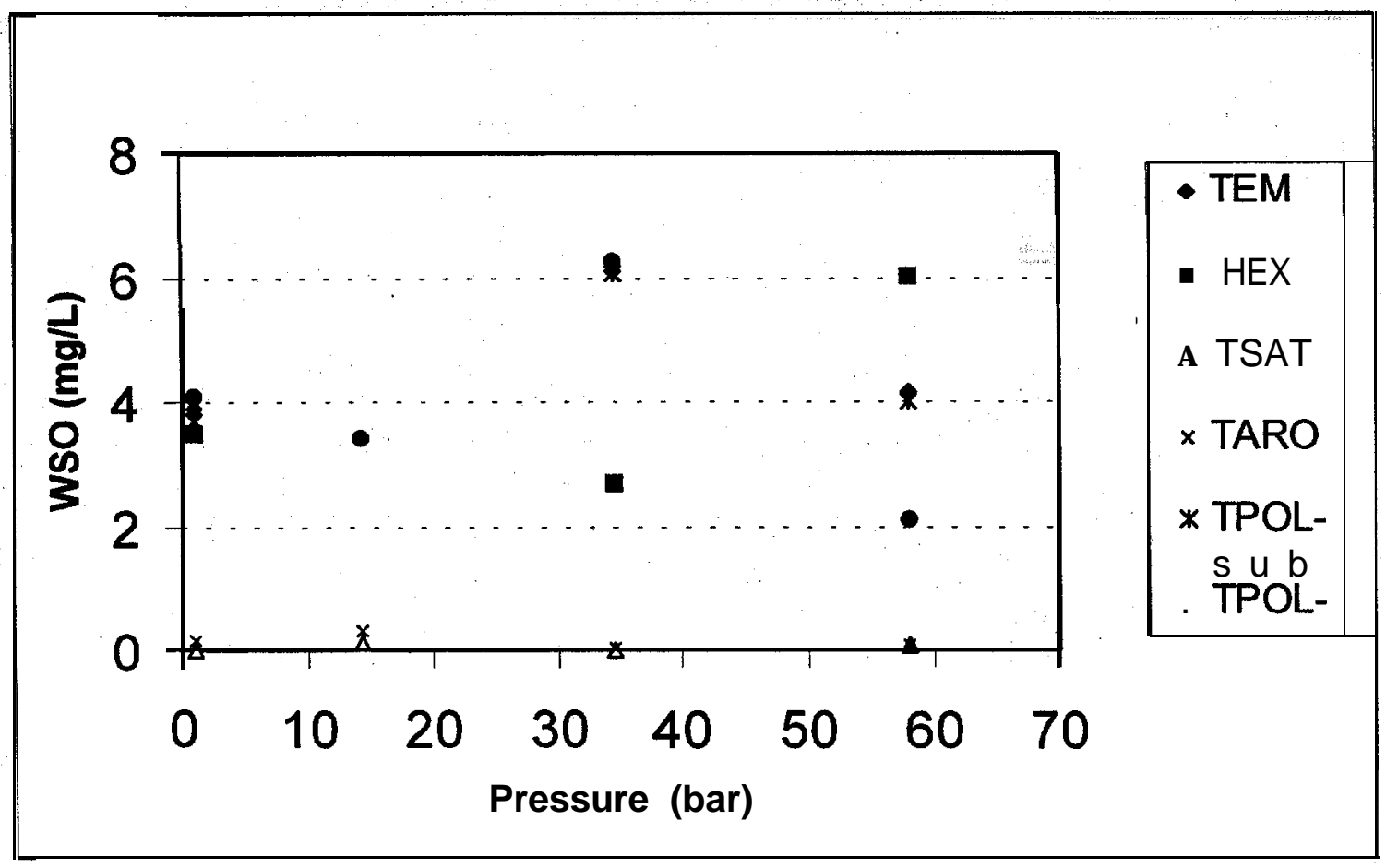

Fig. 8.11 Chemical Character as a function of GOM brine pressure.

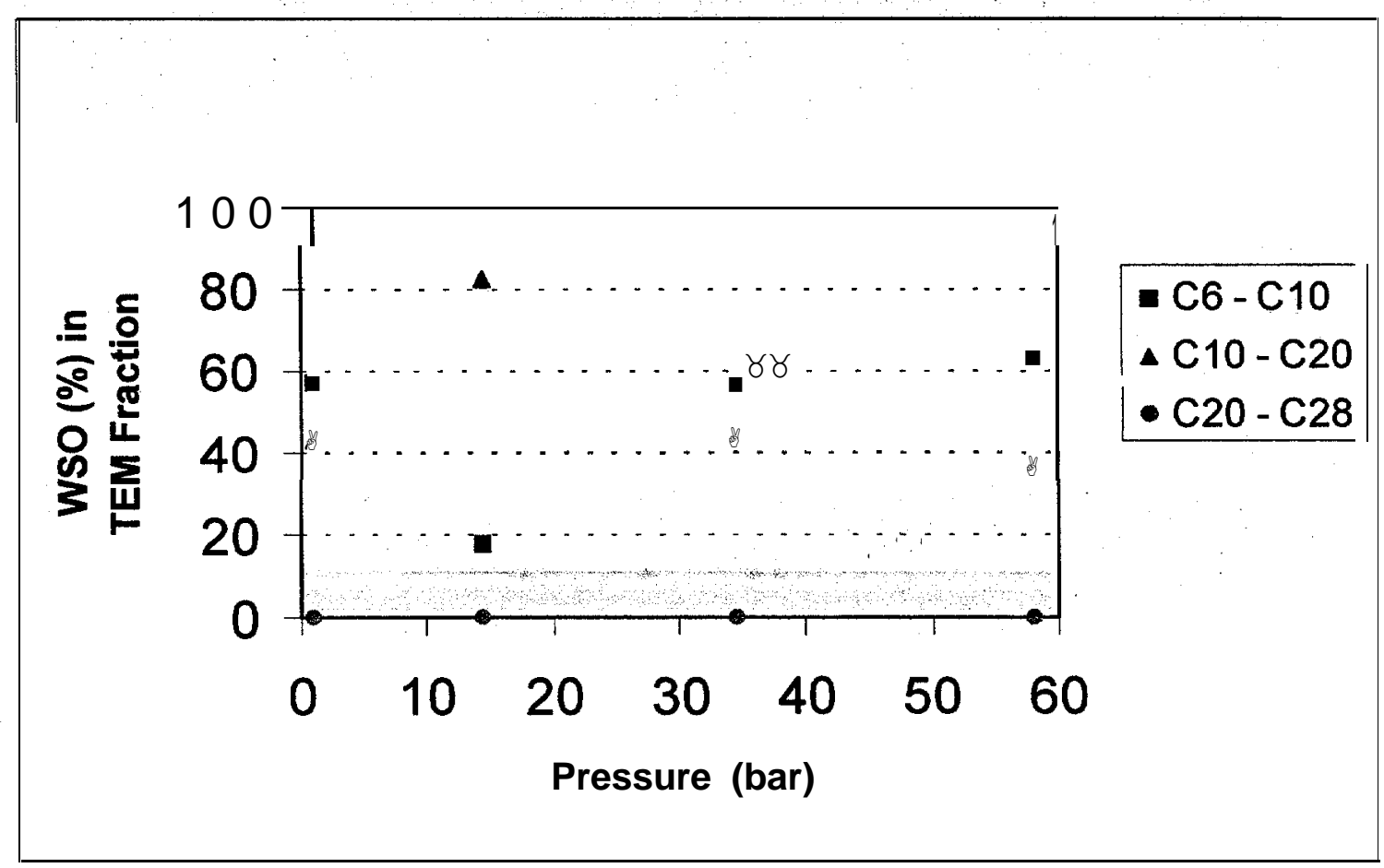

Fig. 8.12 Carbon content in TPOL as a function of GOM brine pressure. 


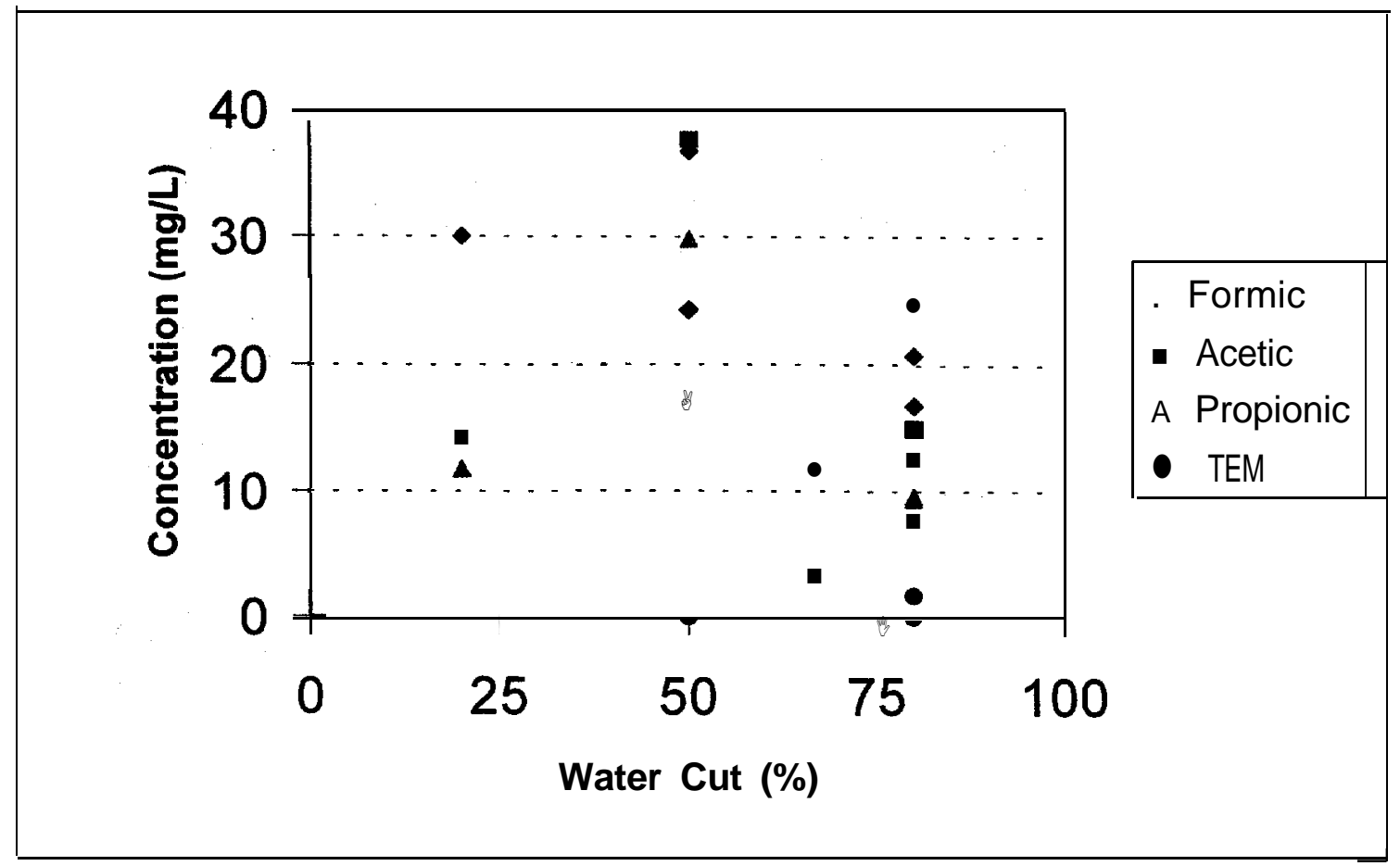

Fig. 8.13. Influence of percent water cut on organic acid content.

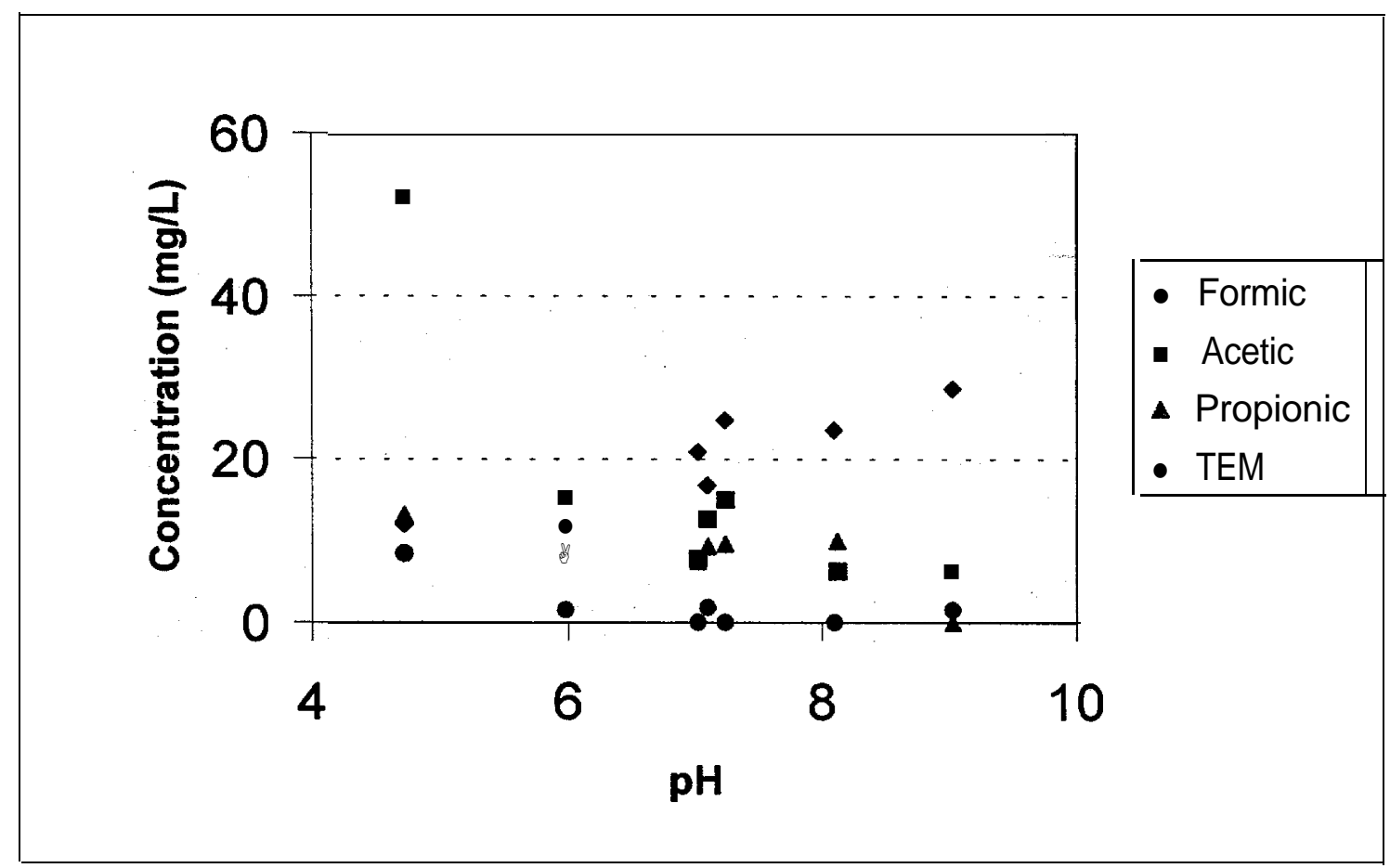

Fig. 8.14. Influence of brine $\mathrm{pH}$ on organic acid content. 


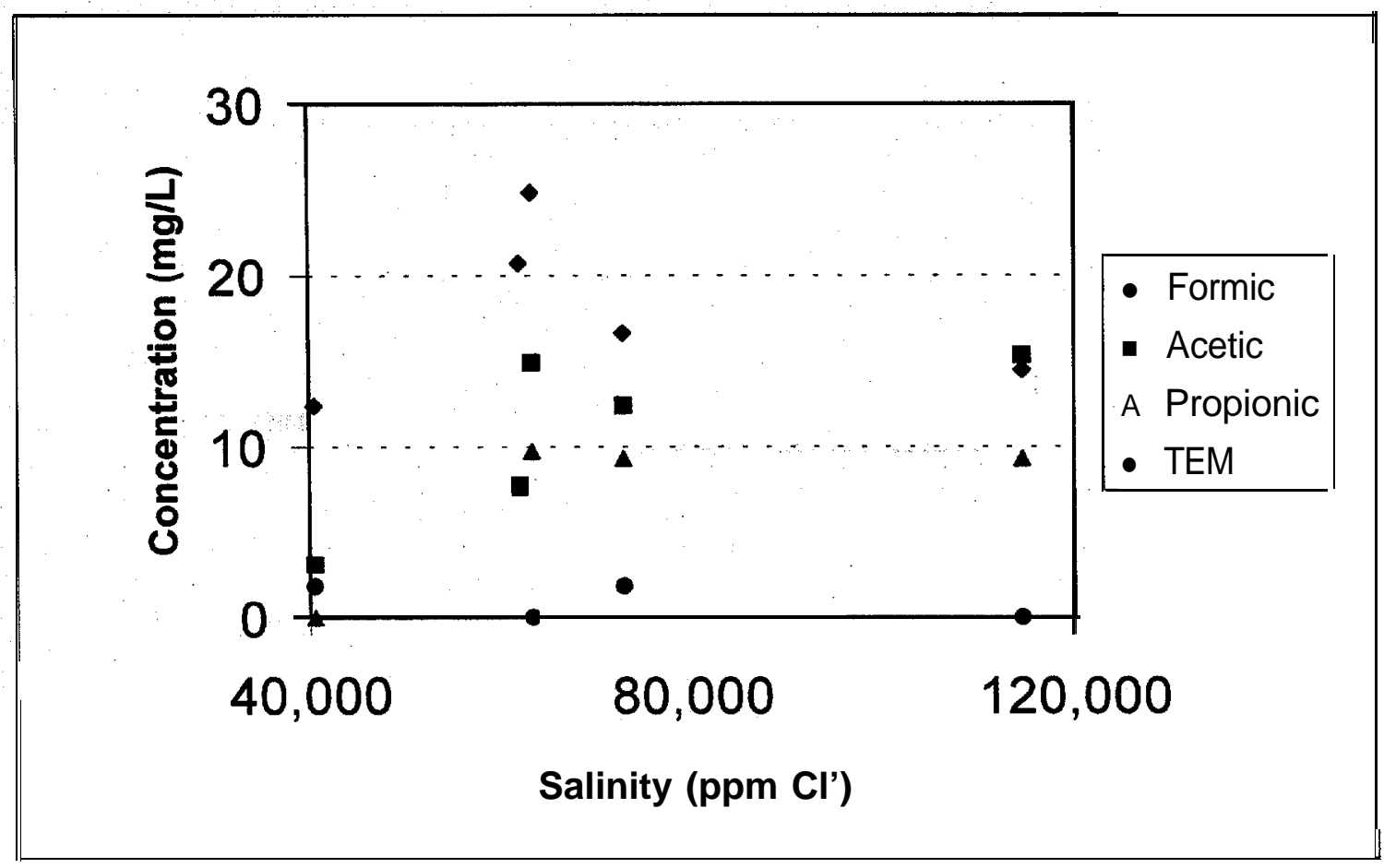

Fig. 8.15. Influence of salinity on organic acid content.

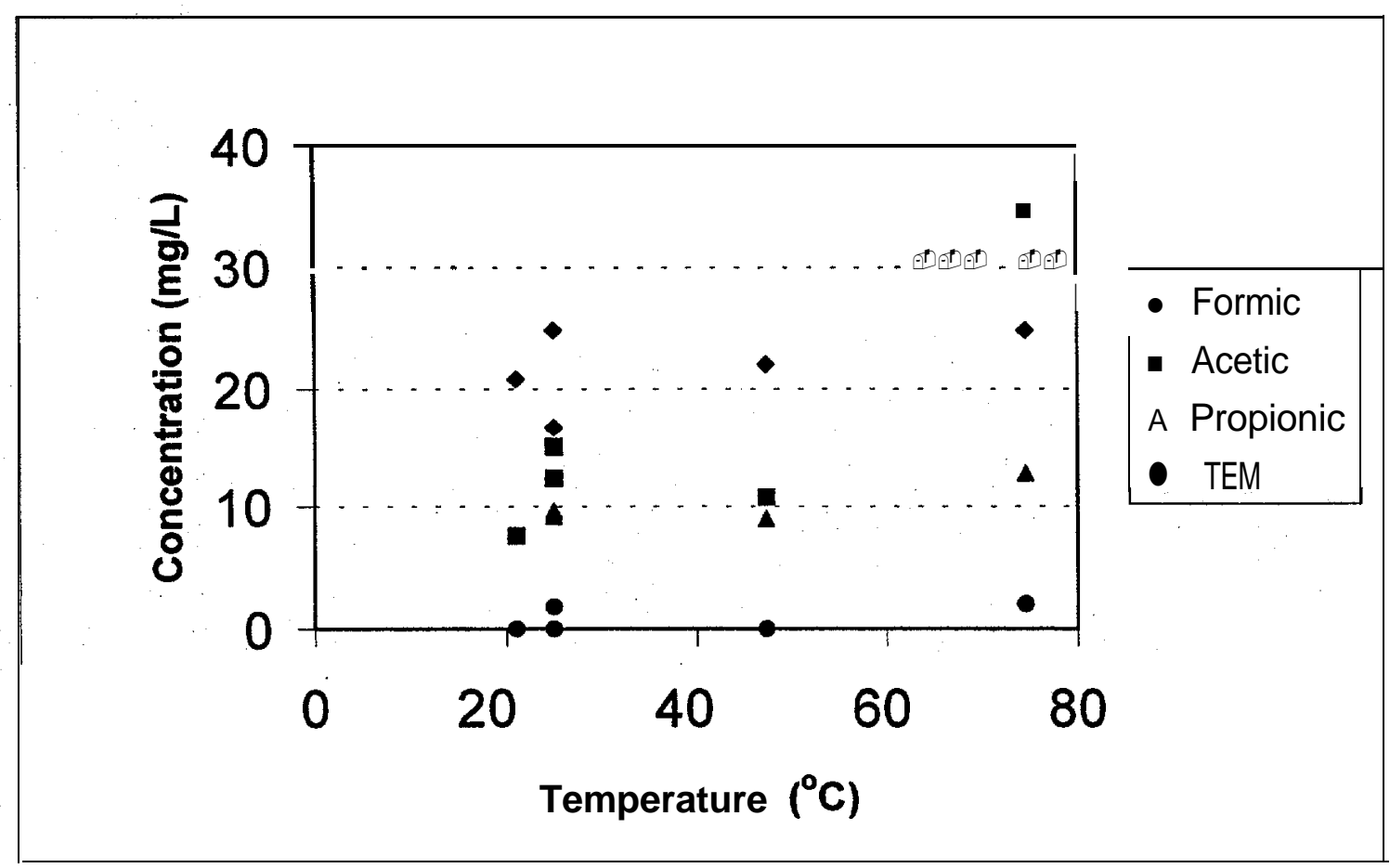

Fig. 8.16. Influence of temperature on organic acid content. 


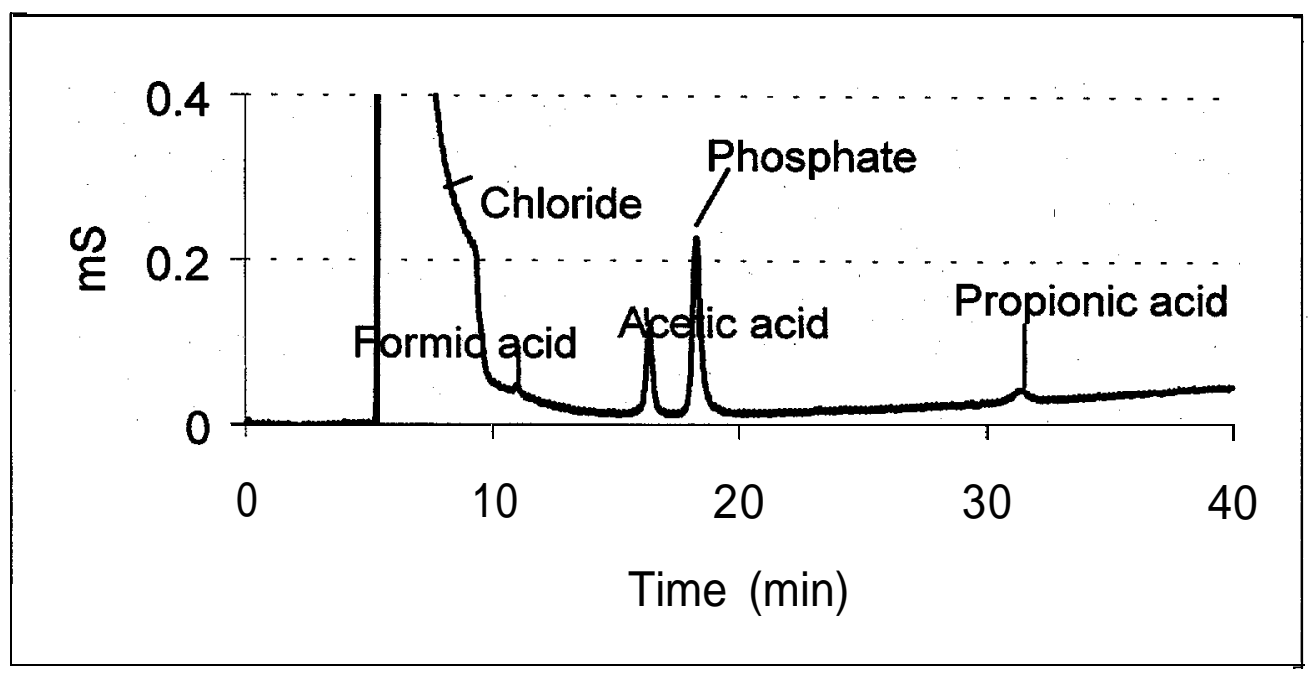

Fig. 8.17. Ion chromatogram of organic acids in produced water. 
APPENDIX 


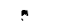




\begin{abstract}
APPENDIX
The tables in this appendix list data acquired for the oil/water contact experiments, analyses of oil samples, certification of GOM brine simulant, and protocol standards. These experiments are denoted by "PERF-", "Deep-", "GOM-", and "STD-", respectively, in each of the tables. The data for PERF designations are further delineated according to the experimental parameter that was being studied. Baseline experimental conditions were defined as $80 \%$ water cut, $65,000 \mathrm{ppm}$ salinity, pH 7 brine, $25^{\circ} \mathrm{C}$, and ambient pressure. Experiment numbers for the oil/water contacts are listed in table A. 1. At least two of these experiments were performed to study the variation in WSO content for a given parameter performed outside the baseline values.
\end{abstract}

Table A.1 PERF experiments associated with each oil/water contact parameter

\begin{tabular}{ll}
\hline Parameter & Oil/water contact \\
\hline Baseline & PERF-8; PERF-16; PERF-20 \\
Water cut & PERF-6; PERF-7; PERF-9; PERF-10 \\
PH & PERF-11; PERF-12; PERF-13 \\
Salinity & PERF-14; PERF-15 \\
Temperature & PERP-17; PERF-18 \\
Pressure & PERF-2 1; PERF-22; PERF-23; PERF-24; \\
& PERF-25; PERF-26; PERF-27; PERF-28 \\
\hline
\end{tabular}

The details pertaining as to the starting conditions of each experiment are summarized in Table A.2. The equilibrium concentrations of major anion species and the $\mathrm{pH}$ levels at the completion of an oil/water contact are listed in Table A.3. Corresponding cation data are presented in Table A.4. Summation of WSO content for oil/water contacts, as-received oil, and recovery standards are contained in Tables A.5 through A.7. The WSO results based on gravimetric and IR analyses are located in Table A.5; those based on the open LC protocol are presented in Tables A.6 and A.7. 
Table A.2 Starting conditions for PERF experiments

\begin{tabular}{|c|c|c|c|c|c|c|c|c|c|}
\hline Experiment & $\begin{array}{l}\text { Simulant } \\
\text { batch }\end{array}$ & $\begin{array}{l}\mathrm{GOM} \\
\mathrm{pH}\end{array}$ & $\begin{array}{l}\text { Temp. } \\
\left({ }^{\circ} \mathrm{C}\right) \quad(\mathrm{i}\end{array}$ & $\begin{array}{l}\text { Pressure } \\
\text { n. } \quad \mathrm{Hg})\end{array}$ & $\begin{array}{l}\text { Salinity } \\
\text { (mg/L) }\end{array}$ & $\begin{array}{l}\text { Water } \\
\text { volume } \\
(\mathrm{mL})\end{array}$ & $\begin{array}{c}\text { Oil } \\
\text { volume } \\
\text { (mL) }\end{array}$ & $\begin{array}{c}\text { Total } \\
\text { contact } \\
\text { time (days) }\end{array}$ & Comments \\
\hline GOM-1 & 4L-Prep & 7.5 & -- & --- & 62975 & -- & --- & $-\cdots$ & \\
\hline PERF-3blk ${ }^{a}$ & GOM-1 & 7.5 & 25.0 & 24.06 & 62975 & 1000 & 0 & --- & $+312.5 \mathrm{ppm} \mathrm{Na}^{+}$plus $8640 \mathrm{ppm} \mathrm{SO}_{4}{ }^{2-}$ \\
\hline PERF-4oil & --- & 7.5 & 25.0 & & --- & 0 & 2 & $-\cdots$ & \\
\hline GOM-2 & 4L-Prep & 6.9 & --- & --- & 60793 & --- & --- & $\cdots$ & Start: no iron added to GOM simulant \\
\hline PERF-6 & GOM-2 & 6.9 & 25.0 & 29.06 & 60793 & 1000 & 500 & 4.83 & Start: addition of recovery standards \\
\hline PERF-7 & GOM-2 & 6.9 & 25.0 & 29.06 & 60793 & 1000 & 1000 & 5.76 & $\begin{array}{l}\text { Start: gravimetric analysis for TEM and HEX } \\
\text { fractions only }\end{array}$ \\
\hline PERF-8 & GOM-2 & 6.9 & 25.0 & 29.06 & 60793 & 1000 & 250 & 4.00 & \\
\hline GOM-3 & 4L-Prep & 6.9 & --- & --- & 65308 & --- & --- & -- & \\
\hline PERF-9 & GOM-3 & 6.9 & 25.0 & 29.06 & 65308 & 1000 & 4000 & 4.00 & \\
\hline PERF-10 & GOM-3 & 6.9 & 25.0 & 29.06 & 65308 & 1100 & 1100 & 5.75 & $\begin{array}{l}\text { GOM pH adjustment to } 8.7 \text { with } 50 \% \mathrm{NaOH} \\
\text { prior to oil contact }\end{array}$ \\
\hline GOM-4 & 4L-Prep & 6.8 & -- & $-\cdots$ & 62143 & --- & $--\infty$ & --- & \\
\hline PERF-11 & GOM-4 & 9.03 & 24.5 & 29.06 & 65308 & 1200 & 300 & 2.96 & pH continuously adjusted with $50 \% \mathrm{NaOH}$ \\
\hline PERF-12 & GOM-4 & 4.73 & 24.5 & 29.1 & 65308 & 1200 & 300 & 5.94 & $\begin{array}{l}\text { pH continuously adjusted with } \\
\text { concentrated } \mathrm{HCl}\end{array}$ \\
\hline PERF-13 & GOM-4 & 9.5 & 24.5 & 29.1 & 65308 & 1200 & 300 & 5.86 & pH continuously adjusted with $50 \% \mathrm{NaOH}$ \\
\hline GOM-5 & 4L-Prep & 7.4 & --- & $-\cdots$ & 40638 & --- & -- & --- & $50 \% \mathrm{NaCl}$ content in simulant \\
\hline PERF-14 & GOM-5 & 7.4 & 24.5 & 29.14 & 40638 & 1200 & 300 & 4.89 & $50 \% \mathrm{NaCl}$ content in simulant \\
\hline PERF-Stdl ${ }^{b}$ & GOM-5 & 7.4 & 24.5 & 29.14 & 40638 & 1000 & 0 & --- & Start standards recovery with hexanoic acid \\
\hline GOM-6 & 2L-Prep & 6.82 & --- & --- & & --- & --- & -- & --- \\
\hline PERF-15 & GOM-6 & 6.82 & 25.0 & 29.31 & 114500 & 1200 & 300 & 5.33 & $150 \% \mathrm{NaCl}$ content \\
\hline PERF-Deep1 & $-\infty$ & --- & 25.0 & 29.31 & $-\cdots$ & --- & 0.995 & $-\cdots$ & $0.8391 \mathrm{~g}$ oil in $17.66 \mathrm{~mL} \mathrm{CH} \mathrm{CH}_{2}$ \\
\hline GOM-7 & 4L-Prep & -- & --- & --- & 62143 & --- & --- & --- & Simulant used for Std2 and Std3 \\
\hline $\mathrm{GOM}-8$ & 6L-Prep & 7.1 & --- & -- & 72900 & --- & -- & --- & 2 L GOM-7 + 4 L GOM-8 \\
\hline PERF-Std2 ${ }^{b}$ & GOM-5 & --- & 24.5 & 29.14 & 40638 & 1000 & 0 & --- & Standards recovery with hexanoic acid \\
\hline
\end{tabular}

"Process blanks

${ }^{\mathrm{b}}$ Recovery of surrogate standards 
Table A.2. (continued)

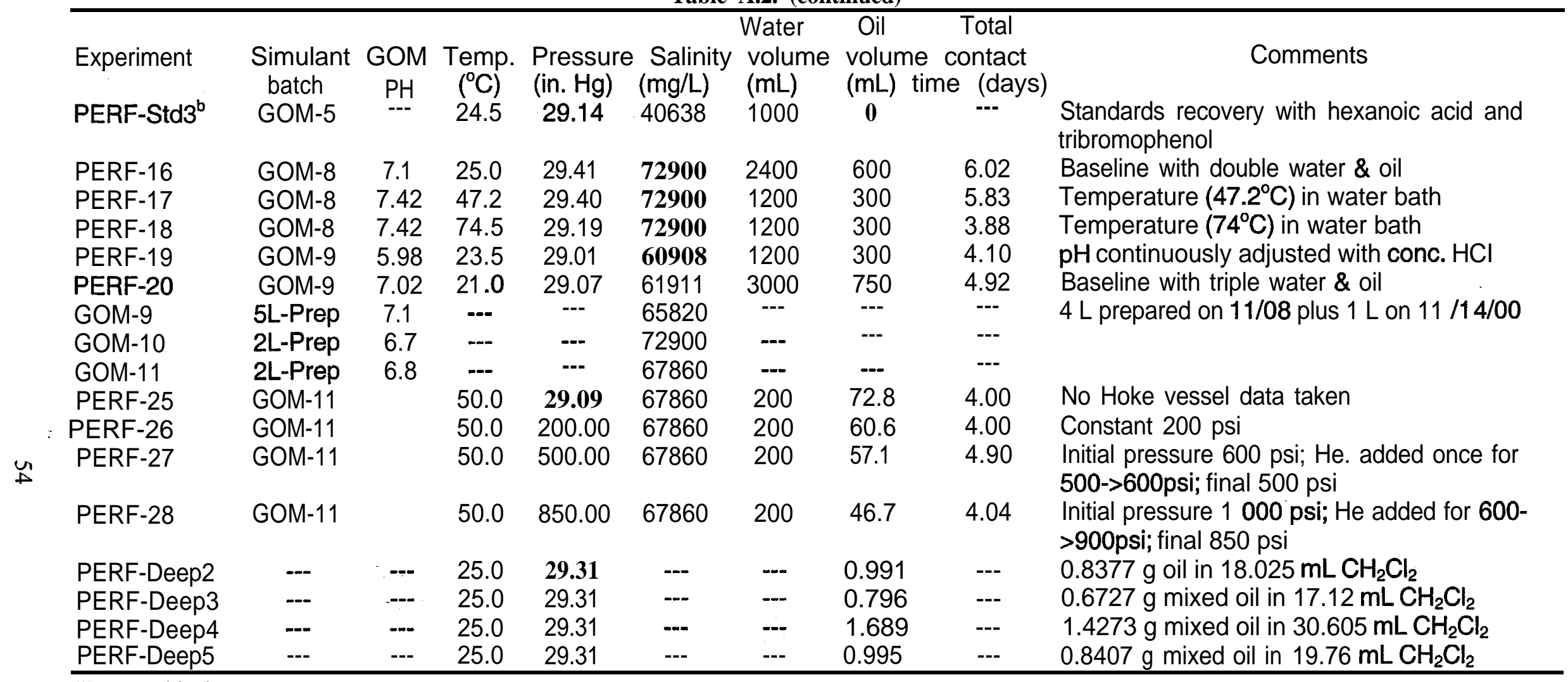

"Process blanks

${ }^{\mathbf{b}}$ Recovery of surrogate standards 
Table A.3 Equilibrium concentrations of inorganic constituent

\begin{tabular}{lcccc}
\hline Experiment & $\begin{array}{c}\text { Salinity } \\
(\mathrm{ppm} \mathrm{Cl})\end{array}$ & $\begin{array}{c}\mathrm{HCO}_{3}{ }^{-} \mathrm{ppm}^{-} \\
\mathrm{CO}_{3}{ }^{2-} \\
(\mathrm{ppm})\end{array}$ & $\mathrm{pH}$ \\
\hline PERFS & 62,487 & 137 & 0 & 6.97 \\
PERF-7 & 64,734 & 163 & 0 & 7.02 \\
PERF-8 & 63,289 & 164 & 0 & 7.24 \\
PERF-9 & 63,788 & 101 & 0 & 6.99 \\
PERF-10 & 67,856 & 77 & 0 & 6.25 \\
PERF-11 & 59,232 & 139 & 6 & 9.03 \\
PERF-12 & 72,793 & 27 & 0 & 4.73 \\
PERF-13 & 71,603 & 32 & 0 & 8.09 \\
PERF-14 & 40,140 & 123 & 0 & 7.6 \\
PERF-15 & 114,480 & 89 & 0 & 7.14 \\
PERF-16 & 65,791 & 124 & 0 & 7.09 \\
PERF-17 & 66,606 & 74 & 0 & 7.14 \\
PERF-18 & 66,333 & 54 & 0 & 7.26 \\
PERF-19 & 66,333 & 21 & 0 & 5.98 \\
PERFPO & 61,911 & 128 & 0 & 7.02 \\
PERF-25 & 65,721 & NA & NA & NA \\
PERF-26 & 71,772 & NA & NA & NA \\
PERF-27 & 79,647 & NA & NA & NA \\
PERF-28 & 67,050 & NA & NA & N/i \\
\hline NA $=$ Not & 6 & &
\end{tabular}

$\mathrm{NA}=$ Not analyzed.

Table A.4. Equilibrium concentrations of ICP metals

\begin{tabular}{lccc|ccccc}
\hline Experiment & \multicolumn{3}{c}{ RCRA metals by ICP $(\mathrm{ppm})$} & \multicolumn{4}{c}{ Non-RCRA metals by $\mathrm{ICP}(\mathrm{ppm})$} \\
\cline { 2 - 8 } & $\mathrm{Se}$ & $\mathrm{Cd}$ & $\mathrm{S} \mathrm{b}$ & $\mathrm{Ba}$ & $\mathrm{Ca}$ & $\mathrm{Mg}$ & $\mathrm{Na}$ & $\mathrm{Sr}$ \\
PERFB & $\mathrm{U}^{\mathrm{a}}$ & $0.079 \pm 0.005$ & $\mathrm{co.75} \pm 0.14$ & 42.3 & 3200 & 850 & 33,400 & 140 \\
PERF-7 & $\mathrm{U}$ & $0.080 \pm 0.006$ & $\mathrm{co.75} \pm 0.29$ & 44 & 3300 & 860 & 33,800 & 140 \\
PERFS & $\mathrm{U}$ & $0.080 \pm 0.009$ & $\mathrm{co.75} \pm 0.20$ & 43 & 3180 & 840 & 32,900 & 138 \\
PERF-9 & $\mathrm{U}$ & $0.080 \pm 0.010$ & $\mathrm{co.75} \pm \mathbf{0 . 1 5}$ & 45 & $\mathbf{3 2 4 0}$ & 860 & 33,500 & 144 \\
PERF-10 & $\mathrm{U}$ & $0.080 \pm 0.010$ & $<0.75 \pm 0.15$ & 40 & 3300 & 880 & 34,200 & 148 \\
PERF-11 & $0.9 \pm 0.4$ & $0.085 \pm 0.015$ & $\mathrm{co.75} \pm 0.15$ & 44 & 3040 & 850 & 33,300 & 146 \\
PERF-12 & $1.0 \pm 0.6$ & $0.086 \pm 0.022$ & $<0.75 \pm 0.27$ & 41 & 3150 & 840 & 33,300 & 146 \\
PERF-13 & $0.7 \pm 0.3$ & $0.076 \pm 0.016$ & $<1.5 \pm 0.85$ & 37.5 & 3080 & 840 & 32,270 & 138 \\
PERF-14 & $\mathrm{U}$ & $0.077 \pm 0.015$ & $\mathrm{U}$ & 94 & 3290 & 860 & 17,250 & 145 \\
PERF-15 & $0.7 \pm 0.7$ & $0.074 \pm 0.020$ & $<1.5 \pm 0.77$ & 90 & 3170 & 823, & 49,418 & 137 \\
PERF-Deep1 & $3.5 \pm 1.0$ & $\mathrm{U}$ & $\mathrm{U}$ & 26 & 924 & 138 & 7,000 & 250 \\
PERF-16 & $\mathrm{U}$ & $0.073 \pm 0.007$ & $<1.5 \pm 0.53$ & 53 & 3260 & 853 & 32,800 & 140 \\
PERF-17 & $\mathrm{U}$ & $0.075 \pm 0.019$ & $<1.5 \pm 0.45$ & 44 & 3280 & 864 & 33,230 & 142 \\
PERF-18 & $\mathrm{U}$ & $0.066 \pm 0.004$ & $<1.5 \pm 0.92$ & 41 & 3320 & 877 & 33,600 & 144 \\
PERF-19 & $\mathrm{U}$ & $0.073 \pm 0.001$ & $<1.5 \pm 0.76$ & 43 & 3240 & 834 & 32,430 & 138 \\
PERF-20 & $\mathrm{U}$ & $0.071 \pm 0.005$ & $<1.5 \pm 0.32$ & 53 & 3255 & 844 & 32,930 & 140 \\
\hline
\end{tabular}

${ }^{\mathrm{a}} \mathrm{U}=$ undetected above ICP detection limit for this element. 
Table A.5 Equilibrium concentrations of organic matter by gravimetric ind IR analyses

\begin{tabular}{|c|c|c|c|c|c|}
\hline \multirow[t]{2}{*}{ Experiment } & \multicolumn{2}{|c|}{ WSO (ppm), gravimetric } & \multicolumn{2}{|c|}{ Oil (g/kg), gravimetric ${ }^{a}$} & \multirow{2}{*}{$\begin{array}{l}\text { VSO (ppm), IR } \\
\text { i produced water }\end{array}$} \\
\hline & TEM fraction & HEX fraction & TEM fraction & HEX fraction & \\
\hline PERFB & 27.0 & 27.0 & 0.064 & 0.048 & \\
\hline PERF-7 & 35 & 26.3 & 0.042 & 0.025 & \\
\hline PERF-8 & 18.0 & 47.8 & 0.085 & 0.176 & \\
\hline PERF-9 & 19.2 & 33.3 & 0.0057 & 0.0074 & \\
\hline PERF-10 & 14.4 & 7.71 & 0.0171 & 0.0071 & \\
\hline PERF-11 & 28.9 & 27.97 & 0.137 & 0.078 & \\
\hline PERF-12 & 28.9 & 28.0 & 0.068 & 0.028 & \\
\hline PERF-13 & 14.4 & 9.00 & 0.094 & 0.057 & \\
\hline PERF-14 & 18.6 & 10.8 & 0.088 & 0.034 & 49.8 \\
\hline PERF-15 & 16 & 7.14 & 0.076 & 0.024 & 12.2 \\
\hline PERF-Deep1 & --- & --- & 673 & 547 & -- \\
\hline PERF-16 & 23.4 & 26 & 0.11 & 0.09 & 10.5 \\
\hline ERF-17 & 35.2 & 33.0 & 0.17 & 0.13 & 17.6 \\
\hline PERF-18 & 46.25 & 42.9 & 0.22 & 0.17 & 23.1 \\
\hline PERF-19 & 16.1 & 10.9 & 0.08 & 0.04 & 8.7 \\
\hline PERF-20 & 16.8 & 14.4 & 0.08 & 0.06 & 10.5 \\
\hline PERF-25 & 32.2 & 7.4 & 0.11 & 0.02 & NA \\
\hline PERF-26 & 83.0 & 37.7 & 0.33 & 0.12 & NA \\
\hline PERF-27 & 39.2 & 26.1 & 0.16 & 0.09 & NA \\
\hline PERF-28 & 29.3 & 35.9 & 0.15 & 0.18 & NA \\
\hline PERF-Deep2 & -.- & --- & 561 & 518 & NA \\
\hline PERF-Deep3 & & --- & 434 & $\cdots$ & NA \\
\hline PERF-Deep4 & & $\cdots$ & 731 & 537 & NA \\
\hline PERF-Deep5 & -.- & -.. & 636 & --- & NA \\
\hline
\end{tabular}

a For produced water samples, an equivalent oil value was calculated by multiplying the quantity of WSO in the water by the volume of water and then dividing this number by the volume of oil used in the contact. 
Table A.6 Eauilibrium concentrations of WSO in open LC fractions TEM, HEiX, and TSAT

\begin{tabular}{|c|c|c|c|c|c|c|c|c|c|c|c|c|}
\hline \multirow{2}{*}{$\begin{array}{l}\text { Experiment } \\
\text { Name }\end{array}$} & \multicolumn{4}{|c|}{ WSO (ppm) in TEM fraction } & \multicolumn{4}{|c|}{ WSO (ppm) in HEX fraction } & \multicolumn{4}{|c|}{ WSO $(\mathrm{mg} / \mathrm{L})$ in TSAT fraction } \\
\hline & Total & $\mathrm{C}_{6}-\mathrm{C}_{10}$ & $\mathrm{C}_{10}-\mathrm{C}_{20}$ & $\mathrm{C}_{20}-\mathrm{C}_{28}$ & Total & $\mathrm{C}_{6}-\mathrm{C}_{10}$ & $\mathrm{C}_{10}-\mathrm{C}_{20}$ & $\mathrm{C}_{20}-\mathrm{C}_{28}$ & Total & $\mathrm{C}_{6}-\mathrm{C}_{10}$ & $\mathrm{C}_{10}-\mathrm{C}_{20}$ & $\mathrm{C}_{20}-\mathrm{C}_{28}$ \\
\hline PERFS & 11.6 & 5.35 & 6.29 & 0 & 10.5 & 2.56 & 7.98 & 0.0 & 0.062 & 0.062 & 0.0 & 0.0 \\
\hline PERF-7 & 36.8 & 12.0 & 24.81 & 0.030 & 21.9 & 6.52 & 15.35 & 0.0 & 0.042 & 0.04 & 0.0 & 0.0 \\
\hline PERF-8 & 24.8 & 7.1 & 15.35 & 2.293 & 15.5 & 0.86 & 14.68 & 0.0 & 0.034 & 0.03 & 0.0 & 0.0 \\
\hline PERF-9 & 30.0 & 9.3 & 20.63 & 0.000 & 13.8 & 3.29 & 10.51 & 0.0 & 0.051 & 0.05 & 0.0 & 0.0 \\
\hline PERF-10 & 24.4 & 6.1 & 18.28 & 0.000 & 9.6 & 2.13 & 7.45 & 0.0 & 0.058 & 0.06 & 0.0 & 0.0 \\
\hline PERF-11 & 28.6 & 7.4 & 21.21 & 0.004 & 10.5 & 0.70 & 9.76 & 0.0 & Lost & Lost & Lost & Lost \\
\hline PERF-12 & 11.9 & 6.0 & 5.87 & 0.014 & 5.8 & 0.24 & 5.57 & 0.0 & 0.039 & 0.04 & 0.0 & 0.0 \\
\hline PERF-13 & 23.5 & 4.3 & 19.19 & 0.038 & 10.0 & 0.50 & 9.46 & 0.0 & 0.010 & 0.00 & 0.0 & 0.0 \\
\hline PERF-14 & 12.4 & 4.5 & 7.86 & 0.064 & 5.4 & 0.48 & 4.86 & 0.01 & 0.066 & 0.03 & 0.02 & 0.008 \\
\hline PERF-15 & 14.5 & 5.1 & 9.34 & 0.007 & 6.6 & 1.21 & 5.39 & 0.00 & 0.253 & 0.05 & 0.21 & 0.000 \\
\hline PERF-Deep1 & 251,028 & 139,915 & 109,871 & 1241 & 73,478 & 9,514 & 58,658 & 5,306 & 66,590 & 11,991 & 50,192 & 4,408 \\
\hline PERF-Std3 & 0.0 & 0.0 & 0.00 & 0.000 & 0.0 & 0.00 & 0.00 & 0.00 & 0.000 & 0.00 & 0.00 & 0.000 \\
\hline PERF-16 & 16.6 & 6.8 & 9.86 & 0.000 & 10.6 & 0.34 & 10.28 & 0.02 & 0.015 & 0.02 & 0.00 & 0.000 \\
\hline PERF-17 & 21.9 & 5.2 & 16.63 & 0.022 & 12.6 & 0.49 & 12.08 & 0.01 & 0.216 & '0.08 & 0.14 & 0.000 \\
\hline PERF-18 & 24.8 & 2.2 & 22.57 & 0.046 & 15.7 & 0.44 & 15.27 & 0.03 & 0.000 & 0.00 & 0.00 & 0.000 \\
\hline PERF-19 & 11.7 & 4.9 & 5.89 & 0.920 & 5.2 & -0.18 & 5.35 & 0.01 & 0.005 & 0.00 & 0.00 & 0.000 \\
\hline PERFQO & 20.8 & 7.6 & 13.12 & 0.006 & 5.9 & -0.04 & 5.89 & 0.00 & 0.000 & 0.00 & 0.00 & 0.000 \\
\hline PERF-25 & 3.9 & 2.2 & 1.7 & 0.000 & 3.48 & 0.59 & 2.89 & 0.00 & 0.016 & 0.00 & 0.01 & 0.00 \\
\hline PERF-26 & 46.4 & 8.4 & 37.9 & 0.107 & 24.36 & 1.13 & 23.22 & 0.0125 & 0.103 & 0.05 & 0.04 & 0.01 \\
\hline PERF-27 & 6.1 & 3.4 & 2.7 & 0.000 & 2.69 & 0.42 & 2.27 & 0.00 & 0.015 & 0.01 & 0.00 & 0.00 \\
\hline PERF-28 & 4.7 & 2.6 & 2.1 & 0.006 & 6.01 & 1.54 & 4.47 & 0.0000 & 0.071 & 0.02 & 0.01 & 0.04 \\
\hline PERF-Deep2 & 220,140 & 120,782 & 80,496 & 18,863 & 88,178 & 5,331 & 70,619 & 12,228 & 83,880 & 8,751 & 71,202 & 3,927 \\
\hline PERF-Deep3 & 142,268 & 79,016 & 52,579 & 10,673 & $N A^{a}$ & NA & NA & NA & NA & NA & NA & NA \\
\hline PERF-Deep4 & 192,785 & 98,182 & 82,188 & 12,415 & 50,321 & 2,528 & 33,407 & 14,386 & 69,514 & 3,828 & 63,158 & 2,529 \\
\hline PERF-Deep5 & 201,116 & 97,367 & 88,838 & 14,912 & NA & NA & NA & NA & NA & NA & NA & NA \\
\hline
\end{tabular}

${ }^{\mathrm{a} N A}=$ not analyzed. 
Table A.7 Equilibrium concentrations of WSO in open LC fractions TARO, TPOL(subtract), and TPOL(GC)

\begin{tabular}{|c|c|c|c|c|c|c|c|c|c|c|c|c|}
\hline \multirow[t]{2}{*}{ Experiment } & \multicolumn{4}{|c|}{ WSO (ppm) in TARO fraction } & \multicolumn{4}{|c|}{$\begin{array}{c}\text { WSO (ppm) in TPOL fraction } \\
\text { (subtract) }\end{array}$} & \multicolumn{4}{|c|}{ WSO (ppm) in TPOL fraction (GC) } \\
\hline & Total & $\mathrm{C}_{6}-\mathrm{C}_{10}$ & $\mathrm{C}_{10}-\mathrm{C}_{20}$ & $\mathrm{C}_{20}-\mathrm{C}_{28}$ & Total & $\mathrm{C}_{6}-\mathrm{C}_{10}$ & $\mathrm{C}_{10}-\mathrm{C}_{20}$ & $\mathrm{C}_{20}-\mathrm{C}_{28}$ & Total & $\mathrm{C}_{6}-\mathrm{C}_{10}$ & $\mathrm{C}_{10}-\mathrm{C}_{20}$ & $\mathrm{C}_{20}-\mathrm{C}_{28}$ \\
\hline PERF-6 & 0.03 & 0.03 & 0.00 & 0.00 & 11.6 & 5.30 & 6.30 & 0 & NA & NA & NA & NA \\
\hline PERF-7 & 0.46 & 0.40 & 0.05 & 0.00 & 36.3 & 11.52 & 24.75 & 0.030 & 5.4 & 1.67 & 3.73 & 0.016 \\
\hline PERF-8 & 0.15 & 0.12 & 0.03 & 0.00 & 24.6 & 6.96 & 15.32 & 2.293 & NA & NA & NA & NA \\
\hline PERF-9 & 0.24 & 0.21 & 0.03 & 0.00 & 29.7 & 9.09 & 20.60 & 0.000 & NA & NA & NA & NA \\
\hline PERF-10 & 0.15 & 0.14 & 0.01 & 0.00 & 24.2 & 5.91 & 18.27 & 0.000 & 6.2 & 1.46 & 4.78 & 0.002 \\
\hline PERF-11. & 0.28 & 0.27 & 0.01 & 0.00 & 28.4 & 7.17 & 21.20 & 0.004 & Lost & Lost & Lost & Lost \\
\hline PERF-12 & 0.07 & 0.05 & 0.02 & 0.00 & 11.7 & 5.71 & 5.85 & 0.014 & 3.1 & 1.18 & 1.92 & 0.000 \\
\hline PERF-13 & 0.11 & 0.09 & 0.01 & 0.00 & 23.4 & 4.18 & 19.17 & 0.038 & 27.9 & 3.90 & 11.78 & 12.3 \\
\hline PERF-14 & 0.03 & 0.01 & 0.02 & 0.00 & 12.3 & 4.46 & 7.82 & 0.057 & 4.6 & 1.35 & 3.03 & 0.25 \\
\hline PERF-15 & 0.05 & 0.04 & 0.01 & 0.00 & 14.2 & 5.05 & 9.12 & 0.007 & 6.1 & 2.70 & 3.37 & 0.003 \\
\hline PERF-Deep1 & 8,438 & 1,098 & 5,726 & 1,614 & 175,999 & 126,826 & 53,954 & $-4,781$ & 14,847 & 13,555 & 445 & 847 \\
\hline PERF-Std3 & 0.00 & 0.00 & 0.00 & 0.00 & 0.0 & 0.00 & 0.00 & 0.000 & 0.0 & 0.02 & 0.00 & 0.000 \\
\hline PERF-16 & 0.17 & 0.09 & 0.05 & 0.00 & 16.5 & 6.68 & 9.81 & 0.000 & 3.6 & 0.00 & 3.57 & 0.004 \\
\hline PERF-17 & 0.08 & 0.03 & 0.05 & 0.00 & 21.6 & 5.11 & 16.44 & 0.022 & 6.7 & 0.00 & 6.41 & 0.314 \\
\hline PERF-18 & 0.33 & 0.03 & 0.23 & 0.07 & 24.5 & 2.16 & 22.34 & -0.028 & 12.6 & 0.00 & 12.46 & 0.145 \\
\hline PERF-19 & 0.04 & 0.01 & 0.03 & 0.00 & 11.7 & 4.87 & 5.86 & 0.920 & 5.3 & 0.02 & 5.29 & 0.005 \\
\hline PERF-20 & -0.01 & -0.02 & 0.02 & 0.00 & 20.8 & 7.65 & 13.11 & 0.006 & 1.1 & 0.00 & 1.11 & 0.005 \\
\hline PERF-25 & 0.370 & 0.20 & 0.17 & 0.00 & 5.0 & 2.16 & 1.92 & 0.90 & 4.07 & 2.65 & 1.42 & 0.004 \\
\hline PERF-26 & 0.093 & 0.00 & 0.05 & 0.05 & 46.2 & 8.32 & 37.8 & 0.05 & 3.43 & 2.59 & 0.84 & 0.004 \\
\hline PERF-27 & 0.024 & 0.00 & 0.01 & 0.01 & 6.05 & 3.41 & 2.64 & 0.00 & 6.25 & 5.44 & 0.78 & 0.027 \\
\hline PERF-28 & 0.213 & 0.12 & 0.07 & 0.01661 & 5.09 & 3.34 & 1.78 & 0.00 & 2.08 & 0.09 & 1.44 & 0.5529 \\
\hline PERF-Deep2 & 19,700 & 3,963 & 13,235 & 2,502 & 116,560 & 106,700 & $-61,326$ & 2,708 & 19,645 & 18,972 & 673 & 0 \\
\hline PERF-Deep3 & $N A^{a}$ & NA & NA & NA & NA & NA & NA & NA & NA & NA & NA & NA \\
\hline PERF-Deep4 & 35,628 & 6,619 & 24,758 & 4,251 & 87,643 & 91,826 & $-14,377$ & $-4,499$ & 13,297 & 11,429 & 648 & 1,220 \\
\hline PERF-Deep5 & NA & NA & NA & NA & NA & NA & NA & NA & NA & NA & NA & NA \\
\hline
\end{tabular}

${ }^{\mathbf{a}} \mathrm{NA}=$ not analyzed. 


\section{INTERNAL DISTRIBUTION}

1-5. D. T. Bostick

6. D. W. DePaoli

7. R. T. Jubin

8. R. R. Judkins

9. K. T. Klasson

10. H. Luo

11. J. McFarlane

12. S. M. Robinson

13. T. W. Schmidt

14. W. V. Steele

15. C. Tsouris

16. ORNL Laboratory Records-OSTI

17. ORNL Laboratory Records-RC

18. Central Research Library

\section{EXTERNAL DISTRIBUTION}

19. D. Alleman, DOE-PTO, P.O. Box 3628, Tulsa, OK 74101

20. Veronica Blackwell, ChevronTexaco, 100 Chevron Way, Richmond, CA 94802-0627

21. Doug Bourg, Phillips Petroleum Company, 6330 West Loop South, Bellaire, Texas 77401

22. Nancy Comstock, DOE-NPTO, P.O. Box 3628, Tulsa, OK 74101

23. Michael Dubrovsky, ChevronTexaco ERTC, 100 Chevron Way, Richmond, CA 94802

24. Art Hartstein, DOE Fossil Energy, 19901 Germantown Road, Germantown, MD 208741290

25. Sung-I Johnson, Analytical and Environmental Services, 256 RF Phillips Research Center, Bartlesville, OK 74004

26. Zara I. Khatib, SIEP, SEPTAR-AWW, 2288 GD, Rijswijk, Netherlands

27. William F. Lawson, DOE-NPTO, P.O. Box 3628, Tulsa, OK 74101

28. Nicholas J. Spiridakis, ChevronTexaco ERTC, 100 Chevron Way, Richmond, CA 94802

29. Dexter Sutterfield, DOE-NPTO, P.O. Box 3628, Tulsa, OK 74101 
. 